\title{
AVALIAÇÃO DA INFLUÊNCIA DA REALIZAÇÃO DA EXPANSÃO RÁPIDA DA MAXILA SOBRE A RECIDIVA DO APINHAMENTO ÂNTERO-SUPERIOR, EM CASOS TRATADOS ORTODONTICAMENTE SEM EXTRAÇÕES
}

\section{Luiz Filiphe Gonçalves Canuto}

Dissertação apresentada à Faculdade de Odontologia de Bauru, da Universidade de São Paulo, como parte dos requisitos para obtenção do título de Mestre em Odontologia, na área de Ortodontia.

Bauru 



\section{AVALIAÇÃO DA INFLUÊNCIA DA REALIZAÇÃO DA \\ EXPANSÃO RÁPIDA DA MAXILA SOBRE A RECIDIVA DO \\ APINHAMENTO ÂNTERO-SUPERIOR, EM CASOS \\ TRATADOS ORTODONTICAMENTE SEM EXTRAÇÕES}

Luiz Filiphe Gonçalves Canuto

Dissertação apresentada à Faculdade de Odontologia de Bauru, da Universidade de São Paulo, como parte dos requisitos para obtenção do título de Mestre em Odontologia, na área de Ortodontia.

Orientador: Prof. Dr. Marcos Roberto de Freitas 


\section{CANUTO, Luiz Filiphe Gonçalves \\ C166a Avaliação da influência da realização da}

expansão rápida da maxila sobre a recidiva do apinhamento ântero-superior, em casos tratados ortodonticamente sem extrações / Luiz Filiphe Gonçalves Canuto - Bauru, 2006.

176 p. + apêndices: il.; $30 \mathrm{~cm}$.

Tese (Mestrado) - Faculdade de Odontologia de Bauru - Universidade de São Paulo.

Orientador: Prof. Dr. Marcos Roberto de Freitas

Autorizo, exclusivamente para fins acadêmicos e científicos, a reprodução total ou parcial desta dissertação, por processos fotocopiadores e/ou meios eletrônicos.

Assinatura do autor:

Data: 8 de novembro de 2006

Projeto de pesquisa aprovado em 06 de novembro de 2006 pelo Comitê de Ética em Pesquisa da FOB.

Processo no. 96/2006 




\section{LUI Z FI LI PHE GONÇALVES CANUTO}

16 de agosto de 1978

Belo Horizonte - MG

Filiação

1998-2001

2002-2005

2005-2006

Associações
Nascimento

Luiz Canuto

Helena Gonçalves Canuto

Curso de Graduação em Odontologia

- Universidade Federal dos Vales do Jequitinhonha e Mucuri

Curso de Aperfeiçoamento em

Ortodontia na ACOPEN - Bauru/SP.

Curso de Pós-graduação em Ortodontia, em nível de Mestrado, pela Faculdade de Odontologia de Bauru - Universidade de São Paulo.

APEO - Associação Paulista de Especialistas em Ortodontia-Ortopedia Facial.

SBPqO - Sociedade Brasileira de Pesquisas Odontológicas. 

"Novas idéias e maneiras de fazer as coisas estarão sempre sendo desafiadas e até rotuladas como heréticas, coisas do diabo, comunistas. Desafiar os velhos caminhos requer muito esforço, mas acomodar-se nos paradigmas do passado, também. 0 mundo está mudando tão rapidamente que podemos ficar paralisados se não desafiarmos nossas crenças e paradigmas."

"As pessoas têm dificuldade em mudar. A mudança nos desinstala, nos tira da nossa zona de conforto e nos força a fazer coisas de modo diferente, o que é difícil. Quando nossas idéias são desafiadas, somos forçados a repensar nossa posição, e isso é sempre desconfortável. É por isso que, em vez de refletir sobre seus comportamentos e enfrentar a árdua tarefa de mudar seus paradigmas, muitos se contentam em permanecer paralisados em pequenos trilhos." 



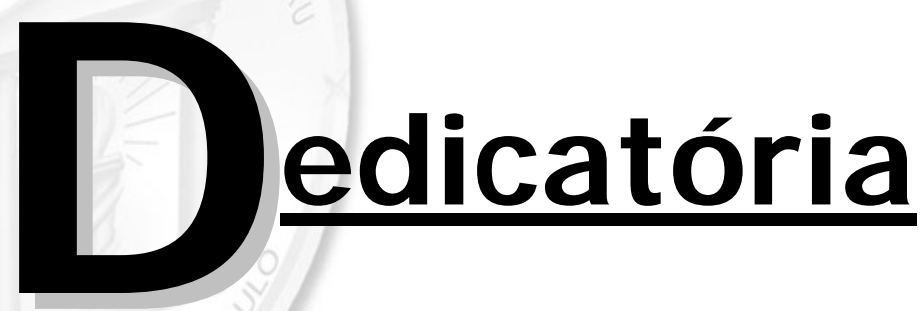





\section{Dedico este trabalho}

À Deus, pela contínua proteção e por me fazer sentir uma pessoa abençoada.

Aos meus queridos pais, LUIZ E HELENA.

Pelo amor incondicional e apoio, pelo ombro amigo de todas as horas. Saibam que a distância pode causar saudades, mas nunca o esquecimento. Vocês são exemplos de honestidade, simplicidade e dedicação.

Aos meus irmãos, VINICIUS, GUSTAVO E EDUARDO.

Ainda que não tenhamos uma convivência diária, o amor e o afeto são permanentes. Agradeço a Deus por vocês existirem.

À vocês, meus queridos pais e irmão,

Eu dedico este trabalho. 


\section{Dedico este trabalho também}

Aos meus avôs e avós: Zizinho (in memorian), Araci, Joaquim (in memorian) e Maria de Jesus (in memorian), pelas boas lembranças, carinho e exemplos dados.

A toda minha FAMÍLIA, tios, tias, primos e primas, que sempre acompanharam a minha trajetória profissional, torcendo e comemorando a cada degrau por mim alcançado. 
$\Delta$ gradecimentos

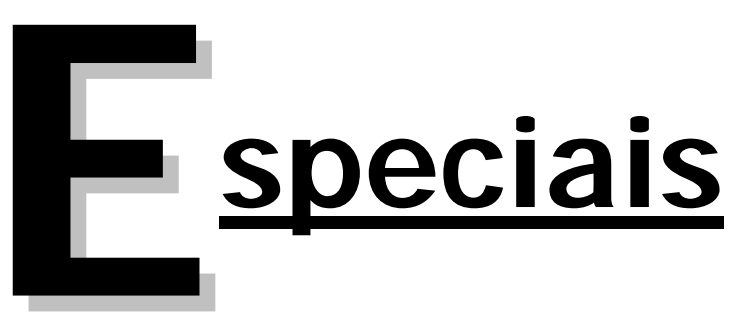





\section{Agradecimentos especiais}

Ao Prof. Dr. Marcos Roberto de Freitas, meu orientador, pelos ensinamentos transmitidos, amizade e confiança. Muito obrigado pela orientação neste trabalho e pela forma atenciosa e amiga com a qual me tratou durante o curso.

Ao Prof. Dr. Guilherme Janson, coordenador do curso de Mestrado em Ortodontia da FOB-USP, pela dedicação e seriedade que conduziu o curso, deixando nítida a sua vontade de efetivamente contribuir para o nosso crescimento profissional técnico e científico. Ao Senhor, minha eterna admiração e meus sinceros agradecimentos.

Ao Prof. Dr. Renato Rodrigues de Almeida, pelos valiosos ensinamentos e experiência de vida transmitida, assim como pela singular simplicidade e cordialidade.

Aos docentes da disciplina de Ortodontia, Professores Doutores Décio Rodrigues Martins, José Fernando Castanha Henriques, Arnaldo Pinzan, meus sinceros agradecimentos pela efetiva contribuição para a minha formação docente e clínica em Ortodontia durante o curso de Mestrado. 

gradecimentos 



\section{Agradecimentos}

À minha tia e Professora, Dra. Conceição Eunice Canuto, por acompanhar e auxiliar em minha formação em Ortodontia, sempre prestativa e paciente. Obrigado pelo apoio incondicional, pelo carinho, e pelas orientações profissionais e pessoais. À você, minha madrinha, meus mais sinceros agradecimentos.

À Prof. Dra. Karina Maria Salvatore de Freitas; pela amizade verdadeira e auxílio durante o curso. Acredito que selecionamos nossos amigos seguindo critérios muito parecidos, imagino que seja por isto que a nossa amizade é tão marcante e especial. Dizem que os alunos com o tempo adquirem algumas características do mestre, posso te dizer que grande parte do que sou hoje, como profissional e pessoalmente, devo à você. Agradeço a Deus por permitir que eu seja amigo de uma pessoa tão especial.

À minha namorada, Juliana, a quem admiro e devo todo o incentivo durante o desenvolvimento do curso, pois sabia o quanto era importante para mim. Muito obrigado pelo seu amor, pela sua paciência e companheirismo. Amo você. 
Aos meus amigos:

"Amigo é aquele que em qualquer circunstância, tem a coragem de se dizer amigo. Amigo não questiona, não julga, não premedita, não é falso. Ele fica do nosso lado sempre que precisamos. É como um anjo sem asas que nos protege. Amigos são como anjos e existem, e, quando encontramos um verdadeiro, temos orgulho em dizer: este... é meu amigo".

À todos os amigos do Curso de Mestrado: Caio, Danilo, Douglas, Eduardo, Janine, Leonardo, Luiz Fernando, Mayara, Patrícia, Tassiana e Vladimir por compartilhar seus pensamentos, pelo apoio no momentos difíceis e presença nos momentos felizes. Aos meus colegas e amigos, muito obrigado por tudo.

À amiga Mayara: tão grande como a sua capacidade profissional é a sua capacidade de cativar as pessoas. Tenho muito orgulho de ser seu amigo. Agradeço a você pelo apoio durante o curso e por me presentear com a sua amizade. Você estará sempre em meu coração. Obrigado.

Aos amigos Danilo, Eduardo Franco e Luiz Fernando Bonfante, posso dizer com muito orgulho que sou, verdadeiramente, amigo de vocês. Obrigado pelo companheirismo ao longo desses anos. 
À amiga e colega Patrícia, agradeço pelo apoio durante o desenvolvimento deste trabalho. Tenha certeza que você também contribuiu para a sua execução. Muito obrigado pela sua amizade.

Aos alunos e ex-alunos do curso de Doutorado em Ortodontia, em especial a Leniana, Rodrigo, Karina Lima, Rafael, Paula, Lívia, Fernando Ozzi, Alexandre, Sérgio, Kelly, Cabrera, e a Renata.

Aos demais colegas do curso de Pós-graduação da FOB-USP, em especial aos amigos Buda, Estevam, Marcela, Renata, Angélica. Breno, Érica, Ian, Fernando Freitas, Ruan, Ismar, Gustavo, Dafna, Viviane, Tiago e Romão.

À todos os amigos do curso de Odontologia da Faculdade Federal de Odontologia de Diamantina. Vocês são presenças constantes em meus pensamentos. A saudade é enorme, queria que cada um de vocês estivesse aqui hoje. Em relação ao crescimento pessoal, vocês fizeram parte da fase mais importante da minha vida. Agradeço em especial aos amigos Bruno Jahn, Eduardo, Matheus, Moysés, Nízio, Wéverson, Márcio, Moysés Nadú, Marcos, Samir e Marquinhos e às amigas Sione, Simone, Marcelle, Arícia, Flávia, Gisele e Carol. Muito obrigado pelas lembranças inesquecíveis.

Aos professores e funcionários da UFVJM, meus sinceros agradecimentos por me proporcionar momentos tão felizes e pela amizade. 
Aos meus tios Márcio e Carlos, pela amizade e apoio constantes. Vocês foram fundamentais na escolha de minha carreira. O sucesso profissional de cada um de vocês despertou em mim, primeiramente, a vontade de realizar o curso superior na área de Odontologia e, posteriormente, de me especializar em Ortodontia. Muito obrigado pela convivência e pelos ensinamentos.

À minha tia e Professora Madalena Canuto, pela amizade, apoio e ensinamentos na área de Reabilitação Oral durante a minha graduação. Agradeço pelos exemplos dados de seriedade e competência.

Aos amigos e funcionários da ACOPEN: Renato, Luis Américo, Evellin, Ana, Bruna, Alice, Celso, Fabiano, Tommyo, Marcelo, Mahmed, Vítor, Luciana, César e Sônia, presentes nos meus primeiros passos em Bauru.

Aos amigos de infância de Belo Horizonte: João Paulo, Ricardo, Robert, André Jordani, Pablo, Vítor, Pablo, Karina, Adriano, Matheus Rubão, Gabriel e Alan. É muito difícil encontrar um bom amigo, mais difícil ainda deixá-lo, e impossível esquecê-lo.

Aos meus novos amigos de Bauru, porém não menos valiosos, Fabiana, Marcela, Ismar, Érica, Juliana Burgo, e Fábio. 
Aos funcionários da Disciplina de Ortodontia da FOB - USP, Neide, Cristina, Daniel, Sérgio, Vera, Luciana e "Tia" Maria pela dedicação, carinho e atenção com que sempre me atenderam.

Aos funcionários da Biblioteca e todos os demais funcionários desta instituição que sempre me atenderam de forma bastante prestativa.

Ao Conselho Nacional de Desenvolvimento Científico e Tecnológico CNPq, pelo apoio financeiro para a realização do curso e viabilização deste projeto.

À todos que direta ou indiretamente contribuíram para o desenvolvimento deste trabalho 



$$
\text { Somito }
$$





\section{SUMÁRIO}

\section{1 - INTRODUÇÃO}

\section{2 - REVISÃO DA LITERATURA}

2.1. Métodos para a avaliação da irregularidade dentária

2.2. Expansão rápida da maxila: efeitos, alterações dimensionais e estabilidade

2.3. A recidiva ortodôntica do apinhamento dentário: fatores etiológicos

2.3.1. Alterações na forma e dimensões dos arcos dentários

2.3.2. Desenvolvimento da oclusão

2.3.3. Forças periodontais

2.3.4 Apinhamento ântero-inferior $X$ apinhamento ânterosuperior

2.3.5. Tempo de contenção e apinhamento

3 - PROPOSIÇÃO

\section{4 - MATERIAL E MÉTODOS}

4.1. Material

4.2. Métodos

4.2.1. Avaliação dos modelos de estudo

4.2.2. Descrição das abreviaturas utilizadas para representar as variáveis estudadas

4.2.3. Análise Estatística.

4.2.3.1. Erro do Método

4.2.3.2. Método Estatístico 
5 - RESULTADOS

6 - DISCUSSÃO

6.1. Erro metodológico

6.2. Amostra utilizada e sua compatibilidade

6.3. Metodologia

6.4. Resultados

6.4.1. Alterações intragrupos (com e sem ERM) nos tempos avaliados

6.4.2. Comparação intergrupos das características pré, póstratamento e pós-contenção

6.4.3. Comparação intergrupos das alterações do tratamento

6.4.4. Comparação intergrupos das alterações pós-contenção.

6.4.5. Comparação intergrupos das alterações totais

6.4.6. Testes de Correlação.

6.5. Implicações clínicas e considerações finais

6.6. Sugestão para trabalhos futuros

\section{7 - CONCLUSÕES}

REFERÊNCIAS BIBLIOGRÁFICAS

\section{APÊNDICES}




\section{LISTA DE FIGURAS}

Figura 1. Índice de Irregularidade de Little $=A+B+C+D+E$

Figura 2. Variáveis estudadas na análise dos modelos superiores: A distância intercaninos, B e B' - distâncias entre os primeiros e segundos pré-molares, respectivamente, C - distâncias intermolares, D + E comprimento do arco e F - perímetro do arco . 


\section{LISTA DE TABELAS}

Tabela 1. Abreviaturas utilizadas

Tabela 2. Resultados do teste t e da fórmula de DAHLBERG, aplicados às variáveis avaliadas, para estimativa dos erros sistemáticos e casuais, respectivamente

Tabela 3. Resultados do teste Qui-Quadrado para avaliação da compatibilidade dos grupos 1 e 2 quanto à proporção dos gêneros

Tabela 4. Resultados do teste Qui-Quadrado para avaliação da compatibilidade dos grupos 1 e 2 quanto à severidade inicial das más oclusões

Tabela 5. Resultados do teste $\mathrm{t}$ independente, aplicado às variáveis índice de Little inicial, idades inicial e final, tempo de tratamento e tempo de avaliação pós-contenção dos grupos 1 e 2, com e sem expansão rápida, respectivamente, para avaliação da compatibilidade intergrupos

Tabela 6. Resultados do ANOVA para as variáveis dos modelos de estudo, do grupo 1 ( $N=25)$, nas três fases estudadas (T1, T2 e T3). Na presença de um resultado significante, realizou-se o teste de Tukey (letras diferentes demonstram diferença significante entre as medições).

Tabela 7. Resultados do ANOVA para as variáveis dos modelos de estudo, do grupo 2 ( $\mathrm{N}=23$ ), nas três fases estudadas ( $\mathrm{T} 1$, T2 e T3). Na presença de um resultado significante, realizou-se o teste de Tukey (letras diferentes demonstram diferença significante entre as medições)...... 
Tabela 8. Resultados do teste $t$ independente, aplicado às variáveis estudadas, para verificar as diferenças iniciais (T1), entre os grupos 1 e 2, com e sem expansão rápida, respectivamente

Tabela 9. Resultados do teste $t$ independente, aplicado às variáveis estudadas, para verificar as diferenças no estágio pós-tratamento (T2), entre os grupos 1 e 2, com e sem expansão rápida, respectivamente

Tabela 10. Resultados do teste $t$ independente, aplicado às variáveis estudadas, para verificar as diferenças no estágio pós-contenção (T3) entre os grupos 1 e 2, com e sem expansão rápida, respectivamente

Tabela 11. Resultados do teste $t$ independente, aplicado às variáveis estudadas, para verificar as diferenças das alterações do tratamento (T2-T1), entre os grupos 1 e 2, com e sem expansão rápida, respectivamente.

Tabela 12. Resultados do teste $t$ independente, aplicado às variáveis estudadas, para verificar as diferenças das alterações no período póstratamento (T3-T2), entre os grupos 1 e 2, com e sem expansão rápida, respectivamente.

Tabela 13. Resultados do teste $t$ independente, aplicado às variáveis estudadas, para verificar as diferenças das alterações no período total de observação (T3-T1), entre os grupos 1 e 2, com e sem expansão rápida, respectivamente

Tabela 14. Resultados do teste de correlação de Pearson

Tabela 15. Resultados do teste de correlação de Pearson 



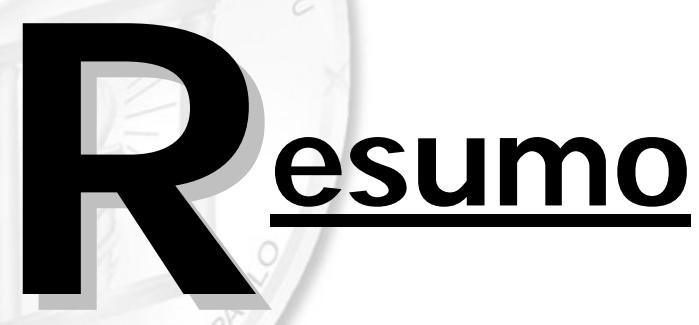





\section{RESUMO}

O presente estudo objetivou comparar, por meio de uma análise retrospectiva, a estabilidade pós-contenção do alinhamento dos incisivos ântero-superiores de pacientes submetidos ou não ao procedimento de expansão rápida da maxila durante o tratamento ortodôntico. A amostra consistiu-se de 48 pacientes de ambos os gêneros, apresentando más oclusões de Classe I e II, tratados sem extrações e mecânica Edgewise. A amostra total foi dividida em dois grupos de acordo com o protocolo de tratamento: Grupo 1 (com ERM) constituído por 25 pacientes (15 do gênero feminino e 10 do gênero masculino), com idade inicial média de 13,53 anos (d.p. $= \pm 1,63)$, submetidos à expansão rápida da maxila durante o tratamento ortodôntico. Grupo 2 (sem ERM) apresentando 23 pacientes (13 do gênero feminino e do 10 gênero masculino), com idade inicial de 13,36 anos (d.p. = $\pm 1,81$ anos), cujo tratamento ortodôntico não priorizou a expansão transversal maxilar. Foram medidos nos modelos de estudo das fases pré (T1), póstratamento (T2) e pós-contenção (T3) o índice de irregularidade de Little, as distâncias intercaninos e entre os primeiros e segundos pré-molares, a distância intermolares, o comprimento e o perímetro do arco superior. Após a obtenção dos dados, realizou-se a análise estatística. Para a comparação intragrupo nos 3 tempos de avaliação, utilizou-se a análise de variância a um critério de seleção, e em caso de resultado significante, o teste de Tukey. A comparação intergrupos foi realizada por meio de testes t independentes. Para verificação da presença de correlação entre a recidiva do apinhamento ânterosuperior e a recidiva das variáveis: distâncias intercaninos, interpré-molares, 
intermolares, comprimento e perímetro do arco, utilizou-se o teste de correlação de Pearson. Os resultados evidenciaram incrementos dimensionais transversais significantemente maiores no grupo tratado com ERM (grupo 1), entretanto, durante o período pós-contenção, não foram observadas diferenças significantes entre os grupos em relação à quantidade de aumento na irregularidade dos incisivos superiores (+1,52 mm em ambos os grupos), bem como em relação à maioria das variáveis estudadas. Concluiu-se que a realização do procedimento de expansão rápida da maxila não apresentou influência na recidiva do apinhamento ântero-superior em longo prazo.

Palavras-chave: Técnica de Expansão Palatina, Ortodontia Corretiva, Recidiva. 


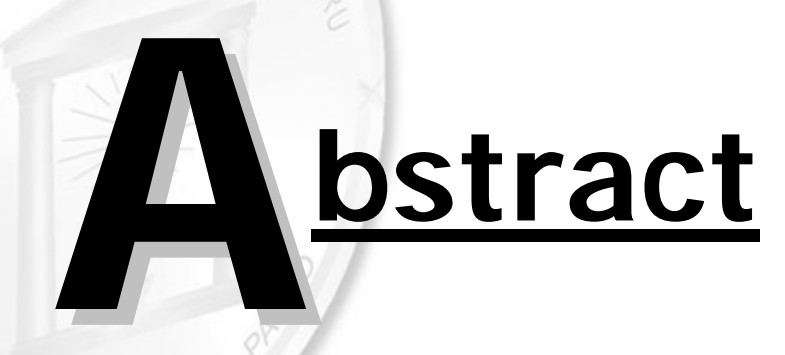





\section{ABSTRACT \\ Influence of rapid maxillary expansion in maxillary anterior alignment stability, in nonextraction cases}

The purpose of this retrospective study was to compare the long-term stability of maxillary incisors alignment in cases treated with or without rapid maxillary expansion (RME) during orthodontic treatment. The sample comprised 48 subjects presenting Class I and Class II malocclusions, treated nonextraction and Edgewise fixed appliances. The sample was divided into 2 groups according to the treatment protocol: Group 1 (with RME) comprised 25 patients (15 female; 10 male) at a mean initial age of 13.53 years (s.d. $= \pm 1.63$ ), who underwent rapid maxillary expansion during orthodontic treatment. Group 2 (without RME) comprised 23 patients (13 female; 10 male) at a mean initial age of 13.36 years (s.d. $= \pm 1.81$ years), treated with fixed appliances and no rapid maxillary expansion. Dental casts measurements were obtained at three times of evaluation (pretreatment, posttreatment and postretention) and the variables assessed were Little Irregularity Index, intercanine, interpremolar and intermolar widths, and maxillary arch length and perimeter. The statistical analysis was performed by one-way ANOVA and Tukey tests if necessary (intragroup comparison) and by independent t-tests (Intergroup comparison). Pearson' correlation coefficients were used to investigate possible associations between the variables evaluated. The results evidenced significant transversal increases in group treated with RME (group 1), however, during the postretention period, no significant differences were observed between the groups in the amount of maxillary incisors alignment relapse $(+1,52 \mathrm{~mm}$ in both groups), as well as in 
most of the variables evaluated. Therefore, it was concluded that the RME procedure did not influence the long-term maxillary anterior crowding relapse.

Keywords: Palatal Expansion Technique, Corrective Orthodontics, Crowding. 
ntrodução 



\section{1 - INTRODUÇÃO}

Os tratamentos ortodônticos têm como objetivo primordial a correção das más oclusões, entretanto, estas correções apresentam considerável variabilidade em relação à estabilidade pós-contenção. Embora exista um consenso na literatura ortodôntica que algumas alterações oclusais irão ocorrer inevitavelmente após o término do tratamento ortodôntico ${ }^{115,145,206}$, evidenciouse que a estabilidade do alinhamento dos dentes é altamente variável e amplamente imprevisível ${ }^{7,121}$. Em relação à abordagem científica, apesar de numerosas pesquisas sobre a etiologia da recidiva ortodôntica do apinhamento ântero-inferior $8,9,24,25,58,65,66,103,106,115,147,163,181,186-188,209,219,220$, uma menor quantidade de estudos foram conduzidos com enfoque às alterações póstratamento na região ântero-superior e aos possíveis fatores associados à magnitude desta recidiva $33,59,94,137,179,200$. A expansão rápida da maxila tem sido sugerida por alguns autores como um procedimento auxiliar na estabilidade pós-contenção do alinhamento dos incisivos superiores e inferiores ${ }^{8,137,184}$. Desta forma, o presente trabalho teve como objetivo analisar retrospectivamente, por meio do Índice de Irregularidade de Little ${ }^{114}$, a estabilidade do alinhamento dentário do segmento ântero-superior, em casos tratados ortodonticamente com ou sem a realização do procedimento de expansão rápida da maxila, visando estabelecer se este procedimento ortopédico teria influência ou não na estabilidade pós-tratamento do alinhamento dos incisivos superiores. 



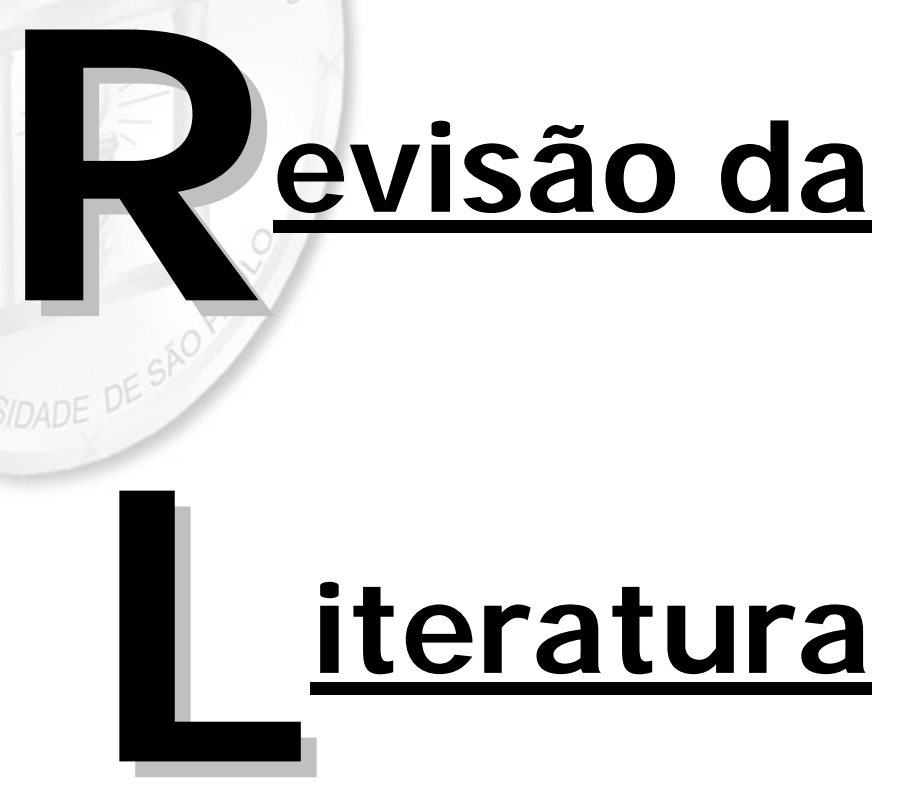





\section{2 - REVISÃO DA LITERATURA}

A presente revisão de literatura será dividida em tópicos com o intuito de facilitar a leitura assim como a compreensão dos assuntos abordados. Desta forma, são descritos cada um dos assuntos pertinentes a este trabalho, até abordar efetivamente estudos que analisaram os fatores relacionados à recidiva do apinhamento dentário, cujos resultados deste estudo se relacionam.

Primeiramente são descritos os métodos utilizados para a avaliação da recidiva da irregularidade dentária, rotineiramente descrita como apinhamento dentário. Em seguida, são abordados estudos referentes aos efeitos e alterações dimensionais proporcionadas pela expansão rápida da maxila, assim como a estabilidade longitudinal deste procedimento. Ao final, realiza-se uma análise da literatura a respeito dos fatores associados à recidiva ortodôntica do apinhamento dentário. Foram incluídos neste último tópico, trabalhos relativos à recidiva do apinhamento dos dentes dos arcos superior e inferior após a remoção das contenções e alguns trabalhos que avaliaram, especificamente, a estabilidade do alinhamento dos dentes ântero-superiores e as possíveis causas da recidiva neste segmento do arco dentário.

\subsection{Métodos para a avaliação da irregularidade dentária}

Um dos objetivos fundamentais do tratamento ortodôntico é o correto alinhamento dos dentes. Um método preciso para a avaliação do apinhamento ou irregularidade dentária, portanto, representa um aspecto crítico e necessário para o correto diagnóstico, planejamento do tratamento, e avaliação dos 
resultados obtidos. Um índice que avalia o grau de apinhamento também pode ser útil em programas de saúde pública, assim como para a avaliação das alterações no período pós-contenção ortodôntica ${ }^{114}$.

O grau de apinhamento dentário pode ser determinado pela subtração do espaço requerido pelo espaço disponível, geralmente expresso em milímetros, ou por meio de índices que avaliam a irregularidade dentária ${ }^{97}$.

A quantificação do apinhamento dentário pode ser baseada na medição do grau de deslocamento vestibulolingual dos pontos de contato anatômicos $^{10,30,114,133,140,151,161,168,212}$. Muitos dos trabalhos que utilizam esta metodologia foram originariamente idealizados com a finalidade de quantificar o apinhamento ântero-inferior, mas foram subseqüentemente modificados para a sua utilização em todo o arco dentário.

Outra maneira de avaliação do apinhamento dentário consiste na análise do perímetro do arco dentário. Nesta situação, afere-se a discrepância existente entre o diâmetro mesiodistal dos dentes e o espaço disponível no arco (perímetro do arco). O perímetro do arco pode ser mensurado a partir dos modelos de estudo por meio de diferentes métodos que incluem a utilização de fios de latão ou multifilamentosos ${ }^{36,95,139}$, mensuração por segmentos de $\operatorname{arco}^{122,133}$, técnicas indiretas utilizando fios metálicos ${ }^{11,223}$, método do $\operatorname{arcograma}^{88}$, catenômetro ${ }^{138}$ e ampliações fotográficas ${ }^{16}$. Outros métodos incluem a utilização de programas para computadores associados a processos de digitalização eletrônica ${ }^{31,93,177}$, avaliação tridimensional pelo aparelho "Reflex metrograph"1 100,166 ou pela aplicação de fórmulas matemáticas ${ }^{148,160}$.

\footnotetext{
${ }^{1}$ H. F. Ross, Ross Instruments Ltd., Salisbury, Wiltshire, Inglaterra.
} 
O emprego de uma análise baseada no perímetro do arco apresenta algumas limitações. Embora a medição dos diâmetros mesiodistais dos dentes seja relativamente simples, nota-se alguma dificuldade para a determinação do perímetro dos $\operatorname{arcos}^{2,88}$. Problemas na determinação da forma do perímetro dos arcos e a subjetividade no julgamento de uma forma ideal resultam em deficiências na precisão, validade e reprodutibilidade desta forma de análise. A substituição da curvatura do perímetro do arco por uma opção de análise que divide o arco em segmentos retilíneos invariavelmente resultará em subestima do espaço disponível ${ }^{2,21}$.

Ao longo dos anos, foram desenvolvidos vários índices que avaliam, além do apinhamento dentário, a situação oclusal geral. Estes índices atribuem valores numéricos às condições oclusais com a finalidade de classificar e avaliar a severidade das más oclusões, geralmente, em relação a condições ortodônticas consideradas normais ou ideais. Vários índices oclusais têm sido aplicados rotineiramente, incluindo o Índice $\mathrm{HLD}^{50}$, Índice de prioridade de Tratamento (IPT) da Associação Americana de Ortodontistas ${ }^{180}$, o Índice Oclusal $^{199}$ e a escala de avaliação de Proffit; Ackerman ${ }^{153}$.

A validade constitui-se a principal qualidade necessária a um índice. A validade de um índice apresenta-se diretamente relacionada com a sua precisão e reprodutibilidade ${ }^{37}$. Desta forma, vários estudos foram realizados ao logo dos anos com o objetivo de analisar a confiabilidade dos diversos índices e, desta forma, testar suas efetividades e validades $62,71,78,86,97,114,150,203$.

Alguns índices que avaliam de forma específica o apinhamento dos incisivos foram propostos. Em 1952, Barrow; White ${ }^{10}$ descreveram a apinhamento dentário em termos de uma fração em relação ao diâmetro 
mesiodistal dos incisivos permanentes. Moorrees; Reed ${ }^{133}$ afirmaram que 0 apinhamento pode ser visualizado como uma diferença numérica entre o diâmetro mesiodistal das coroas e o espaço disponível, desta maneira, priorizaram uma avaliação em relação ao perímetro do arco.

Van Kirk; Pennel ${ }^{212}$, em 1959, sugeriram um método numérico de avaliação do apinhamento, muito embora não fosse efetivamente um método quantitativo. Segundo a metodologia preconizada pelos autores ${ }^{212}$ à presença de um alinhamento ideal dos dentes era atribuído o escore zero, a uma rotação dos incisivos menor que $45^{\circ}$ ou a um deslocamento linear menor que $1.5 \mathrm{~mm}$ era atribuído o escore 1 . Em relação à valores de rotação e deslocamento dentário superiores a $45^{\circ}$ e $1.5 \mathrm{~mm}$, respectivamente, era atribuído o escore 2 . Este mesmo método foi também utilizado por Grainger $^{76}$ para o calculo do índice IPT. Björk; Krebs; Solow ${ }^{22}$ realizaram pequenas modificações no método proposto por Van Kirk; Pennel ${ }^{212}$, utilizando o valor de $15^{\circ}$ como a quantidade limite de rotação entre uma condição caracterizada como normal ou com apinhamento. Neste método, também eram levados em consideração desvios da linha média maiores do que $2 \mathrm{~mm}$ em relação à linha média do processo alveolar. Summers ${ }^{199}$ preconizava um método similar ao proposto por Van Kirk; Pennel $^{212}$, atribuindo 0 escore 1 aos casos que apresentavam um deslocamento de incisivos de 1,5 a $2 \mathrm{~mm}$ ou uma rotação de 35 a $45^{\circ} \mathrm{em}$ relação ao alinhamento normal do arco. O escore 2 seria atribuído a deslocamentos dentários superiores a $2 \mathrm{~mm}$ ou rotações maiores que $45^{\circ}$.

Draker $^{50}$, em 1960, propôs o índice das más posições dentárias vestibulolinguais (IMPDVL). O apinhamento ou deslocamento vestibulolingual era definido como a distância linear dos dentes em relação ao arco em 
condições normais. De acordo com o autor ${ }^{50}$, o índice proporciona condições para avaliar, nos pacientes ou em modelos de estudo, os fatores causadores de deformações faciais que podem influenciar na aceitação do paciente na escola ou trabalho. Além do apinhamento anterior e deslocamento vestibulolingual dos dentes eram observadas condições como a presença de fenda palatina, desvios traumáticos severos, trespasse horizontal, trespasse vertical, protrusão mandibular, presença de mordida aberta e erupção ectópica.

O Índice de Prioridade de Tratamento (IPT) proposto por Salzmann ${ }^{180} \mathrm{e}$ utilizado pela Associação Americana de Ortodontistas (AAO) avalia o componente apinhamento de forma subjetiva, apenas atribuindo escore pela sua presença, desta forma, não há diferenciação em relação à quantidade de apinhamento. Proposta por Proffit; Ackerman ${ }^{153}$, em 1973, a denominada "Escala de Avaliação" descreve também de forma subjetiva a avaliação do apinhamento. Neste método, a severidade do apinhamento apresenta-se dividida em uma escala de 0 a 5.

Little $^{114}$, em 1975, atribuiu ao apinhamento dentário na região anterior um dos maiores fatores motivadores para a busca pelo tratamento ortodôntico por parte dos pacientes, e destaca a grande preocupação dos ortodontistas, pais e do público em geral que avidamente buscam por sua correção. $\mathrm{O}$ autor ${ }^{114}$ cita que termos como irregularidade dentária ou apinhamento apresentam certa subjetividade. Adjetivos como suave, moderado, severo ou significante auxiliam durante o diagnóstico, mas podem gerar grande variabilidade em suas interpretações. Desta forma, o autor ${ }^{114}$ propôs o chamado Índice de Irregularidade de Little, com o objetivo de eliminar a subjetividade na 
interpretação dos dados, quantificando e atribuindo escores ao apinhamento dos incisivos.

Para Little ${ }^{114}$, a evidência da progressiva instabilidade do tratamento ortodôntico é sempre primeiramente notada pelo apinhamento dos incisivos inferiores após a remoção das contenções. Uma vez que a condição dentária ântero-inferior parece ser um fator limitante no tratamento e na estabilidade, o autor desenvolveu um índice de diagnóstico que refletisse precisamente a condição desses dentes. Sendo assim, Little ${ }^{114}$, introduziu um método que envolve a medição direta do deslocamento linear dos pontos de contato anatômicos dos incisivos inferiores adjacentes, no qual a soma das cinco medições representa o valor do índice de irregularidade. A medida é realizada preferencialmente a partir do modelo de estudo pela maior facilidade em relação ao correto posicionamento do paquímetro. O paquímetro (calibrado até pelo menos em décimos de milímetro e apresentando pontas finas) deve ser mantido paralelamente ao plano oclusal. $\mathrm{O}$ autor ${ }^{114}$ recomenda que espaços mesiodistais sejam desconsiderados desde que os dentes em questão estejam alinhados apropriadamente. Little ${ }^{114}$ qualificou o apinhamento ântero-inferior de acordo com o escore obtido durante a medição do apinhamento ântero-inferior. O apinhamento foi qualitativamente classificado em alinhamento perfeito ou apinhamentos suave, moderado, severo e muito severo. Foi considerado como alinhamento perfeito valores de 0 a $1 \mathrm{~mm}$, apinhamento suave de 1 a $3 \mathrm{~mm}$, moderado de 4 a $6 \mathrm{~mm}$, severo de 7 a $9 \mathrm{~mm}$, e muito severo, acima de $9 \mathrm{~mm}$, medidos pelo índice de irregularidade de Little. O autor ${ }^{114}$, neste mesmo artigo, testou a validade e reprodutibilidade do seu "Índice de Irregularidade" e comprovou sua efetividade. Little ${ }^{114}$ atribuiu ao índice, além da função 
específica de quantificar de forma objetiva o apinhamento, a função de auxiliar os ortodontistas em suas pesquisas. Também ressaltou ${ }^{114}$ sua aplicabilidade em programas de saúde pública e assistenciais como um guia no estabelecimento de prioridades de tratamento, uma vez que o índice afere a severidade da má oclusão. O índice de Irregularidade proposto por Little ${ }^{114}$ pode ser utilizado como um dos vários métodos para a avaliação da situação inicial de uma má oclusão assim como para o estudo das alterações após o tratamento.

O índice PAR ("Peer Assessment Rating"), foi introduzido por Richmond et al. $^{167,168}$, em 1992, e tem sido amplamente utilizado pela sua precisão e validade. Além da análise do alinhamento dos segmentos ântero-superior e ântero-inferior, são avaliados os segmentos posteriores, a oclusão dos segmentos posteriores, os trespasses vertical e horizontal e a discrepância da linha média. A análise dos componentes individuais é realizada a partir dos modelos de gesso. O apinhamento dentário é aferido pela distância linear entre os pontos de contato anatômico de dentes adjacentes por meio de régua específica, compasso de ponta seca ou paquímetro. O princípio do índice PAR consiste em atribuir um escore às várias características oclusais que constituem uma determinada má oclusão e, posteriormente, às características oclusais ao término do tratamento ortodôntico e durante o período póscontenção. Os valores individuais de cada componente deste índice são somados para a obtenção do índice total e podem representar o grau de complexidade da má oclusão, o resultado que foi obtido com o tratamento, ou a estabilidade oclusal pós-contenção. O objetivo do índice PAR, portanto, 
consiste em quantificar os resultados obtidos pelo tratamento ortodôntico, assim como o grau de sucesso e estabilidade do tratamento.

Com a finalidade de avaliar um novo método de quantificação do apinhamento dentário a partir dos modelos de gesso, Johal; Battagel ${ }^{97}$, em 1997, realizaram um estudo que avaliou o grau de irregularidade dentária por meio da microscopia reflexa associada a um programa computadorizado. Este método foi testado em relação a duas estratégias: estimativa visual e por meio do fio de latão. Para a realização do trabalho, um único examinador comparou as medidas de trinta pares de modelos de estudo, obtidas para cada método, em dois tempos. Os resultados demonstraram que o método do microscópio reflexo apresenta validade e maior reprodutibilidade que os métodos de exame visual e do fio de latão. Esses dois métodos mostraram uma tendência positiva em direção a sobre-estima. O exame visual foi associado a uma subestima da quantidade de apinhamento.

As diferentes metodologias aplicadas para a avaliação da estabilidade oclusal em longo prazo foram revisadas por BeGole; Sadowsky ${ }^{13}$, em 1999. Os autores $^{13}$ concentraram-se na avaliação realizada utilizando os modelos de estudo, pois consideram ${ }^{13}$ que as alterações oclusais são mais refletidas em modelos longitudinais e consistem nas principais causas de preocupação por parte dos pacientes muitos anos após o término do tratamento ortodôntico. $\mathrm{O}$ trabalho concentrou-se em métodos de verificação do apinhamento dentário e nos procedimentos físicos e matemáticos utilizados para avaliação e medição

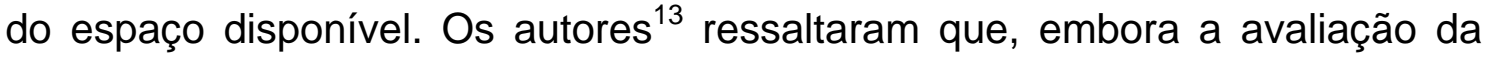
estabilidade do tratamento seja geralmente realizada avaliando-se características oclusais, outros fatores com a estética facial, estabelecimento 
de uma oclusão funcional e a satisfação do paciente em relação ao tratamento devem ser considerados. Comentaram ${ }^{13}$ que a estabilidade em longo prazo sempre será uma preocupação dos pacientes e dos ortodontistas. Entretanto, os resultados obtidos nos diferentes trabalhos tendem a ser desapontadores, particularmente com respeito à irregularidade dos incisivos inferiores. Alguns relatos por parte de clínicos apresentam-se sempre mais otimistas e estes resultados favoráveis representam o sucesso, atingidos por meio de um rigoroso protocolo de contenção e pelo uso de estratégias para aumentar a estabilidade, incluindo atenção a detalhes na finalização, fibrotomia supracristal, realização de desgaste interproximal e o uso de contenção fixa em longo prazo. Os autores ${ }^{13}$ observaram ao final do trabalho que é insensato esperar um resultado perfeitamente estável por toda a vida devido aos processos de maturação da face e dos dentes.

\subsection{Expansão rápida da maxila: efeitos, alterações dimensionais e} estabilidade

Na extensa bibliografia relacionada ao procedimento da expansão rápida da maxila, o primeiro a comentar sobre a expansão maxilar por meio da abertura da sutura palatina mediana foi a Angell ${ }^{4}$, em 1860, que também foi 0 primeiro a citar a necessidade de contenção após a movimentação ortodôntica. Nesta época, o trabalho foi desacreditado, mas atualmente o procedimento de expansão rápida da maxila se tornou amplamente aceito e caracterizado como uma intervenção ortodôntica relativamente simples e previsível ${ }^{208}$. 
O primeiro estudo cefalométrico dos resultados ortodônticos, publicado por Brodie ${ }^{28}$, em 1938, derrubou o denominado Conceito Funcional de Desenvolvimento quando constatou que os efeitos resultantes somente da movimentação ortodôntica eram restritos a alterações dentoalveolares. Este fato, associado aos excelentes resultados obtidos pelos europeus empregandose a expansão rápida da maxila, impulsionou a pesquisa e a propagação deste procedimento no cenário da Ortodontia norte-americana e mundial, a partir da década de 50.

O princípio da expansão rápida consiste na utilização de um aparelho expansor capaz de aplicar forças ortopédicas sobre os dentes ou sobre os dentes e palato duro. A aplicação desta força torna possível a separação da sutura palatina mediana e, deste modo, o arco superior é expandido ${ }^{79-}$ $81,105,128,221,222$. Os aparelhos para a expansão rápida produzem forças de grande magnitude sobre a sutura por um curto intervalo de tempo 20,227 . Estas forças intensas maximizam a separação da sutura palatina mediana antes que algum movimento dentário ou adaptação sutural fisiológica possam ocorrer $^{81,222}$. A expansão decorrente da abertura da sutura é caracterizada como uma expansão esquelética, uma expansão dentária é obtida como resultado da inclinação para vestibular dos dentes pósterosuperiores $^{20,43,79,81,89,96,107,128,222,227}$. A proporção entre os movimentos dentários e os efeitos esqueléticos apresenta-se diretamente relacionada à quantidade de expansão e à idade do paciente durante o tratamento ${ }^{43,89,105,107}$. O objetivo da expansão rápida consiste em maximizar os efeitos esqueléticos e minimizar os movimentos dentários ${ }^{79,96}$. O procedimento tem sido defendido por Haas ${ }^{79-82}$ e outros autores ${ }^{4,20,32}$ como o método mais favorável para a correção da 
deficiência transversal da maxila, principalmente em idades precoces. Uma vez que a terapia produz efeitos ortopédicos, a expansão do arco envolve alterações esqueléticas e, portanto, mais estáveis ${ }^{17,80}$.

Haas $^{79-82}$ e Sandstrom; Klapper; Papaconstantinou ${ }^{182}$ observaram que, após a ERM, o arco inferior também apresentava uma pequena expansão dentária. Os autores ${ }^{79-82,182}$ sugeriram que esta resposta era resultado de alterações na função muscular, modificada pela expansão transversal da maxila. Desta forma, uma vez que a maxila é expandida, a alteração no equilíbrio muscular resulta em redução nas forças exercidas pelo bucinador sobre o arco inferior e em um aumento da influência da língua sobre os dentes inferiores. O aumento da influência da língua no arco inferior é proporcionado pelo seu deslocamento para baixo pela presença do parafuso expansor. Tem sido discutido que a expansão do arco superior pela abertura da sutura palatina mediana pode ser considerada permanente porque o reparo sutural envolve a neoformação óssea. Por outro lado, as alterações resultantes do movimento dentário e inclinação dos processos alveolares apresentam-se questionáveis quanto as suas estabilidades ${ }^{79}$.

Os aparelhos para expansão rápida podem apresentar ancoragem restrita aos dentes posteriores, ou uma ancoragem sobre os dentes e mucosa. O expansor dentossuportado mais comum é o Hyrax, apoiando-se apenas nos dentes posteriores. O expansor preconizado por Haas é classificado como um aparelho dentomucosuportado por apresentar uma parte em acrílico que recobre parcialmente o palato duro ${ }^{79-81}$. Tem-se ainda o expansor com cobertura oclusal em acrílico ${ }^{42}$, também classificado como dentossuportado. Os três aparelhos apresentam efeitos similares ${ }^{195}$. 
A expansão rápida da maxila (ERM) consiste em um procedimento com renovado interesse na mecânica ortodôntica, principalmente nas últimas duas décadas, devido a sua potencialidade em aumentar o perímetro do arco e conseqüentemente permitir a correção do apinhamento no arco superior sem efeitos adversos significativos no perfil facial ${ }^{20,79-82}$. Apesar dos principais efeitos do tratamento serem notados clinicamente em relação ao arco dentário superior, incrementos transversais da base apical e estruturas ósseas podem ser consideradas como contribuições adicionais ${ }^{35}$.

No plano frontal, a ERM promove a separação das duas metades da maxila súpero-inferiormente de forma não-equivalente, com o fulcro de rotação localizado próximo a sutura frontomaxilar ${ }^{79,105,222}$. Em relação a uma vista oclusal, pode-se observar uma maior abertura da sutura palatina mediana na região anterior, que diminui proporcionalmente em amplitude seguindo-se uma direção posterior ${ }^{48,55,79,222}$.

Em 1964, os efeitos da expansão rápida da maxila sobre as dimensões transversais do arco dentário superior e da base óssea maxilar, bem como a estabilidade dessas alterações em longo prazo, foram estudados por Krebs ${ }^{105}$ utilizando implantes metálicos. Neste estudo clássico, o autor ${ }^{105}$ observou que os maiores aumentos transversos na base óssea maxilar foram obtidos em idades precoces (antes e durante a puberdade), e embora houvesse uma pequena recidiva logo após a expansão, o efeito ortopédico apresentou estabilidade. O incremento em largura do arco dentário exibiu uma constante recidiva durante um período de quatro a cinco anos após o término do tratamento. A estabilidade das alterações dentárias e esqueléticas atribuídas à expansão rápida da maxila também foi avaliada por Linder-Aronson; 
Lindgren $^{111}$ quinze anos mais tarde. Os resultados deste estudo ${ }^{111}$ evidenciaram que o aumento das distâncias intermolares e intercaninos superiores, após o período de cinco anos, representou apenas 45\% e 23\%, respectivamente, da quantidade de expansão obtida inicialmente. Estes resultados corroboram com os obtidos por Haas ${ }^{81,82}$ e outros pesquisadores $^{135,183,191}$, que também observaram quantidades significativas de recidiva transversal e ressaltaram que durante o procedimento expansão rápida, para atingir todos os benefícios desta técnica, deveria se realizar a sobrecorreção da expansão transversal.

No intento de esclarecer aos clínicos as alterações dentoesqueléticas que acompanham a expansão rápida da maxila, Wertz; Dreskin ${ }^{221}$, em 1977 , avaliaram 56 casos, por meio de telerradiografias em norma frontal e lateral, em quatro fases distintas: pré-tratamento, pós-expansão, pós-contenção e ao final do tratamento corretivo completo. Os pacientes, com idades de 8 a 29 anos, usaram diferentes tipos de aparelhos de expansão rápida. Os resultados obtidos foram comparados com o crescimento normal, a fim de se identificar as alterações atribuídas à mecânica. Os autores ${ }^{221}$ observaram que a expansão maxilar foi efetiva em todos os casos, porém em pacientes com idades mais avançadas, ocasionou pequeno efeito ortopédico. Estes resultados corroboram com os previamente obtidos por Melsen ${ }^{128}$, Zimring; Isaacson ${ }^{227}$ e Isaacson; Ingram $^{96}$ que observaram uma menor efetividade do procedimento de ERM quanto maior o grau de maturação esquelética e, conseqüentemente, de fusão da sutura palatina mediana. Além disso, Wertz; Dreskin ${ }^{221}$ observaram um aumento estável em relação à largura da base maxilar, principalmente em pacientes jovens. 
Com o objetivo de verificar a relação entre expansão rápida da maxila e a quantidade de aumento no perímetro do arco dentário superior, Adkins; Nanda; Currier $^{2}$, em 1990, realizaram um estudo em 21 jovens submetidos à expansão com o aparelho Hyrax. Os pacientes apresentavam idades variando entre 11 anos e seis meses e 17 anos. O aparelho foi ativado duas vezes por dia, um quarto de volta de manhã e outro quarto de tarde, até que a expansão desejada fosse obtida. A quantidade de expansão média foi de $0,5 \mathrm{~mm}$ por dia. O tempo médio de estabilização realizada com o próprio aparelho foi de 14,5 semanas (mínimo de 10 semanas, máximo de 21 semanas). Os autores ${ }^{2}$ utilizaram para realização das medições os modelos de gesso nos períodos pré-expansão e pós-estabilização. Os resultados indicaram que a expansão rápida da maxila produz um aumento no perímetro do arco dentário superior equivalente a 0,7 vezes a quantidade de aumento na distância interprémolares, informação que facilita o planejamento de casos sem extrações, uma vez que torna possível prever incrementos no perímetro do arco em relação a uma determinada quantidade de expansão. Os autores ${ }^{2}$ observaram ainda um pequeno movimento lingual dos incisivos superiores, inclinação vestibular dos dentes de ancoragem e uma suave verticalização compensatória dos dentes póstero-inferiores. Durante o período de estabilização, ocorreu uma maior verticalização dos dentes póstero-inferiores nos pacientes que não apresentavam mordida cruzada posterior ao início do tratamento.

Betts et al. $^{17}$, em 1995, ressaltaram como vantagens da expansão ortopédica da maxila: 1- a maior estabilidade da correção transversal; 2- a menor necessidade de extrações dentárias nos casos de apinhamento; 3- a melhora na estética do sorriso com a diminuição do corredor bucal; 4- o 
favorecimento da saúde periodontal; 5- ocasionalmente, o aumento da permeabilidade nasal.

Vardimon et al. ${ }^{213}$, em 1998, se propuseram a determinar a participação dos componentes esqueléticos e dentários no aumento da largura do arco dentário superior, assim como na recidiva, após a expansão rápida da maxila. Para tanto, realizaram um estudo em gatos, utilizando radiografias oclusais obtidas finda a fase de ativação do parafuso expansor, após um período de 60 dias de contenção e após 60 dias da remoção do aparelho. Os resultados apontaram que o aumento na largura intercaninos, após a expansão, resultou da abertura da sutura palatina mediana (45\%) e da inclinação dentoalveolar para vestibular (55\%). Na última fase do estudo, ocorreu uma recidiva de $46 \%$ na largura da região anterior do arco dentário, devido à verticalização dentoalveolar e à reaproximação parcial dos processos palatinos da maxila.

No ano 2000, McNamara ${ }^{125}$ destacou a importância do procedimento de expansão rápida da maxila não somente para a correção das mordidas cruzadas posteriores, mas em todas as más oclusões que apresentem uma deficiência transversal da maxila. Salientou ${ }^{125}$ que problemas transversais maxilares talvez sejam um dos problemas esqueléticos mais freqüentes da região craniofacial. $\mathrm{O}$ autor ${ }^{125}$ recomenda a análise do comprimento transversal do palato como parte da avaliação inicial do paciente. Deve-se medir a distância entre os pontos mais próximos localizados na face palatina dos primeiros molares. O comprimento transversal deve apresentar-se, aproximadamente, entre 36 e $39 \mathrm{~mm}$ para que o arco dentário possa acomodar satisfatoriamente todos os dentes, desde que apresentem diâmetros mésiodistais dentro do padrão médio. Arcos superiores com dimensões transversais 
menores que $31 \mathrm{~mm}$ podem apresentar apinhamentos e conseqüentemente necessidade de expansão rápida ${ }^{93}$. McNamara ${ }^{125}$ comentou sobre a aplicabilidade do procedimento em pacientes que não apresentam mordida cruzada posterior. Segundo o autor ${ }^{125}$, o apinhamento e a protrusão dentária derivam de uma discrepância entre o tamanho dos dentes e o tamanho da base óssea, afirmação que corrobora com relatos de Howe; McNamara; O'Connor ${ }^{93}$, que observaram que o apinhamento dentário em descendentes Europeus parece estar mais relacionado com a deficiência no perímetro do arco do que com um diâmetro mesiodistal dos dentes excessivo. McNamara ${ }^{125}$ ressalta ainda que as deficiências transversal e sagital constituem os principais fatores causadores do apinhamento dentário.

Ciambotti et al. ${ }^{41}$, em 2001, compararam a efetividade do expansor palatino de níquel-titânio (expansão lenta) com os aparelhos para expansão maxilar rápida. Os autores utilizaram o aparelho expansor proposto por $\mathrm{Arndt}^{5}$, em 1993, que proporcionava a aplicação de forças suaves e contínuas sobre a sutura palatina. A amostra consistiu de 25 pacientes que necessitavam de expansão palatina como parte de seus tratamentos ortodônticos. A amostra foi dividida em dois grupos, com 13 pacientes no grupo utilizando expansores de NITI e 12 pacientes no grupo tratado com expansão rápida da maxila. Os modelos de estudo foram analisados antes da expansão e ao final do período de contenção (aproximadamente 3 meses após a expansão). Os resultados demonstraram que ambas as técnicas forma capazes de corrigir as mordidas cruzadas posteriores, mas o aparelho de NITI apresentou uma menor efetividade em relação à abertura da sutura palatina mediana. Os aparelhos de expansão rápida promoveram maior aumento na amplitude do palato, enquanto 
que os casos tratados por meio do procedimento de expansão lenta (molas de NITI) apresentaram maior inclinação vestibular e rotação distal dos molares.

Com o propósito de avaliar as alterações dimensionais proporcionadas pelo procedimento de ERM sobre os arcos dentários a curto e longo prazo, McNamara et al. ${ }^{126}$, em 2003, avaliaram 112 pacientes submetidos à ERM seguida de mecânica Edgewise. Constataram ${ }^{126}$ alterações significantes nas dimensões dos arcos superior e inferior, tanto ao final do tratamento (3 anos) quanto ao final do período de avaliação pós-contenção (6 anos). Observaram $^{126}$ um ganho de $3 \mathrm{~mm}$ no perímetro do arco superior da fase inicial ao período pós-contenção em comparação ao grupo controle sem tratamento que sofreu uma redução de $3 \mathrm{~mm}$ neste mesmo intervalo.

Não obstante as vantagens do procedimento de expansão rápida da maxila se apresentem de forma clara na literatura científica, questiona-se se algumas alterações dentárias e esqueléticas resultantes desta terapia representam efeitos adversos ou desvantagens do procedimento. A literatura apresenta vários estudos que afirmam que a ERM resulta em abertura da mordida na região anterior devido a extrusão do segmento posterior e estabelecimento de contatos prematuros ${ }^{89,172}$, além de promover 0 deslocamento da maxila para baixo e para frente ${ }^{18,68,81}$. Entretanto, a maioria das investigações que citam essas alterações, avaliou os efeitos da terapia de ERM a curto prazo $34,40,79,81,190,222$. Poucos foram os estudos que avaliaram os pacientes cinco anos ou mais após o tratamento ${ }^{70,82,111,126,221}$, além disso, alguns destes trabalhos apresentavam deficiências metodológicas como a falta de grupo controle, inadequado poder estatístico, e amostras com grande variação nas idades. Chang; McNamara; Herberger ${ }^{38}$, em 1997, buscando 
resultados mais confiáveis, avaliou as alterações em longo prazo do expansor tipo Haas em relação aos efeitos de abertura da mordida e reposicionamento ântero-posterior da maxila. O grupo experimental consistiu-se de 25 pacientes com média de idade inicial de 11 anos e 8 meses e que foram submetidos à terapia de expansão rápida da maxila, seguida pelo tratamento ortodôntico fixo. Esta amostra foi comparada a dois grupos controles, um tratado exclusivamente por terapia fixa (25 pacientes) e outro sem qualquer intervenção (23 pacientes). Todos os três grupos apresentavam pacientes com más oclusões de Classe I ou II, apresentando características similares e idades compatíveis. As alterações para os três grupos foram comparadas após o tratamento ativo (idade de 14 anos e 8 meses) e no período pós-contenção (idade de 21 anos). Os resultados demonstraram que não houve diferença estatisticamente significante entre os três grupos para oito das dez variáveis cefalométricas estudadas (ângulo do eixo facial, SNB, ANB, P-Nperp, Nperp-A, plano facial, plano palatino e AFAI). Uma diferença estatisticamente significante entre os grupos foi observada para a variável SNA após a fase ativa de tratamento, entretanto, esta diferença foi clinicamente insignificante (aproximadamente $1^{\circ}$ ). Além disso, não houve diferença total entre os grupos para os valores do SNA. Houve diferença significante em relação à inclinação do plano mandibular entre o grupo experimental e os grupos controles, entretanto esta inclinação reduziu durante o período de observação em todos os grupos. A redução foi menor em $1,6^{\circ}$ para o grupo submetido à ERM que pode, entretanto, não ser clinicamente significante ${ }^{38}$. Os autores ${ }^{38}$ concluíram $^{2}$ que a ERM empregada no tratamento de pacientes apresentando más 
oclusões de Classe I ou II não apresenta efeitos significantes em longo prazo tanto na dimensão vertical como na dimensão ântero-posterior da face.

Ao avaliar as referências na literatura sobre os efeitos transversais proporcionados pela expansão rápida da maxila, observa-se que o incremento transversal ósseo do arco superior e conseqüente aumento tanto do perímetro quanto das distâncias intercaninos e intermolares no arco superior e, em menor proporção, no arco inferior, apresenta-se inquestionável. A recidiva das alterações transversais mostra-se significativa, muito embora não implique na invalidação de tal procedimento, uma vez que artifícios como a sobrecorreção podem ser utilizados ${ }^{80,81,134,183,191}$. À expansão rápida é atribuída uma capacidade de minimizar a expansão dentoalveolar em casos corrigidos sem extrações, o que favoreceria a estabilidade e, até certo ponto, reduziria a necessidade de extrações dentárias ${ }^{17}$ por proporcionar um aumento efetivo no perímetro do arco superior ${ }^{20,32,70,81,82}$. As alterações transversais ortopédicas promovidas pela expansão rápida da maxila ${ }^{2,4,17,105,111,125,214,221}$, principalmente em pacientes jovens, sugerem uma tendência à menor recidiva do apinhamento dos dentes ântero-superiores no período pós-contenção pela maior estabilidade destes efeitos sobre o arco superior, entretanto, tal afirmação não se apresenta fundamentada na literatura científica de forma específica $^{137}$.

\subsection{A recidiva ortodôntica do apinhamento dentário: fatores etiológicos}

A instabilidade do alinhamento dentário tem sido atribuída, após décadas de estudos, a vários fatores $6,7,25,54,69,75,118,121,123,127,144,171,186,210$. Além disso, 
nota-se uma grande variabilidade individual na recidiva $^{6,7,54,75,101,118,121,123,127,144,169,171,176,210,211}$ e a habilidade para identificar os pacientes de maior risco apresenta-se limitada ${ }^{54,121,123,127,171}$. Observa-se que um padrão de recidiva oposto ao padrão da irregularidade inicial não é incomum ${ }^{121}$.

A severidade da má oclusão inicial ${ }^{6,211}$, alterações na dimensão $9,58,75,99,101,106,121,127,143,144,169,176,186,198,210,220$ e forma do arco dentário $9,101,176,198,220$, a tração das fibras periodontais que foram estiradas durante a movimentação ortodôntica ${ }^{25,51,52,54,121,156,157,159,170}$ e alterações das propriedades elásticas do tecido gengival ${ }^{155,159}$ representam riscos significantes. Embora muitas controvérsias existam sobre o papel dos terceiros molares na recidiva do apinhamento ântero-inferior ${ }^{1,103,112,164}$, foi sugerido que um crescimento mandibular relativamente excessivo ${ }^{23,162,188,211}$ ou um padrão de crescimento do esqueleto facial e do tecido tegumentar circundante desfavorável ${ }^{109,188}$ possam aumentar o risco de recidiva neste segmento do arco. Houve especulações de que incisivos com reduzida proporção entre os diâmetros vestibulolingual e mesiodistal apresentam maior tendência à recidiva $^{74,147}$, e que fatores funcionais também possam estar relacionados ${ }^{28,29,58,61,121,143,152,170}$.

Outras explicações para a recidiva estão relacionadas ao fato de que o movimento dos incisivos inferiores na maioria dos casos está limitado pela face palatina dos incisivos superiores. Conseqüentemente, variáveis como a posição e a forma da superfície palatina dos incisivos superiores, assim como a forma de contato existente entre os incisivos e a função lingual podem ser fatores importantes na recidiva do apinhamento ântero-inferior ${ }^{94}$. Alguns outros 
fatores etiológicos relacionam-se diretamente ao tratamento ortodôntico ${ }^{219}$, como: falta de completa correção da giroversão dos dentes, levando à quebra dos pontos de contato $^{226}$; protrusão excessiva dos incisivos ${ }^{9,24,28,99,121,220}$; falta de harmonia da oclusão ${ }^{219}$; não remoção das causas da má oclusão ${ }^{83}$; tempo de contenção ${ }^{116,121,186,206,217}$. Outros fatores mencionados, entretanto, apresentam-se inerentes ao paciente, como: a recidiva da correção do trespasse vertical ${ }^{9,178,211}$; o componente anterior de força da oclusão e o grau de união entre os contatos interdentários ${ }^{9,121,143}$; a idade e o gênero ${ }^{58,61,121}$; a morfologia das bases apicais ${ }^{66,121,181}$; e a presença de hábitos bucais ${ }^{9,173}$. A maioria desses fatores associados à recidiva parece estar relacionada ao crescimento craniofacial, ao desenvolvimento dentário e à função muscular $^{28,90,206}$.

Evidenciou-se, após várias décadas de estudos, que a estabilidade do alinhamento dos dentes apresenta grande variabilidade entre os pacientes ${ }^{63,119}$. Little $^{115}$, em 1990, observou que casos tratados com ou sem extrações, assim como em casos que não sofreram intervenção ortodôntica apresentaram redução do perímetro e comprimento do arco, achados estes concordantes aos relatados por outros pesquisadores ${ }^{85,121,132,193,194,211}$. C Citou $^{115}$ que nenhuma variável, seja ela de achados clínicos, modelos de estudo ou radiográficos, antes ou após o tratamento, parece prever utilmente a recidiva. Entretanto, assim como na maioria dos estudos relacionados à recidiva do apinhamento na região anterior, tais achados foram descritos somente para o arco inferior, portanto, a extrapolação destas conclusões para o arco superior deve ser feita com restrições. 
A recidiva do apinhamento ântero-superior apresenta menor prevalência quando comparada à recidiva na região dos incisivos inferiores ${ }^{178,201,210,211}$. Fatores como a severidade inicial do apinhamento ${ }^{200}$ e tração das fibras periodontais $^{51,52,54}$ são considerados por alguns autores, fatores de risco para a recidiva do apinhamento dentário ântero-superior.

Os incisivos superiores tendem a rotacionar no sentido de suas posições iniciais $^{200,201}$ apesar da recidiva no sentido vestibulolingual apresentar-se imprevisível $^{200}$. Os contatos palatinos existentes com os incisivos inferiores representam limites ao deslocamento no sentido lingual dos incisivos superiores e qualquer movimento no sentido vestibular é provavelmente determinado pela posição e função dos lábios ${ }^{94}$.

Buscando encontrar fatores possivelmente associados à recidiva do apinhamento nas regiões ântero-superior e ântero-inferior dos arcos, KahlNieke; Fischbach; Schwarze ${ }^{101}$, em 1995, analisaram os modelos inicial, final e pós-contenção de pacientes tratados ortodonticamente. A amostra consistiu de 226 casos ortodônticos, de jovens de ambos os gêneros, tratados com ou sem extrações, apresentando diferentes más oclusões. O tratamento envolveu diferentes mecânicas e. assim como em estudos prévios ${ }^{47,176}$, não foi abordada a realização ou não do procedimento de expansão rápida da maxila durante a mecânica ortodôntica. A amostra foi dividida em dois grupos: um grupo constituído por casos de relativa estabilidade (recidiva menor que $3 \mathrm{~mm}$ ), e outro grupo constituído por casos que apresentaram significativa recidiva do apinhamento. Na tentativa de identificar possíveis fatores associados à recidiva, foram criados subgrupos, de acordo com o gênero, a má oclusão inicial, a forma de terapia, a quantidade de movimentação dentária e a 
presença de terceiros molares. Durante a análise dos modelos foram aferidos os valores das distâncias intercaninos e intermolares, o comprimento do arco, o índice de irregularidade de Little, a quantidade de apinhamento, sobressaliência, sobremordida e o relacionamento ântero-posterior dos arcos. Tais medições foram realizadas para os arcos superior e inferior, ao início, ao término e no período pós-contenção do tratamento ortodôntico. Os autores ${ }^{101}$ observaram que a recidiva dos apinhamentos ântero-superior e ântero-inferior, no período pós-contenção, ocorreu em aproximadamente metade da amostra e que o apinhamento ântero-inferior foi mais significativo, aumentando em $68,8 \%$ dos casos. Variáveis pré-tratamento, como apinhamento severo, deficiência no comprimento do arco, deficiências transversais e sobremordida profunda foram consideradas fatores associados ao aumento do apinhamento e da irregularidade na região anterior. O aumento das distâncias intermolares foi associado apenas à recidiva do apinhamento ântero-inferior e ocorreu com mais freqüência em casos com significativa expansão deste arco. Os casos tratados com extrações revelaram maior quantidade de recidiva dos apinhamentos ântero-superior e ântero-inferior e de giroversões quando comparados aos casos sem extrações. Ao citar como variável pré-tratamento a presença de deficiências transversais, o autor não comenta como tais deficiências foram corrigidas no transcorrer do tratamento. Tal fato impossibilita qualquer interpretação quanto a uma maior ou menor estabilidade durante o período pós-tratamento no alinhamento dos dentes ânterosuperiores, ou até mesmo ântero-inferiores, se os casos fossem tratados com expansão rápida ou por expansão dentoalveolar do arco superior. 
Vaden; Harris; Gardner ${ }^{211}$, em 1997, avaliaram as alterações na irregularidade dos incisivos superiores e inferiores e nas dimensões dos arcos dentários 6 e 15 anos após a remoção das contenções. A amostra foi constituída por 36 pacientes tratados com extrações, por um único clínico. Observaram $^{211}$ que tanto o arco superior quanto o inferior apresentaram alguma redução dimensional durante o período pós-contenção. Após 15 anos do término do tratamento, os resultados demonstraram uma redução de apenas $0,3 \mathrm{~mm}$ na irregularidade dos incisivos superiores, que correspondeu a uma manutenção de $96 \%$ da correção obtida durante o tratamento. De forma geral, $90 \%$ dos pacientes apresentaram condições oclusais no período póscontenção melhores que as iniciais.

Poucos foram os estudos que avaliaram especificamente a recidiva no alinhamento dos dentes ântero-superiores. Em 1998, Surbeck et al. ${ }^{200}$ avaliaram os modelos de estudo de 745 pacientes ortodônticos e estudaram o alinhamento dos dentes ântero-superiores nos períodos pré, pós-tratamento e pós-contenção, buscando verificar a influência da quantidade de apinhamento inicial na recidiva pós-contenção. Foi utilizado como critério de seleção da amostra a presença dos todos os dentes ântero-superiores e casos de pacientes tratados ortodonticamente com ou sem a realização de extrações dentárias. A amostra foi dividida em três grupos de acordo com a configuração dos modelos de estudo no período pós-contenção: 1- com espaçamento interdentário significante; 2- com significativa recidiva do apinhamento; 3- com perfeito alinhamento dos dentes ântero-superiores. Após análise dos resultados, os autores ${ }^{200}$ observaram que a quantidade de irregularidade no período pós-contenção apresentou-se diretamente relacionada com a 
quantidade de deslocamento dos pontos de contato anatômico no início do tratamento e que dentes rotacionados no período de pré-tratamento apresentam tendência estatisticamente significante de retornarem às suas posições iniciais. Neste estudo realizado por Surbeck et al. ${ }^{200}$ não foi citado se houveram pacientes submetidos à expansão rápida da maxila ou uma possível associação deste procedimento a uma maior ou menor estabilidade no alinhamento dos dentes ântero-superiores.

\subsubsection{Alterações na forma e dimensões dos arcos dentários}

A recidiva ortodôntica há muitos anos tem sido parcialmente atribuída a uma negligência na manutenção da forma do arco durante o tratamento ortodôntico $^{39}$. Mais especificamente, o posicionamento lateral dos caninos inferiores tem sido sugerido como a base na qual a forma dos arcos deveriam ser planejados ${ }^{124}$

Está bem estabelecido na literatura que o aumento da largura e do comprimento do arco, durante o tratamento, resultará em uma tendência de retorno às dimensões iniciais, no período pós-contenção. Os dentes e as estruturas de suporte apresentam uma tendência natural de se moverem em direção à má oclusão inicial| $\left.\right|^{8,29,46,47,69,116,169,186,187,198,209,218 . ~}$

Vários foram os autores que investigaram sobre a influência das alterações na forma dos arcos dentários superior e inferior sobre a estabilidade dos tratamentos ortodônticos em longo prazo $8,28,46,69,120,169,186,187,198,209,218$. A maioria dos estudos suporta a teoria que a expansão na região de caninos e pré-molares tende a recidivar após a remoção da contenção ${ }^{46,146,186,210}$, embora 
alguns trabalhos demonstrem que alguma expansão permanente pode ser obtida na região de caninos em alguns $\operatorname{casos}^{179,218}$, assim como na região de molares, em casos sem extrações ${ }^{39,75,137,179}$. A expansão dos arcos dentários vem sendo utilizada como um procedimento usual para a obtenção de um comprimento do arco suficiente para permitir o correto alinhamento dos dentes, entretanto, há controvérsias em relação à prudência desta estratégia de tratamento ${ }^{13}$.

Em 1995, de la Cruz et al. ${ }^{47}$, avaliaram a estabilidade do tratamento ortodôntico utilizando modelos de estudo de 45 pacientes, de ambos os gêneros, com má oclusão inicial de Classe I ou II de Angle e tratados com extrações de quatro pré-molares. Foram utilizados os modelos das fases inicial, pós-tratamento e pós-contenção. Demonstraram ${ }^{47}$ que os arcos tendem a retornar a forma inicial (pré-tratamento) durante o período pós-contenção, resultado que corrobora os relatados em outras pesquisas $^{8,28,46,69,115,169,186,187,198,209,218}$. Verificaram ${ }^{47}$ que, quanto maior a alteração na forma do arco em conseqüência ao tratamento ortodôntico, maior a tendência de alterações no posicionamento dentário no período póscontenção. Desta maneira, segundo os autores ${ }^{47}$, a manutenção da forma inicial do arco parece ser o melhor guia na busca da estabilidade dos arcos, entretanto, esta manutenção não fornece garantias de estabilidade no período pós-tratamento ortodôntico. Ressaltaram ${ }^{47}$ que a forma do arco pode ser modificada durante o tratamento quando o clínico entender que essa alteração será estável e necessária e que, como todos os casos foram tratados por meio de extrações dentárias, houve um favorecimento em relação à magnitude das alterações nas dimensões dos arcos, quando comparados os tempos inicial e 
final de tratamento, entretanto, as alterações pós-tratamento foram pequenas. Assim como em estudos anteriores ${ }^{176,179}$, a expansão dos arcos durante o tratamento dos pacientes que constituíram a amostra basicamente restringiu-se a alterações dentoalveolares proporcionadas pela mecânica ortodôntica fixa.

Em um estudo Iongitudinal, Moussa; O'Reilly; Close ${ }^{137}$, em 1995, avaliaram longitudinalmente 55 pacientes tratados sem extrações e submetidos à expansão rápida. Os autores ${ }^{137}$ observaram uma alteração média de apenas 0,6 mm na irregularidade dos incisivos superiores no período pós-contenção. Sugeriram $^{137}$ que o procedimento de expansão rápida poderia ter favorecido nesta estabilidade, porém devido a falta de um grupo controle, não foram realizadas conclusões mais objetivas quanto à influência do procedimento de expansão da maxila sobre a recidiva do apinhamento. O tempo médio de uso da contenção foi de 7 anos, o que também poderia ter auxiliado na estabilidade ${ }^{137}$

No intuito de avaliar uma possível influência da expansão ortopédica do arco superior na estabilidade no segmento ântero-inferior do arco, Azizi et al. ${ }^{8}$, em 1999, avaliaram 58 pacientes com más oclusões de Classe I, tratados sem extrações, envolvendo a mecânica Tandem (AEB, PLA e elásticos de Classe III) e utilizando dois tipos aparelhos de ortopédicos (Haas e Klöehn com arco interno expandido). Na avaliação pós-contenção (média de 8 anos), houve uma tendência dos dentes retornarem levemente à posição ao início do tratamento, porém, sem comprometer a correção ortodôntica. Observaram ${ }^{8}$, assim como em estudos prévios ${ }^{115,121}$, que nenhuma das variáveis pôde ser considerada útil para a de previsão da recidiva e citaram que a expansão ortopédica parece contribuir para a estabilidade dos incisivos inferiores. 
Observaram $^{8}$ ainda que o grupo tratado com o expansor tipo Haas apresentou maior estabilidade dimensional em relação ao grupo tratado com o aparelho de Klöehn. Em contraste com várias publicações anteriores, o índice de irregularidade no período pós-contenção praticamente não sofreu alteração. Nenhum dos 58 modelos do período pós-contenção apresentou recidiva acima do padrão mínimo aceitável estabelecido pelas categorias do índice de irregularidade de Little. Os autores sugeriram que esta maior estabilidade estaria associada a três fatores: 1- expansão ortopédica da base apical superior e à mecânica tandem; 2- tempo prolongado de contenção; 3- todos os pacientes foram tratados por um único clínico. Entretanto, o estudo baseou-se exclusivamente na avaliação da recidiva do apinhamento ântero-inferior.

Little $^{116}$ relata que, por mais de 40 anos, o Departamento de Ortodontia da Universidade de Washington, em Seattle, avaliou mais de 800 conjuntos de exames de pacientes para verificar a estabilidade e a recidiva do tratamento ortodôntico. Todos os pacientes completaram o tratamento há uma década ou mais antes do último conjunto de dados. Os pacientes, tratados com diferentes protocolos de tratamento, apresentaram as mesma alterações nas dimensões dos arcos no período pós-contenção. Segundo o autor ${ }^{116}$, as extrações de prémolares, a fim de permitir o alinhamento dos dentes apinhados, têm sido um procedimento aceito por décadas e continua sendo o tratamento mais comumente utilizado para pacientes apresentando apinhamento. Apesar de se alcançar normas cefalométricas sugeridas e aceitas, e apesar de se aderir aos padrões clínicos usuais de forma do arco, trespasse vertical, entre outros, a manutenção, em longo prazo, de resultados aceitáveis é desapontadora, com apenas $30 \%$ dos pacientes mostrando resultados aceitáveis em longo prazo. 
Neste estudo, as alterações pós-tratamento foram restritas ao arco inferior e, assim como o trabalho realizado por Azizi et al. ${ }^{8}$, apresenta-se limitado em relação a um esclarecimento sobre as alterações no arco superior durante o período pós-contenção.

Com o propósito de comparar as alterações do perímetro e dimensões dos arcos dentários, assim como do índice de irregularidade de casos tratados com ou sem extrações, Heiser et al. ${ }^{84}$, em 2004, avaliaram, utilizando recursos tridimensionais, as alterações presentes nos modelos de gesso de pacientes nas fases inicial, pós-tratamento, final da contenção e 5 anos pós-contenção. Os autores ${ }^{84}$ concluíram que: 1 - a tendência à recidiva apresentou-se menor para o arco superior quando comparado ao arco inferior no dois grupos, corroborando com estudos prévios ${ }^{101,119,179,211}$;; 2- o grupo tratado com extrações apresentou recidiva similar nos arcos superior e inferior; 3- a área A (circunscrita pelo perímetro anterior do arco e a distância que se estende da distal do canino à distal do canino oposto) apresentou significativa redução no período pós-contenção nos dois grupos; 4- houve aumento estatisticamente significante no perímetro do arco superior no grupo tratado sem extrações; 5- a recidiva no alinhamento dos dentes mostrou-se similar entre os grupos tratados.

Ormiston et al. ${ }^{142}$, em 2005, avaliou retrospectivamente e em longo prazo casos considerados estáveis e não estáveis. Para tanto, utilizou os valores do índice PAR inicial, final, assim como as alterações neste índice no período póscontenção. O estudo teve como objetivo identificar possíveis fatores associados à estabilidade ortodôntica. A amostra foi dividida em dois grupos, estável ( $n=45)$ e não estável $(n=41)$, e foram avaliados os modelos de estudo e 
telerradiografias iniciais, pós-tratamento e após o período de contenção (média de 14,4 anos). Os resultados demonstraram uma relação entre o gênero masculino e a manutenção de um maior período de crescimento e que ambos foram associados a um aumento na instabilidade. A severidade inicial da má oclusão apresentou correlação negativa com a estabilidade pós-contenção. Observaram $^{142}$ que tratamentos finalizados com grande qualidade tenderam a deteriorar, entretanto, os tratamentos finalizados com menor qualidade tenderam a melhorar no aspecto oclusal. As diferenças entre os grupos em relação ao comprimento do arco eram significantes no período inicial, o grupo estável apresentava arcos dentários de maior amplitude ao inicio do tratamento quando comparado ao grupo não estável. Segundo os resultados desses autores, a cada milímetro adicional do comprimento do arco, aumenta-se a chance de estabilidade em cerca de 12\%. Desta forma, um paciente com 5 $\mathrm{mm}$ a mais de comprimento do arco antes do tratamento, terá aproximadamente metade do risco de se apresentar instável. As medidas do comprimento do arco após o tratamento tenderam a diminuir para ambos os grupos, mas não foi observada diferença significante entre os grupos.

Buschang $^{32}$, em 2006, revisou sobre alguns trabalhos ${ }^{33,59,91,215}$ conduzidos na Faculdade de Odontologia de Baylor que avaliaram a estabilidade de tratamentos ortodônticos sem extrações, realizados ao final da dentadura mista. Os tratamentos envolviam o ganho de espaço nos arcos por meio da associação da expansão rápida da maxila com o uso contínuo de placa lábio-ativa para a expansão do arco inferior e manutenção do Lee Way Space. Citou $^{32}$ seu estudo longitudinal realizado em $2001^{33}$, no qual demonstrou resultados favoráveis em relação à manutenção em longo prazo 
(3,5 anos pós-contenção) dos incrementos transversais obtidos durante 0 tratamento e uma recidiva da irregularidade do incisivos inferiores de apenas 0,7 mm. Relacionou ${ }^{32}$ a estabilidade dos tratamentos executados segundo esta mecânica à manutenção e utilização do Lee Way Space, à expansão do arco inferior e à prevenção do apinhamento terciário proporcionada pelo uso da placa lábio-ativa. Além disso, especulou ${ }^{32}$ que a ERM resultaria em um meio capaz de proporcionar uma expansão transversal mandibular maior que o normal e, conseqüentemente, favorecesse a estabilidade do arco inferior. Ferris et al. ${ }^{59}$, em 2005, avaliou a estabilidade de um protocolo de tratamento que envolvia a expansão rápida da maxila, o uso de placa lábio-ativa e, posteriormente, correções ortodônticas com aparelhos fixos. A amostra apresentava 20 pacientes submetidos ao tratamento ortodôntico ao final da dentadura mista (média de 11,1 anos), reavaliados após um período póscontenção médio de 7,9 anos. Os resultados demonstraram que os incrementos nas dimensões dos arcos dentários superior e inferior foram, em sua maioria, mantidos no período pós-contenção. Apesar de reduções nos valores das variáveis estudadas, incrementos dimensionais residuais foram observados em 21 das 30 medidas. A principal exceção foi em relação ao perímetro do arco que diminuiu para valores menores que os obtidos na fase inicial de tratamento. Em longo prazo, a irregularidade dos incisivos superiores e inferiores aumentaram 0,5 mm (d.p.= 1,2) e $1,1 \mathrm{~mm}$ (d.p.= 1,5), respectivamente. Concluíram ${ }^{59}$ que o emprego deste protocolo de tratamento consiste em uma forma efetiva de correção da discrepância entre o tamanho dos dentes e o comprimento do arco. 
Erdinc; Nanda; Isiksal ${ }^{57}$, em 2006, propuseram a avaliação em longo prazo do apinhamento dos incisivos em pacientes ortodônticos tratados com e sem extrações de pré-molares. Mediram modelos e telerradiografias de 98 pacientes nas fases pré, pós-tratamento e pós-contenção. Os resultados demonstraram que a irregularidade, medida pelo índice de irregularidade, diminuiu 5,51 mm no grupo com extração e 2,38 mm no grupo sem extração. A irregularidade dos incisivos inferiores aumentou $0,97 \mathrm{~mm}$ no grupo com extração e 0,99 mm no grupo sem extração, respectivamente, no período póscontenção. A recidiva da irregularidade dos incisivos superiores foi mínima (0,19 $\mathrm{mm}$ e 0,12 $\mathrm{mm}$ para os grupos com e sem extrações, respectivamente). A largura intercaninos expandiu durante o tratamento. Na fase pós-contenção, a largura intercaninos inferiores diminuiu em ambos os grupos, mas as diferenças não foram estatisticamente significantes. Na fase pós-contenção, a largura intermolares permaneceu estável, o comprimento do arco diminuiu, o overjet e o overbite aumentaram suavemente, e as posições dos incisivos em ambos os grupos tenderam a retornar aos valores pré-tratamento. Porém, foi obtida uma estabilidade clinicamente aceitável ${ }^{57}$.

\subsubsection{Desenvolvimento da oclusão}

Moorrees $^{131}$, em 1959, publicou o livro: The dentition of the growing child. A longitudinal study of dental development between 3 and 18 years of age. Neste livro, o autor ${ }^{131}$ relatou as alterações nas dimensões dos arcos dentários em indivíduos apresentando más oclusões e que não sofreram intervenção ortodôntica. O autor ${ }^{131}$ demonstrou que o comprimento do arco geralmente 
diminui ao longo dos anos da dentadura mista para a dentadura permanente jovem. Ao demonstrar que o comprimento do arco aos 5 anos se apresentava maior do que aos 18 anos de idade, o autor ${ }^{131}$ chocou os leitores da época. Apesar da idéia inicial que se possa ter em relação a um aumento das dimensões do arco pelo crescimento da infância a vida adulta, infelizmente, a tendência é de constrição nas dimensões do arco no sentido ântero-posterior e transversal $^{131}$.

A alteração da distância intercaninos foi estudada por Barrow; White ${ }^{10}$, Moorrees; Chadha ${ }^{132}$, Sillman ${ }^{189}$ e Bishara et al. ${ }^{19}$ que observaram em amostras não tratadas um rápido aumento nessa distância dos 6 aos 9 anos, devido à irrupção dos incisivos e caninos. A distância intercaninos diminuiu dos 10 aos 12 anos, e esta diminuição permaneceu estável ${ }^{132,189}$. Contudo, Barrow; White ${ }^{10}$ e Bishara et al. ${ }^{19}$ observaram uma contínua redução desta distância.

A distância intercaninos apresenta maior redução que a distância intermolares, que geralmente permanece a mesma ${ }^{193,194}$ e, de forma geral, na ausência de tratamento, a deficiência no comprimento do arco tenderá sempre a aumentar ${ }^{117}$.

Com o intuito de comparar a estabilidade de casos tratados e não tratados ortodonticamente, Fastlicht ${ }^{58}$, em 1970, encontrou maior apinhamento ântero-inferior nos casos que não sofreram intervenção ortodôntica, concluindo que o tratamento ortodôntico pode aumentar a estabilidade dos arcos dentários.

Pesquisas realizadas por Little ${ }^{115}$ e Little; Riedel ${ }^{118}$ tornaram evidente que a tendência de redução dimensional existe em indivíduos normais que não 
sofreram tratamento, assim como naqueles que apresentam espaçamento prétratamento ${ }^{118,193}$. A redução dimensional dos arcos com o passar dos anos geralmente resultará na presença do apinhamento em um arco que já apresente espaço inadequado ${ }^{117}$.

Para Thilander ${ }^{206}$, a falta de estabilidade nos arcos dentários da maioria das oclusões normais durante o crescimento aumenta o questionamento sobre a possibilidade de se conseguir uma efetiva estabilidade dos resultados após o tratamento ortodôntico. Uma vez que alterações fisiológicas nos arcos dentários continuam lentamente a partir da adolescência, não há um método definido para se distinguir os eventos normais, relacionados com 0 desenvolvimento normal da oclusão, da recidiva pós-tratamento.

\subsubsection{Forças periodontais}

O problema da recidiva no posicionamento dos dentes tratados ortodonticamente e, especificamente, de dentes em que o tratamento consistiu na correção de giroversões apresenta-se bem estabelecido na literatura há décadas. Reitan ${ }^{156}$, em 1959, possivelmente foi o primeiro a formular uma explicação para a recidiva das giroversões dentárias quando demonstrou histologicamente a persistência de alterações nas fibras teciduais conectivas do tecido periodontal supracristal, sete meses após a rotação ortodôntica dos dentes.

A estabilidade do posicionamento dos dentes após movimentação ortodôntica pode ser influenciada por dois constituintes do periodonto de proteção; o grupo de fibras supra-alveolares e as fibras principais do ligamento 
periodontal. O mecanismo que torna possível que estes tecidos exerçam forças capazes de movimentar os dentes ainda é incerto, uma vez que o ligamento periodontal apresenta-se composto principalmente por fibras colágena sem propriedades elásticas ${ }^{54}$. Presumidamente, os únicos tecidos elásticos encontrados no ligamento periodontal humano estão localizadas nas paredes dos vasos sanguíneos, na porção intersticial do ligamento ${ }^{54}$. Parece existir alguma quantidade de fibras elásticas no tecido supracristal, entretanto, se presentes, mostram-se escassas ${ }^{73}$. Qualquer que seja o caso, o potencial para que as forças exercidas pelas fibras do ligamento periodontal e grupos transeptais adjacentes à crista alveolar provoquem a recidiva é certamente mínimo, uma vez que estes tecidos apresentam um mecanismo dinâmico de remodelação bastante eficiente e que se completa histologicamente por um período de apenas dois a três meses após a rotação dentária ${ }^{12,49,51,53,156,204,205}$.

Os grupos de fibras colágenas da gengiva livre e as fibras transeptais apresentam-se similares morfologicamente às fibras principais do ligamento periodontal, entretanto, demonstram maior estabilidade. O turnover destas fibras, que pode ser indicado pela incorporação de precursores radioativos, é relativamente lento nos tecidos não localizados de forma adjacente ao osso alveolar morfologicamente plástico ${ }^{129,158,197}$.

Segundo Beertsen ${ }^{12}$, em 1979, uma posição estável dos dentes após o movimento dentário ortodôntico pode ser estabelecida apenas quando os tecidos do ligamento periodontal tenham se adaptado à nova posição dentária. Se a adaptação não ocorrer, os dentes podem mostrar uma tendência a voltarem às suas posições originais após a remoção dos aparelhos ortodônticos. 
Entretanto, uma tentativa de generalização do relacionamento dos tecidos supra-alveolares à problemas relativos a contenção e recidiva ortodôntica não deve ser realizada ${ }^{54}$. Como um tecido que se apresenta constituído essencialmente por componentes teciduais inelásticos e não-contráteis poderia aplicar uma força capaz de gerar movimentação dentária? Uma possibilidade envolveria observações in vitro de que o comprimento de uma fibra colágena pode ser alterado por ajustes na concentração de íons, resultando em propriedade contráteis ${ }^{12,73}$. Uma outra explicação histológica para as forças de recidiva parece estar relacionada ao aumento da fibra oxylatan elastic-like que aparentemente aumenta em concentração nos tecidos supracristais durante a movimentação dentária induzida ${ }^{51,53,154,192}$. Entretanto, embora essas fibras apresentem algumas propriedades similares às fibras elásticas não existem evidências de que possam ter similaridades em termos de fisiologia. Redlich et al. ${ }^{155}$, em 1996, questionava sobre a metodologia utilizada em trabalhos mais antigos, nos quais a explicação para a recidiva da rotação ortodôntica tinha sido baseada em estudos com microscopia óptica que demonstravam que fibras gengivais supra-alveolares estiradas movimentariam o dente. Sendo assim, a recidiva rotacional poderia ser prevenida realizando-se a fibrotomia gengival supra-alveolar. Para testar essas hipóteses, foram realizadas análises no tecido periodontal utilizando a microscopia eletrônica de varredura e de transmissão. Os resultados desse estudo ${ }^{155}$ sugerem que a recidiva pode não ser devido ao estiramento das fibras colágenas, mas sim originada de uma alteração das propriedades elásticas de todo o tecido gengival.

Edwards $^{54}$, em 1988, conduziu um estudo prospectivo durante um período de aproximadamente 15 anos a fim de avaliar a eficácia da fibrotomia 
circunferencial supracristal na diminuição da recidiva após o tratamento ortodôntico. O procedimento cirúrgico da fibrotomia foi realizado na época da remoção do aparelho e seguido imediatamente pela instalação das contenções. As quantidades médias de recidiva do grupo controle e do grupo em que foi realizada a fibrotomia foram significantemente diferentes durante o período pós-contenção. Os resultados sugeriram que o procedimento cirúrgico apresenta-se mais efetivo em minimizar a recidiva rotacional pura que a recidiva no sentido vestibulolingual. Em termos longitudinais, a fibrotomia mostrou ser mais efetiva na redução da recidiva do segmento ântero-superior que no ântero-inferior.

Taner et al. ${ }^{202}$, em 2000, também avaliou os efeitos da fibrotomia na estabilidade do alinhamento de incisivos superiores e inferiores. Os autores ${ }^{202}$ observaram um aumento significante no índice de Little no grupo controle em ambos os segmentos anteriores. O grupo em foi realizada a fibrotomia não apresentou aumento significante no índice de Little.

Boese $^{26}$, em 2000, relatou que embora existam muitas discussões sobre as várias estratégias para promover a estabilidade, estas têm pouco impacto sobre a rotina clínica ortodôntica. Para o autor ${ }^{26}$, causa desapontamento o fato de que apenas $20 \%$ dos ortodontistas americanos utilizem a fibrotomia como uma estratégia para melhorar a estabilidade pós-tratamento e que opções como um protocolo de contenção permanente seja empregado. 


\subsubsection{Apinhamento ântero-inferior X apinhamento ântero-superior}

Para Little ${ }^{114}$, a evidência da progressiva instabilidade do tratamento ortodôntico é sempre primeiramente notada pelo apinhamento dos incisivos inferiores após a remoção das contenções. Independentemente do fator causal da recidiva ortodôntica, a irregularidade dos incisivos inferiores apresenta-se sempre como a precursora do apinhamento superior. Além disso, a recidiva do apinhamento ântero-inferior pode estar relacionada com o aprofundamento da sobremordida assim como a deterioração generalizada do caso tratado ${ }^{114}$.

Huang; Artun ${ }^{94}$, em 2001, avaliaram uma possível associação entre a irregularidade no alinhamento dos incisivos inferiores e a recidiva do apinhamento ântero-superior. Sugeriram ${ }^{94}$ que o contato dos dentes ânterosuperiores com os dentes inferiores limitaria os movimentos dos dentes superiores. Desta forma, alterações no posicionamento dos dentes superiores são geralmente resultantes de forcas exercidas pelos lábios. De acordo com os autores ${ }^{94}$, o posicionamento dos incisivos inferiores e a função labial poderiam ter maior importância na recidiva no sentido vestibulolingual dos dentes ântero-superiores do que os movimentos realizados durante a movimentação ortodôntica. Sugeriram ${ }^{94}$ que o posicionamento dos dentes ântero-inferiores influencia no posicionamento dos dentes superiores e viceversa e, desta maneira, a recidiva na região anterior em um dos arcos poderia estar associada à recidiva no alinhamento dos dentes do arco oposto. A amostra avaliada consistiu de 96 pacientes, apresentando em sua maioria má oclusão de Classe II, tratados com e sem extrações. O período pós-contenção variou de 4 a 25 anos. Os resultados demonstraram uma associação 
estatisticamente significante entre a irregularidade no alinhamento dos dentes ântero-superiores e a recidiva no alinhamento dos dentes do arco inferior nesta mesma região, assim como uma associação entre o deslocamento dos dentes no sentido vestibulolingual nos segmentos anteriores superior e inferior. Apesar dos autores ${ }^{94}$ investigarem sobre a recidiva na região ântero-superior não a relacionaram com o procedimento de expansão rápida, nem citaram a realização ou não do procedimento em determinados pacientes da amostra.

$\mathrm{Shah}^{184}$, em 2003, afirmou que de uma forma geral, os ortodontistas se preocupam mais com a estabilidade do arco inferior já que este se apresenta menos estável quando comparado ao arco superior ${ }^{178,201,210}$. Para o autor ${ }^{184} \mathrm{a}$ estabilidade no arco inferior é "a chave" para a estabilidade pós-contenção dos casos, uma vez que o arco superior tende a acompanhar as alterações no arco inferior $^{184}$.

\subsubsection{Tempo de contenção e o apinhamento}

Buscando verificar uma associação entre um período de contenção prolongado e uma maior estabilidade no alinhamento dos dentes ânterosuperiores e inferiores, Sadowsky et al. ${ }^{179}$, em 1994, avaliaram em 22 pacientes as alterações proporcionadas pelo tratamento e aquelas ocorridas durante o período pós-contenção. Os pacientes foram tratados com mecânica Edgewise, sem extrações e apresentavam um período pós-contenção médio de 6 anos. Durante o tratamento não houve alterações significantes no comprimento dos arcos superior e inferior e ambos os arcos apresentaram aumentos transversais, embora o arco superior tenha apresentado maior 
expansão. No período pós-contenção, verificaram ${ }^{179}$ uma pequena recidiva no alinhamento dos dentes ântero-superiores e inferiores, entretanto não houve recidiva das distâncias intermolares e intercaninos para o arco superior. A recidiva do alinhamento dos dentes ântero-inferiores foi menor quando comparada aos resultados obtidos por outros autores, sugerindo uma maior estabilidade quando o tempo de contenção é prolongado. A prorrogação do período de contenção parece ser interessante durante a fase de crescimento. A literatura relata que os incisivos tendem a apinhar mesmo em pacientes que não sofreram tratamento ortodôntico ${ }^{163,165,176,181,188,193}$. Dentre as limitações da pesquisa, observou-se: 1- um período pós-contenção relativamente curto quando comparado a outros trabalhos similares. Um período pós-contenção maior provavelmente implicaria em maiores incrementos no índice de irregularidade dentária, uma vez que a literatura demonstra que o índice de irregularidade apresenta incrementos por períodos de 10 a 20 anos póscontenção, embora a quantidade de alteração diminua com o passar do tempo ${ }^{119} ;$ 2- deficiência em relação ao tamanho da amostra; 3- foi realizada a expansão rápida no arco superior durante o tratamento somente em 4 pacientes, portanto, não foi verificada uma possível influência deste procedimento na estabilidade.

O uso indefinido de contenções fixas ou removíveis, talvez por toda a vida, pareça ser o único recurso lógico e citado por alguns autores ${ }^{90,115,119,225}$. Infelizmente, as seqüelas indesejáveis de tal programa de contenção são desconhecidas. A falta de previsibilidade em relação à recidiva não deveria gerar uma atitude negativa entre os ortodontistas ${ }^{58}$, mas sim, estimular maiores esforços no sentido de se tentar conseguir os melhores resultados possíveis 
para os pacientes ${ }^{226}$, além de uma intensificação na elaboração de estudos que possam detectar e preferencialmente anular os fatores etiológicos relacionados à recidiva ortodôntica, propiciando maior estabilidade pós-tratamento ortodôntico.

Frente a necessidade da contínua busca por meios que propiciem um maior estabilidade dos resultados ortodônticos no período pós-contenção e devido à escassa abordagem científica em relação à recidiva do apinhamento ântero-superior e os possíveis fatores que possam influenciar na estabilidade neste segmento do arco, propôs-se avaliar a influência da realização da expansão rápida da maxila durante a terapia ortodôntica na preservação do alinhamento dos dentes ântero-superiores em longo prazo. 



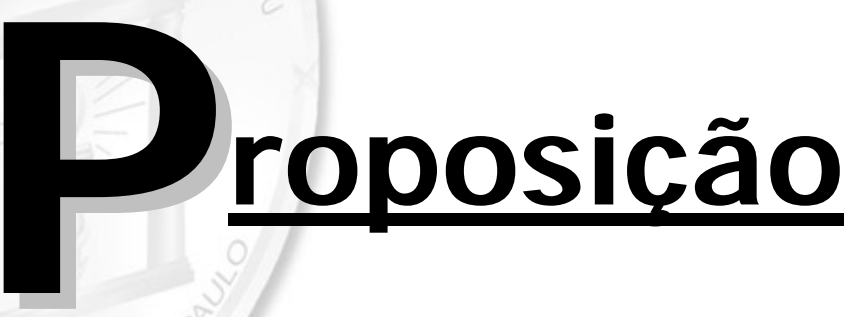





\section{3 - PROPOSIÇÃO}

Após a revisão da literatura ortodôntica propusemo-nos a avaliar retrospectivamente, por meio do Índice de Irregularidade de Little ${ }^{114}$, a recidiva do apinhamento ântero-superior em casos tratados sem extrações, submetidos ou não à expansão rápida da maxila, objetivando os seguintes tópicos:

3.1 Verificar a presença da recidiva do apinhamento ântero-superior e quantificá-la.

3.2 Verificar, em longo prazo, se a realização da expansão rápida da maxila teve ou não influência sobre a recidiva do apinhamento ântero-superior. 


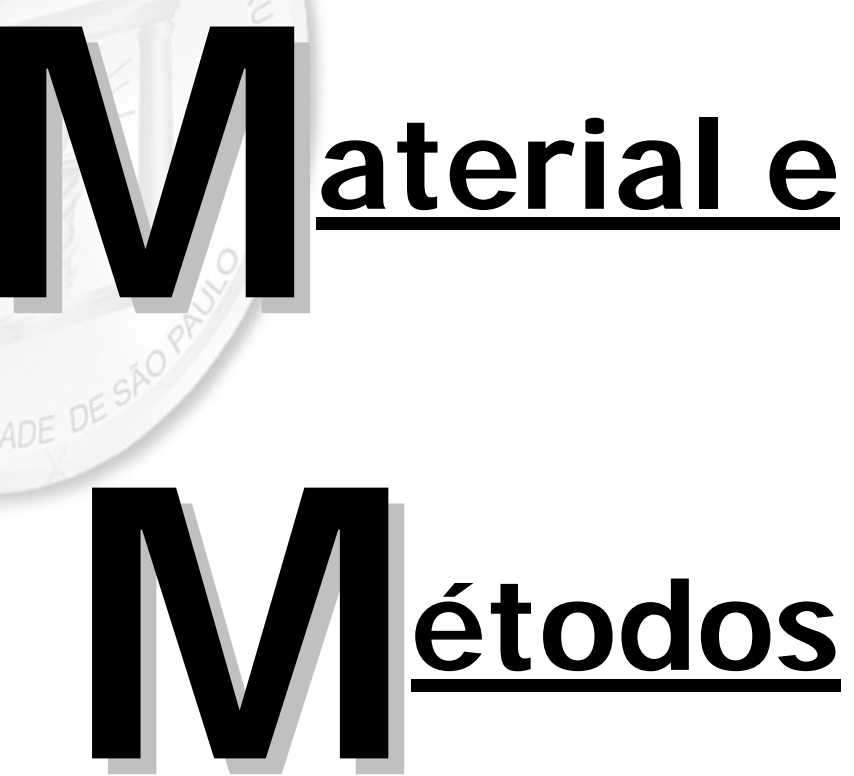



\section{4 - MATERIAL E MÉTODOS}

\subsection{Material}

A amostra utilizada neste estudo retrospectivo constitui-se de 48 documentações ortodônticas de pacientes tratados no curso de Pós-Graduação em Ortodontia da Universidade de São Paulo - Faculdade de Odontologia de Bauru que apresentavam inicialmente más oclusões de Classe I ou Classe II, tratados ortodonticamente sem extrações. Os critérios para a seleção da amostra também incluíram a presença de todos os dentes permanentes irrompidos ao início do tratamento ortodôntico (até os primeiros molares) e a ausência de anomalias dentárias de forma e/ou número. Todos os pacientes foram tratados com aparelhos fixos e mecânica Edgewise e apresentavam documentação ortodôntica completa, incluindo os modelos de estudo das fases inicial, final de tratamento e de controle pós-contenção.

A amostra foi dividida em 2 grupos conforme a realização ou não do procedimento de expansão rápida da maxila (ERM) durante o tratamento ortodôntico. Desta forma, os grupos foram assim distribuídos:

a) Grupo 1 - COM ERM - constituído por 25 pacientes submetidos à expansão rápida da maxila durante o tratamento ortodôntico.

b) Grupo 2 - SEM ERM - apresentando 23 pacientes cujo procedimento de expansão maxilar não consistiu em parte integrante do tratamento ortodôntico.

Todos os pacientes utilizaram como contenção, ao final do tratamento ortodôntico ativo, uma placa de Hawley removível no arco superior e um $3 \times 3$ 
colado de canino a canino no arco inferior. A placa de contenção superior foi utilizada, em média, por 1 ano, enquanto que o $3 \times 3$ permaneceu por um período médio de 3 anos. O tempo médio de avaliação pós-contenção foi de 5,60 anos (d.p. $= \pm 1,41$ ) para o grupo 1 e 4,92 anos (d.p= $\pm 1,11$ ) para 0 grupo 2.

\subsubsection{Grupo submetido à expansão rápida da maxila (ERM): Grupo 1}

O grupo submetido a ERM (Grupo 1) apresentou 25 pacientes leucodermas (15 do gênero feminino e 10 do gênero masculino), com idade inicial média de 13,53 anos $(\mathrm{dp}= \pm 1,63)$. O tempo médio de tratamento ortodôntico, incluindo-se tanto a fase ortopédica mecânica quanto a fase de ortodontia corretiva, foi de 2,07 anos $(d p= \pm 0,55)$. Ao término do tratamento, todos os pacientes apresentavam uma finalização satisfatória. Nesta fase, os pacientes apresentavam uma média de idade de 15,51 anos ( $\mathrm{dp}= \pm 1,74$ anos). Os pacientes pertencentes ao grupo 1 foram reavaliados após um período pós-contenção médio de 5,60 anos ( $d p= \pm 1,41$ anos).

Em relação à má oclusão inicial, o grupo 1 apresentou 16 pacientes com má oclusão de Classe I e 9 pacientes com má oclusão de Classe II (7 pacientes apresentando $1 / 4$ de Classe II e 2 pacientes apresentando $1 / 2$ Classe II). Todos os pacientes pertencentes ao Grupo 1 apresentavam algum grau de deficiência transversal maxilar ao início do tratamento, entretanto, apenas 16 dos 25 pacientes que constituíram este grupo apresentavam mordida cruzada posterior, uni ou bilateral, ao início do tratamento. 


\subsubsection{Grupo não submetido ao procedimento de expansão rápida da maxila: Grupo 2}

O grupo 2, constituído por pacientes que não foram submetido a ERM durante a terapia ortodôntica, apresentou 23 pacientes leucodermas (13 do gênero feminino e 10 pacientes do gênero masculino), com idade média de 13,36 anos (d.p. $= \pm 1,81$ anos) ao início do tratamento ortodôntico. O tempo médio de tratamento foi de 2,18 anos (d.p.= $= \pm 0,93$ anos). Ao término do tratamento, todos os pacientes, assim como os pacientes pertencentes ao grupo 1, apresentavam uma finalização satisfatória. Nesta fase, os pacientes apresentavam uma média de idade de 15,54 anos (d.p.= $\pm 1,86$ anos) e foram reavaliados após um período pós-contenção médio de 4,92 anos (d.p.= $\pm 1,11$ anos).

Em relação à má oclusão inicial, o grupo 2 apresentou 10 pacientes com má oclusão de Classe I e 13 pacientes com má oclusão de Classe II (8 pacientes apresentando $1 / 4$ de Classe II e 5 pacientes com $1 / 2$ Classe II). Nenhum dos pacientes pertencentes ao grupo 2 apresentavam mordida cruzada posterior ao início do tratamento.

Os dados referentes aos tempos de tratamento e idades dos pacientes, para ambos os grupos, se encontram na Tabela 5.

\subsection{Métodos}

No arquivo do Departamento de Odontopediatria, Ortodontia e Saúde Coletiva da Faculdade de Odontologia de Bauru (FOB) - Universidade de São 
Paulo, examinaram-se todas as pastas ortodônticas e os modelos de gesso iniciais, finais e de avaliação pós-contenção, no intuito de selecionar a amostra seguindo os critérios supracitados. Todos estes pacientes haviam sido tratados por alunos de pós-graduação, nos cursos de Especialização (Latus sensu) e Mestrado/Doutorado (Strictu sensu) em Ortodontia, da referida instituição de ensino. Após o registro de todos os casos selecionados, descartaram-se aqueles cujos modelos apresentavam-se com artefatos de técnica, ausentes para uma ou mais fases avaliadas (inicial, final e pós-contenção de 5 anos), ou mesmo, bastante danificados, a ponto de impossibilitarem seu uso.

As pastas ortodônticas relativas à amostra selecionada foram utilizadas para a obtenção de alguns dados relevantes à condução desta pesquisa. A ficha de dados cadastrais foi utilizada para o registro do nome completo dos pacientes, o gênero e a data de nascimento. As fichas de procedimentos terapêuticos foram examinadas quanto às datas de início e término do tratamento e da realização dos controles pós-tratamento. Também se observou a data de remoção das contenções. Estes dados, em conjunto com a data de nascimento do paciente, permitiram a determinação exata do tempo total de tratamento, do tempo de controle pós-tratamento e a idade dos pacientes nas fases estudadas.

Os pacientes incluídos no grupo com ERM (Grupo 1) submeteram-se a um tratamento que incluiu uma fase ortopédica mecânica que priorizou a expansão transversal do arco superior por meio da abertura da sutura palatina mediana, visando a correção da deficiência transversal maxilar inicial. Desta maneira, as fichas de procedimentos terapêuticos também foram examinadas para a obtenção de informações sobre o protocolo de ativação, tempo de 
ativação e tempo de contenção do procedimento de expansão rápida destes pacientes. Durante essa fase do tratamento, os pacientes do grupo 1 utilizaram um aparelho dentomucossuportado (expansor fixo do tipo $\mathrm{Haas}^{81}$ modificado), ou um expansor do tipo Hyrax, ou o expansor colado ${ }^{42}$. Embora o procedimento de expansão rápida tenha sido realizado por meio de três diferentes tipos de expansores, a literatura relata que não existem diferenças significantes nos efeitos dentoesqueléticos proporcionados por estes aparelhos e, conseqüentemente, nos resultados finais obtidos ${ }^{195}$. Também foram constatadas algumas incertezas em relação ao protocolo de ativação destes aparelhos, já que nem sempre se apresentavam especificados nos prontuários. De modo geral, pode-se afirmar que a velocidade de expansão foi a do tipo rápida, uma vez que, segundo a literatura ${ }^{79,89,196}$, esta é assim considerada quando maior ou igual a $1 \frac{1}{2}$ volta/dia (até 14 anos de idade) ou maior ou igual a $1 / 4$ volta/dia (a partir dos 15 anos de idade). Nestas faixas etárias, velocidades de ativação ligeiramente inferiores são consideradas semi-rápidas ${ }^{79,89}$. Somente protocolos de ativação de aproximadamente 2/4 - 1 volta/semana, ou de 2 - 3mm/mês são denominados de expansão lenta ${ }^{79,89}$. Geralmente, os pacientes que constituíram o grupo 1 foram instruídos a girar $1 / 4$ do parafuso pela manhã, repetindo-se o mesmo procedimento à noite. $A$ ativação do parafuso foi realizada até que se obtivesse uma sobrecorreção da discrepância transversal entre os arcos dentários. Geralmente, esta sobrecorreção correspondia clinicamente ao estabelecimento de contato das cúspides palatinas dos dentes póstero-superiores com as cúspides vestibulares dos dentes póstero-inferiores. 
Depois de alcançada esta sobrecorreção, o parafuso expansor do aparelho era fixado com resina acrílica ou com fio de amarrilho até que se visualizasse radiograficamente o restabelecimento da sutura palatina mediana por meio de neoformação óssea. O período de contenção com o próprio expansor variou de 2 a 6 meses. Em seguida, para prosseguir como contenção, os pacientes eram instruídos a utilizar, por aproximadamente um ano, uma placa removível superior de acrílico. No entanto, como implícito nos prontuários, não se costumava obedecer a este tempo quando se iniciava a ortodontia corretiva, de modo que o tempo de contenção após a remoção dos expansores deve ter variado significantemente entre os pacientes que constituíram este grupo.

Com o objetivo de compor o grupo 2, foram selecionados 23 pacientes, de ambos os gêneros, que haviam sido exclusivamente submetidos, há pelo menos cinco anos, ao tratamento ortodôntico corretivo por meio do aparelho Edgewise. A seleção foi realizada analisando-se todas as fichas clínicas e prontuários de procedimentos, assim como os modelos de gesso inicial, final e pós-contenção, presentes no arquivo supracitado.

Quando constatados fatores que prejudicassem a padronização da amostra como, por exemplo, falhas na manutenção da documentação e modelos, incompatibilidades em relação à severidade e tipo de má oclusão inicial ou tempo de avaliação pós-contenção inadequado, o caso era imediatamente excluído da amostra. 


\subsubsection{Avaliação dos modelos de estudo}

Os modelos de gesso das fases de início do tratamento (T1 - inicial), final de tratamento (T2 - final) e pós-contenção (T3 - pós-contenção) foram avaliados. Os modelos de avaliação pós-tratamento foram obtidos, em média, 5 anos após o término do tratamento. Todas as medidas realizadas foram aferidas utilizando-se um paquímetro digital da marca MITUTOYO (Mitutoyo Sul Americana Ltda., São Paulo, Brasil, modelo/código 500-143B), com capacidade de 150 mm, capaz de imprimir às medidas realizadas uma precisão de até $0,01 \mathrm{~mm}$.

As variáveis estudadas nos modelos de estudo superiores foram:

\section{A) Índice de irregularidade de Little (modificado):}

O índice de irregularidade proposto por Little ${ }^{114}$ foi idealmente elaborado para a avaliação do apinhamento dentário no segmento ântero-inferior. Entretanto, devido a sua grande reprodutibilidade e precisão, a mesma metodologia para a avaliação do deslocamento dentário foi utilizada no presente estudo para a avaliação do apinhamento ântero-superior. O índice de Little foi calculado nos modelos de gesso superiores nas três fases estudadas (LITTLE1, LITTLE2 e LITTLE3). Para esta medição utilizou-se um paquímetro digital, posicionado paralelamente ao plano oclusal. Aferiu-se, deste modo, o índice de irregularidade, que se caracterizou pelo somatório das distâncias lineares entre os pontos de contato anatômicos dos dentes ântero-superiores (caninos e incisivos). Essa medida representa a distância para a qual os pontos 
de contato devem ser movidos para atingir um alinhamento. De acordo com Little $^{114}$, apesar dos pontos de contato poderem variar no sentido vertical, a correção destas discrepâncias não afetará significantemente o comprimento anterior do arco, sendo assim, alterações no sentido vertical foram desconsideradas (Figura 1).

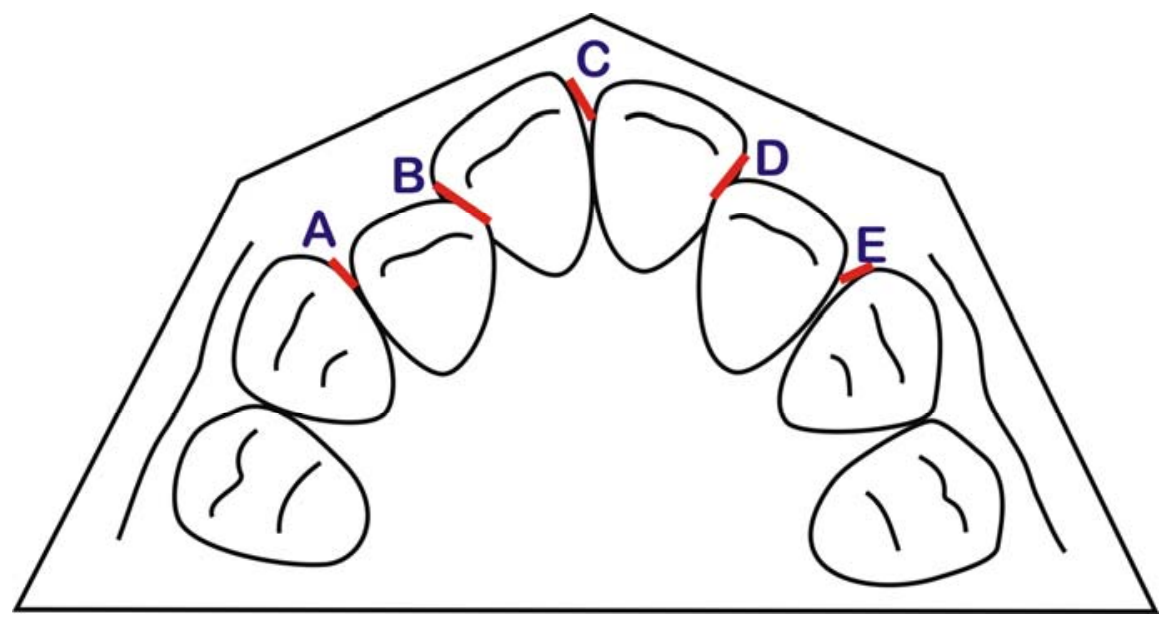

Figura 1. Índice de Irregularidade de Little (modificado) $=A+B+C+D+E$.

B) Distância intercaninos (A): distância, medida em milímetros, de ponta a ponta das cúspides dos caninos superiores direito e esquerdo. Nos casos em que os caninos apresentavam facetas de desgastes, a ponta da cúspide era estimada (Figura 2).

C) Distâncias interpré-molares (B e B'): distâncias, medidas em milímetros, entre as fossas mesiais dos primeiros pré-molares superiores direito e esquerdo (B) e dos segundos pré-molares superiores direito e esquerdo (B'), respectivamente (Figura 2). 
D) Distância intermolares (C): distância, medida em milímetros, de ponta a ponta das cúspides mesiovestibulares dos primeiros molares superiores direito e esquerdo. Nos casos em que os molares apresentavam facetas de desgaste, a ponta da cúspide era estimada (Figura 2).

E) Comprimento do arco superior (D+E): correspondeu ao somatório das distâncias medidas entre o ponto de contato dos incisivos centrais superiores e a face mesial dos primeiros molares dos lados direito e esquerdo (Figura 2).

F) Perímetro do arco superior (F): distância, medida em milímetros, que se estende da face mesial do primeiro molar superior direito à fase mesial do primeiro molar superior esquerdo (Figura 2).

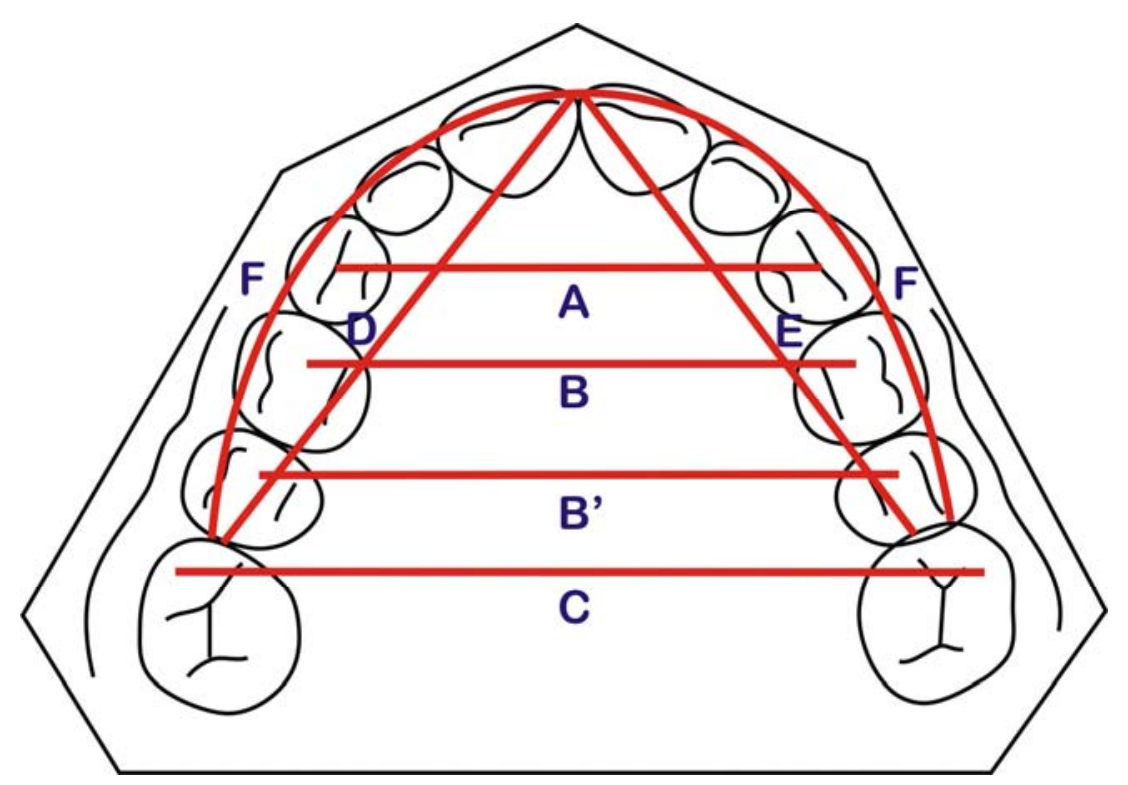

Figura 2. Variáveis estudadas na análise de modelos: A - distância intercaninos, B e B' - distâncias interpré-molares, C - distâncias intermolares, D + E - comprimento do arco e F - perímetro do arco. 


\subsubsection{Descrição das abreviaturas utilizadas para representar as variáveis estudadas}

Com o intuito de simplificar a manipulação e tabulação dos dados, as variáveis utilizadas nesta pesquisa foram representadas pelas abreviaturas descritas na tabela 1.

Tabela 1. Abreviaturas utilizadas

\begin{tabular}{c|l}
\hline Abreviaturas & \multicolumn{1}{c}{ Descrição } \\
\hline LITTLE1 & Índice de irregularidade de Little inicial \\
\hline LITTLE2 & Índice de irregularidade de Little final \\
\hline LITTLE3 & Índice de irregularidade de Little pós-contenção \\
\hline LITTLE2-1 & $\begin{array}{l}\text { Alteração do índice de irregularidade de Little durante o } \\
\text { tratamento }\end{array}$ \\
\hline LITTLE3-2 & $\begin{array}{l}\text { Alteração do índice de irregularidade de Little durante o } \\
\text { período pós-contenção }\end{array}$ \\
\hline LITLLE3-1 & $\begin{array}{l}\text { Alteração total do índice de irregularidade de Little, da } \\
\text { fase inicial ao término do período pós-contenção }\end{array}$ \\
\hline INTERC & Distância intercaninos superiores \\
\hline INTERPB & Distância interpré-molares (1os. pré-molares) superiores \\
\hline INTERPB' & Distância interpré-molares (2os. pré-molares) superiores \\
\hline INTERM & Distância intermolares superiores \\
\hline COMPR & Comprimento do arco superior \\
\hline PERIM & Perímetro do arco superior \\
\hline Id T1 & Idade inicial \\
\hline Id T2 & Idade final \\
\hline TTRAT & Tempo de tratamento \\
\hline TPOS & Tempo de avaliação pós-contenção \\
\hline
\end{tabular}




\subsubsection{Análise estatística}

\subsubsection{Erro do método}

O erro intra-examinador foi avaliado realizando-se novas medidas das variáveis estudadas nos modelos iniciais, finais e pós-contenção de 15 pacientes pertencentes a ambos os grupos e selecionados aleatoriamente. As variáveis reavaliadas (LITTLE1, INTERC3, INTERPB1, INTERPB'1, INTERM3, COMPR1 e PERIM1) também foram selecionadas de forma aleatória. A primeira e a segunda medições foram realizadas com intervalo de tempo de um mês. A fórmula proposta por Dahlberg ${ }^{45}\left(\operatorname{Se}^{2}=\Sigma \mathrm{d}^{2} / 2 \mathrm{n}\right)$ foi aplicada para estimar a ordem de grandeza dos erros casuais. Os erros sistemáticos foram analisados pela aplicação de testes t pareados, de acordo com Houston ${ }^{92}$, em 1983.

\subsubsection{Método estatístico}

Foi realizada a estatística descritiva (média, desvio padrão e número) para os grupos 1 (com realização de expansão rápida) e 2 (sem expansão) das medidas obtidas para as variáveis: Índice de irregularidade de Little, distância intercaninos, distâncias entre os primeiros e segundos pré-molares, distância intermolares, comprimento e perímetro do arco, nas fases inicial (T1), final (T2) e pós-contenção (T3). A estatística descritiva também foi realizada para a diferença das medidas obtidas a partir dos modelos entre as fases final e inicial (T2-1), caracterizando a correção do tratamento, para a diferença entre as fases pós-contenção e final (T3-2), caracterizando a alteração durante o período pós-contenção, e para a diferença entre as fases pós-contenção e 
inicial (T3-T1), caracterizando as alterações ocorridas durante o período total de observação.

Para avaliação da compatibilidade entre os grupos 1 e 2 quanto à distribuição dos gêneros e em relação à severidade inicial da má oclusão utilizou-se o teste Qui-Quadrado. Com o intuito de verificar a compatibilidade dos grupos quanto à quantidade de apinhamento inicial (LITTLE1), idades inicial (Id T1) e final (Id T2), tempo de tratamento (TTRAT), e de avaliação póscontenção (TPOS), utilizou-se o teste t independente.

Para a comparação intragrupo nos 3 tempos de avaliação (Inicial - T1; Fina - T2; Pós-contenção - T3), utilizou-se a análise de variância a um critério de seleção e, em caso de resultado significante, o teste de Tukey. O teste foi empregado para avaliação do comportamento das variáveis medidas nos modelos dos grupos 1 e 2, nos três tempos estudados.

Para a comparação intergrupos quanto aos valores obtidos para as variáveis nas fases inicial, final de tratamento e pós-contenção, assim como em relação às alterações destas variáveis durante o tratamento (T2-1), durante 0 período pós-contenção (T3-2) e totais (T3-1), utilizou-se o teste t independente.

Por fim, para verificar a presença de correlação entre a recidiva do apinhamento ântero-superior e a recidiva das variáveis: distâncias intercaninos, interpré-molares, intermolares, comprimento e perímetro do arco, utilizou-se o teste de correlação de Pearson.

Todos os testes foram realizados com o programa STATISTICA ${ }^{2}$, adotando-se um nível de significância de 5\%.

\footnotetext{
${ }^{2}$ Statistica for Windows - Release 6.0 - Copyright StatSoft, Inc. 2001.
} 


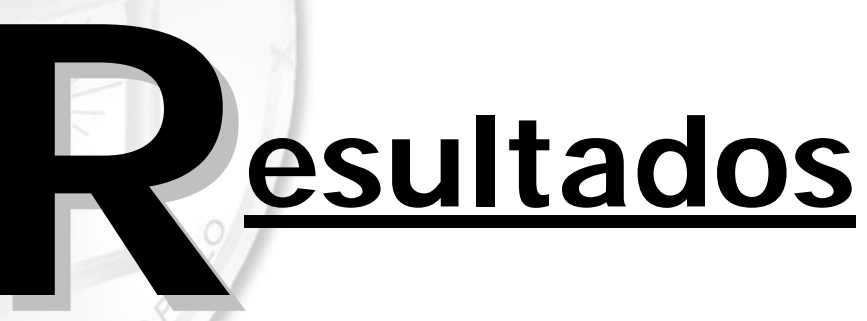





\section{5 - RESULTADOS}

A Tabela 2 apresenta os resultados da avaliação dos erros casuais e sistemáticos, realizados por meio da fórmula de Dahlberg ${ }^{45}$ e de testes $\mathrm{t}$ pareados, respectivamente, aplicados às variáveis LITTLE, INTERC, INTERPB, INTERPB', INTERM, COMPR e PERIM, medidas nos modelos de estudo com intervalo de tempo de um mês. Não foram observadas diferenças estatisticamente significantes entre as duas medições.

A compatibilidade dos grupos quanto à proporção dos gêneros e quanto à severidade inicial das más oclusões foi avaliada pelo teste Qui-Quadrado (Tabela 3 e 4). Não houve diferenças estatisticamente significantes entre os grupos em relação à distribuição dos gêneros e severidade inicial da má oclusão.

O teste $t$ independente foi utilizado para avaliação da compatibilidade dos grupos quanto à quantidade de apinhamento inicial (LITTLE1), quanto à idade inicial (Id T1), e quanto aos tempos de tratamento (TTRAT) e de avaliação póscontenção (TPOS) (Tabela 5). Não foram observadas diferenças significantes entre os grupos em relação a estas variáveis.

As Tabelas 6 e 7 apresentam os resultados do ANOVA para as variáveis medidas nos modelos de estudo do grupo 1 e 2, respectivamente, nas três fases estudadas (T1, T2 e T3). Na presença de um resultado significante, realizou-se o teste de Tukey, em que letras diferentes demonstram diferença significante entre as medições. Os resultados para o grupo 1 (Tabela 6) demonstram uma significante redução do apinhamento ântero-superior e incrementos dimensionais estatisticamente significantes entre as fases inicial 
(T1) e final (T2), com exceção da distância intercaninos (INTERC). Observa-se que estas alterações tenderam a se mostrar estáveis no período póscontenção, com exceção da irregularidade dos incisivos que aumentou significantemente. Os resultados do ANOVA para o grupo 2 (Tabela 7) demonstram que o índice de Little sofreu alterações significantes durante o tratamento e durante o período de pós-contenção. Entretanto, não houve alterações estatisticamente significantes para a maioria das demais variáveis estudadas durante estas fases, com exceção da distância entre os primeiros pré-molares (INTERPB), que sofreu um aumento significante entre os tempos inicial (T1) e final (T2).

As Tabelas 8, 9 e 10 apresentam os resultados do teste $t$ independente para comparação intergrupos das variáveis estudadas nos tempos inicial (T1), final (T2) e pós-contenção (T3), respectivamente. Na fase inicial, o grupo 1 apresentou menores distâncias entre os primeiros e segundos pré-molares (Tabela 8). Nas fases final e pós-contenção (Tabelas 9 e 10, respectivamente), não foram observadas diferenças significantes entre os grupos para todas as variáveis estudadas.

As alterações das variáveis medidas nos modelos durante o tratamento (T2-1), durante o período pós-contenção (T3-2) e totais (T3-1), em ambos os grupos, foram comparadas por meio de testes t (Tabelas 11, 12 e 13, respectivamente). Em relação às alterações ocorridas durante o tratamento (T2-1), foram observadas diferenças significantes entre os grupos paras as variáveis INTERB, INTERB' e INTERMOL. O grupo 1 apresentou incrementos dimensionais transversais maiores que o grupo 2 (Tabela 11). Durante 0 período pós-contenção (T3-2), somente a alteração da distância entre os 
primeiros pré-molares (INTERPB) apresentou diferença estatisticamente significante entre os grupos (Tabela 12). Em relação às alterações totais (T3-1), foram observadas diferenças estatisticamente significantes entre os grupos 1 e 2 para as variáveis INTERPB, INTERPB' e INTERMOL, ou seja, em relação às alterações dimensionais totais, o grupo 1 apresentou incrementos transversais significantemente maiores que o grupo 2 (Tabela 13).

Por último, são apresentados nas tabelas 14 e 15 os resultados dos testes de correlação de Pearson. Observou-se uma correlação negativa, estatisticamente significante, entre a quantidade de recidiva do apinhamento ântero-superior e a quantidade de redução das distâncias intercaninos e entre os primeiros pré-molares. 
Tabela 2. Resultados do teste $t$ e da fórmula de Dahlberg, aplicados às variáveis avaliadas para estimativa dos erros sistemáticos e casuais, respectivamente.

\begin{tabular}{c|c|c|c|c|c|c|c}
\hline \multirow{2}{*}{ Variáveis } & \multicolumn{2}{|c|}{$\mathbf{1}^{\text {a }}$. Medição } & \multicolumn{2}{c|}{$\mathbf{2}^{\mathbf{a}}$. Medição } & \multirow{2}{*}{$\mathbf{N}$} & \multirow{2}{*}{ Dahlberg } & \multirow{2}{*}{$\mathbf{p}$} \\
\cline { 2 - 5 } & Média & $\mathbf{d . p .}$ & Média & $\mathbf{d . p .}$ & & & \\
\hline LITTLE & 8,42 & 5,02 & 8,64 & 4,77 & 15 & 0,569 & 0,384 \\
\hline INTERC & 34,88 & 2,03 & 34,99 & 1,89 & 15 & 0,162 & 0,148 \\
\hline INTERPB & 33,78 & 2,69 & 33,72 & 2,65 & 15 & 0,180 & 0,313 \\
\hline INTERPB' & 38,69 & 3,23 & 38,72 & 3,21 & 15 & 0,083 & 0,403 \\
\hline INTERMOL & 52,71 & 3,38 & 52,74 & 3,39 & 15 & 0,315 & 0,577 \\
\hline COMPR & 71,26 & 4,88 & 71,21 & 4,95 & 15 & 0,225 & 0,440 \\
\hline PERIM & 75,22 & 4,13 & 75,36 & 4,37 & 15 & 0,487 & 0,511 \\
\hline
\end{tabular}

Tabela 3. Resultados do teste Qui-Quadrado para avaliação da compatibilidade dos grupos 1 e 2 quanto à proporção dos gêneros.

\begin{tabular}{c|c|c|c}
\hline GÊNERO & Feminino & Masculino & Total \\
\hline $\begin{array}{c}\text { Grupo 1 } \\
\text { COM ERM }\end{array}$ & 15 & 10 & 25 \\
\hline $\begin{array}{c}\text { Grupo 2 } \\
\text { SEM ERM }\end{array}$ & 13 & 10 & 23 \\
\hline Total & $28 \quad \mathbf{2 0}$ & $\mathbf{4 8}$ \\
\hline \multicolumn{2}{c|}{$X^{2}=\mathbf{0 , 0 6}$} & $\mathbf{d f = 2} \quad \mathbf{p = 0 , 2 6 4 7}$ \\
\hline
\end{tabular}


Tabela 4. Resultados do teste Qui-Quadrado para avaliação da compatibilidade dos grupos 1 e 2 quanto à severidade inicial das más oclusões.

\begin{tabular}{c|c|c|c}
\hline GRUPO & $\begin{array}{c}\text { Grupo 1 } \\
\text { COM ERM }\end{array}$ & $\begin{array}{c}\text { Grupo 2 } \\
\text { SEM ERM }\end{array}$ & Total \\
\hline Classe I & 16 & 10 & 26 \\
\hline $1 / 4$ Classe II & 7 & 8 & 15 \\
\hline $1 / 2$ Classe II & 2 & 5 & 7 \\
\hline Total & 25 & 23 & 48 \\
\hline$X^{2}=\mathbf{2 , 6 5 8}$ & df= 2 & \multicolumn{2}{|c|}{$\mathbf{0 , 2 6 4 7}$} \\
\hline
\end{tabular}

Tabela 5. Resultados do teste t independente, aplicado às variáveis índice de Little inicial, idades inicial e final, tempo de tratamento e tempo de avaliação pós-contenção dos grupos 1 e 2, com e sem expansão rápida, respectivamente, para avaliação da compatibilidade intergrupos.

\begin{tabular}{c|c|c|c|c|c}
\hline \multirow{2}{*}{ Variáveis } & \multicolumn{2}{|c|}{$\begin{array}{c}\text { Grupo 1 } \\
\text { COM EXPANSÃo } \\
\text { RÁPIDA } \\
\text { (N= 25) }\end{array}$} & \multicolumn{2}{c|}{$\begin{array}{c}\text { Grupo 2 } \\
\text { SEM EXPANSÃo } \\
\text { RÁPIDA } \\
\text { (N= 23) }\end{array}$} & \multirow{2}{*}{ P } \\
\cline { 2 - 5 } & Média & d.p. & Média & d.p. & \\
\hline LITTLE1 & 7,65 & 2,96 & 6,56 & 2,84 & 0,201 \\
\hline Id T1 & 13,53 & 1,63 & 13,36 & 1,81 & 0,729 \\
\hline Id T2 & 15,51 & 1,74 & 15,54 & 1,86 & 0,956 \\
\hline TTRAT & 2,07 & 0,55 & 2,18 & 0,93 & 0,625 \\
\hline TPOS & 5,60 & 1,41 & 4,92 & 1,11 & 0,072 \\
\hline
\end{tabular}


Tabela 6. Resultados do ANOVA para as variáveis dos modelos de estudo, do grupo $1(\mathrm{~N}=25)$, nas três fases estudadas (T1, T2 e T3). Na presença de um resultado significante, realizou-se o teste de Tukey (letras diferentes demonstram diferença significante entre as medições).

\begin{tabular}{|c|c|c|c|c|}
\hline \multirow[t]{2}{*}{ Variáveis } & Inicial - T1 & Final - T2 & $\begin{array}{c}\text { Pós-contenção - } \\
\text { T3 }\end{array}$ & \multirow[t]{2}{*}{$\mathbf{p}$} \\
\hline & Média (d.p.) & Média (d.p.) & Média (d.p.) & \\
\hline LITTLE & $7,65(2,96)^{A}$ & $1,42(1,05)^{\mathrm{B}}$ & $2,93(1,97)^{C}$ & $0,000^{*}$ \\
\hline INTERC & $34,16(2,41)^{A}$ & $35,04(1,41)^{A}$ & $34,46(1,70)^{A}$ & 0,254 \\
\hline INTERPB & $33,26(2,12)^{A}$ & $36,90(1,64)^{\mathrm{B}}$ & $35,76(1,82)^{B}$ & $0,000^{*}$ \\
\hline INTERPB' & $38,39(2,98)^{A}$ & $42,20(2,04)^{B}$ & $41,43(2,24)^{B}$ & $0,000 *$ \\
\hline INTERMOL & $49,46(4,15)^{A}$ & $52,43(2,55)^{\mathrm{B}}$ & $52,24(2,92)^{B}$ & $0,003^{*}$ \\
\hline COMPR & $70,97(4,35)^{A}$ & $73,47(2,91)^{B}$ & $71,90(3,12)^{B}$ & $0,046^{*}$ \\
\hline PERIM & $74,41(3,54)^{A}$ & $77,10(2,77)^{\mathrm{B}}$ & $75,45(2,79)^{B}$ & 0,010 * \\
\hline
\end{tabular}

* Estatisticamente significante para $p<0,05$

Tabela 7. Resultados do ANOVA para as variáveis dos modelos de estudo, do grupo $2(\mathrm{~N}=23)$, nas três fases estudadas (T1, T2 e T3). Na presença de um resultado significante, realizou-se o teste de Tukey (letras diferentes demonstram diferença significante entre as medições).

\begin{tabular}{c|c|c|c|c}
\hline \multirow{2}{*}{ Variáveis } & Inicial - T1 & Final - T2 & $\begin{array}{c}\text { Pós-contenção } \\
- \text { T3 }\end{array}$ & \multirow{2}{*}{ p } \\
\cline { 2 - 4 } & Média (d.p.) $^{*}$ & Média (d.p.) & Média (d.p.) $^{*}$ & \multirow{2}{*}{$0,000^{*}$} \\
\hline LITTLE & $6,56(2,83)^{\mathrm{A}}$ & $1,59(0,73)^{\mathrm{B}}$ & $3,11(1,41)^{\mathrm{C}}$ & 0,653 \\
\hline INTERC & $34,07(3,79)^{\mathrm{A}}$ & $34,65(1,44)^{\mathrm{A}}$ & $34,53(1,87)^{\mathrm{A}}$ & $0,012^{*}$ \\
\hline INTERPB $^{*} 34,71(1,86)^{\mathrm{A}}$ & $36,34(1,81)^{\mathrm{B}}$ & $35,76(1,81)^{\mathrm{B}}$ & 0,186 \\
\hline INTERPB' $_{\text {INTERMOL }}$ & $40,20(2,31)^{\mathrm{A}}$ & $41,35(2,15)^{\mathrm{A}}$ & $41,09(2,16)^{\mathrm{A}}$ & 0,560 \\
\hline COMPR & $51,13(2,62)^{\mathrm{A}}$ & $51,52(2,50)^{\mathrm{A}}$ & $51,94(2,51)^{\mathrm{A}}$ & 0,118 \\
\hline PERIM & $72,09(4,08)^{\mathrm{A}}$ & $73,76(2,49)^{\mathrm{A}}$ & $72,07(2,58)^{\mathrm{A}}$ & 0,269 \\
\hline
\end{tabular}

\footnotetext{
* Estatisticamente significante para $p<0,05$
} 
Tabela 8. Resultados do teste t independente, aplicado às variáveis estudadas, para verificar as diferenças iniciais (T1), entre os grupos 1 e 2, com e sem expansão rápida, respectivamente.

\begin{tabular}{c|c|c|c|c|c}
\hline \multirow{2}{*}{ Variáveis } & \multicolumn{2}{|c|}{$\begin{array}{c}\text { Grupo 1 } \\
\text { COM EXPANSÃo } \\
\text { RÁPIDA } \\
\text { (N= 25) }\end{array}$} & \multicolumn{2}{c|}{$\begin{array}{c}\text { Grupo 2 } \\
\text { SEM EXPANSÃo } \\
\text { RÁPIDA } \\
\text { (N= 23) }\end{array}$} & \multirow{2}{*}{ P } \\
\cline { 2 - 5 } & Média & d.p. & Média & d.p. & \\
\hline LITTLE1 & 7,65 & 2,96 & 6,56 & 2,84 & 0,201 \\
\hline INTERC1 & 34,16 & 2,41 & 34,08 & 3,08 & 0,914 \\
\hline INTERPB1 & 33,26 & 2,12 & 34,71 & 1,86 & $0,015^{*}$ \\
\hline INTERPB'1 & 38,39 & 2,98 & 40,20 & 2,31 & $0,024^{*}$ \\
\hline INTERMOL1 & 49,46 & 4,15 & 51,13 & 2,62 & 0,106 \\
\hline COMPR1 & 70,97 & 4,35 & 72,09 & 4,08 & 0,362 \\
\hline PERIM1 & 74,41 & 3,54 & 75,18 & 3,77 & 0,471 \\
\hline
\end{tabular}

* Estatisticamente significante para $p<0,05$

Tabela 9. Resultados do teste t independente, aplicado às variáveis estudadas, para verificar as diferenças no estágio pós-tratamento (T2), entre os grupos 1 e 2, com e sem expansão rápida, respectivamente.

\begin{tabular}{c|c|c|c|c|c}
\hline \multirow{2}{*}{ Variáveis } & \multicolumn{2}{|c|}{$\begin{array}{c}\text { Grupo 1 } \\
\text { COM EXPANSÃo } \\
\text { RÁPIDA } \\
\text { (N= 25) }\end{array}$} & \multicolumn{2}{c|}{$\begin{array}{c}\text { Grupo 2 } \\
\text { SEM EXPANSÃo } \\
\text { RÁPIDA } \\
\text { (N= 23) }\end{array}$} & \multirow{2}{*}{ P } \\
\cline { 2 - 5 } & Média & d.p. & Média & d.p. & \\
\hline LITTLE2 & 1,42 & 1,05 & 1,60 & 0,73 & 0,497 \\
\hline INTERC2 & 35,04 & 1,41 & 34,66 & 1,44 & 0,351 \\
\hline INTERPB2 & 36,90 & 1,64 & 36,34 & 1,81 & 0,260 \\
\hline INTERPB'2 & 42,20 & 2,04 & 41,35 & 2,15 & 0,166 \\
\hline INTERMOL2 & 52,43 & 2,55 & 51,52 & 2,50 & 0,219 \\
\hline COMPR2 & 73,47 & 2,91 & 73,76 & 2,49 & 0,709 \\
\hline PERIM2 & 77,10 & 2,77 & 76,52 & 2,66 & 0,459 \\
\hline
\end{tabular}


Tabela 10. Resultados do teste $t$ independente, aplicado às variáveis estudadas, para verificar as diferenças no estágio pós-contenção (T3) entre os grupos 1 e 2, com e sem expansão rápida, respectivamente.

\begin{tabular}{c|c|c|c|c|c}
\hline \multirow{2}{*}{ Variáveis } & \multicolumn{2}{|c|}{$\begin{array}{c}\text { Grupo 1 } \\
\text { COM EXPANSÃo } \\
\text { RÁPIDA } \\
\text { (N= 25) }\end{array}$} & \multicolumn{2}{c|}{$\begin{array}{c}\text { Grupo 2 } \\
\text { SEM EXPANSÃo } \\
\text { RÁPIDA } \\
\text { (N= 23) }\end{array}$} & \multirow{2}{*}{ P } \\
\cline { 2 - 5 } & Média & d.p. & Média & d.p. & \\
\hline LITTLE3 & 2,93 & 1,97 & 3,12 & 1,42 & 0,713 \\
\hline INTERC3 & 34,46 & 1,70 & 34,55 & 1,87 & 0,876 \\
\hline INTERPB3 & 35,76 & 1,82 & 35,76 & 1,81 & 0,990 \\
\hline INTERPB'3 & 41,43 & 2,24 & 41,09 & 2,16 & 0,587 \\
\hline INTERMOL3 & 52,24 & 2,92 & 51,94 & 2,51 & 0,709 \\
\hline COMPR3 & 71,90 & 3,12 & 72,07 & 2,58 & 0,838 \\
\hline PERIM3 & 75,45 & 2,79 & 75,32 & 2,55 & 0,868 \\
\hline
\end{tabular}

Tabela 11. Resultados do teste $t$ independente, aplicado às variáveis estudadas, para verificar as diferenças das alterações do tratamento (T2-T1), entre os grupos 1 e 2, com e sem expansão rápida, respectivamente.

\begin{tabular}{c|c|c|c|c|c}
\hline \multirow{2}{*}{ Variáveis } & \multicolumn{2}{|c|}{$\begin{array}{c}\text { Grupo 1 } \\
\text { COM EXPANSÃo } \\
\text { RÁPIDA } \\
\text { (N= 25) }\end{array}$} & \multicolumn{2}{c}{$\begin{array}{c}\text { Grupo 2 } \\
\text { SEM EXPANSÃo } \\
\text { RÁPIDA } \\
\text { (N= 23) }\end{array}$} & \multirow{2}{*}{$\mathbf{P}$} \\
\cline { 2 - 5 } & Média & d.p. & Média & d.p. & \\
\hline LITTLE2-1 & $-6,23$ & 2,90 & $-4,97$ & 3,11 & 0,151 \\
\hline INTERC2-1 & 0,88 & 1,89 & 0,58 & 2,52 & 0,639 \\
\hline INTERPB2-1 & 3,65 & 1,84 & 1,62 & 1,70 & $0,000^{\star}$ \\
\hline INTERPB'2-1 & 3,82 & 2,12 & 1,15 & 2,15 & $0,000^{*}$ \\
\hline INTERMOL2-1 & 2,97 & 3,56 & 0,39 & 2,57 & $0,006^{*}$ \\
\hline COMPR2-1 & 2,50 & 2,85 & 1,67 & 3,73 & 0,390 \\
\hline PERIM2-1 & 2,69 & 2,48 & 1,34 & 3,20 & 0,107 \\
\hline
\end{tabular}

* Estatisticamente significante para $p<0,05$ 
Tabela 12. Resultados do teste $\mathrm{t}$ independente, aplicado às variáveis estudadas, para verificar as diferenças das alterações no período póstratamento (T3-T2), entre os grupos 1 e 2, com e sem expansão rápida, respectivamente.

\begin{tabular}{c|c|c|c|c|c}
\hline \multirow{2}{*}{ Variáveis } & \multicolumn{2}{|c|}{$\begin{array}{c}\text { Grupo 1 } \\
\text { COM EXPANSÃo } \\
\text { RÁPIDA } \\
\text { (N= 25) }\end{array}$} & \multicolumn{2}{c}{$\begin{array}{c}\text { Grupo 2 } \\
\text { SEM EXPANSÃo } \\
\text { RÁPIDA } \\
\text { (N= 23) }\end{array}$} & \multirow{2}{*}{ p } \\
\cline { 2 - 5 } & Média & d.p. & Média & d.p. & \\
\hline LITTLE3-2 & 1,52 & 1,60 & 1,52 & 1,38 & 0,992 \\
\hline INTERC3-2 & $-0,58$ & 0,72 & $-0,11$ & 1,00 & 0,066 \\
\hline INTERPB3-2 & $-1,14$ & 0,90 & $-0,58$ & 0,98 & $0,045^{\star}$ \\
\hline INTERPB'3-2 & $-0,77$ & 1,05 & $-0,27$ & 0,99 & 0,095 \\
\hline INTERMOL3-2 & $-0,20$ & 1,64 & 0,42 & 1,16 & 0,146 \\
\hline COMPR3-2 & $-1,57$ & 1,24 & $-1,69$ & 1,26 & 0,732 \\
\hline PERIM3-2 & $-1,65$ & 1,29 & $-1,20$ & 1,09 & 0,194 \\
\hline
\end{tabular}

* Estatisticamente significante para $p<0,05$

Tabela 13. Resultados do teste $\mathrm{t}$ independente, aplicado às variáveis estudadas, para verificar as diferenças das alterações no período total de observação (T3-T1), entre os grupos 1 e 2, com e sem expansão rápida, respectivamente.

\begin{tabular}{c|c|c|c|c|c}
\hline & \multicolumn{2}{c|}{$\begin{array}{c}\text { Grupo 1 } \\
\text { COM EXPANSÃo } \\
\text { RÁPIDA } \\
\text { (N= 25) }\end{array}$} & $\begin{array}{c}\text { Grupo 2 } \\
\text { SEM EXPANSÃo } \\
\text { RÁPIDA } \\
\text { (N= 23) }\end{array}$ & p \\
\cline { 2 - 5 } & Média & d.p. & Média & d.p. & \\
\hline LITTLE3-1 & $-4,72$ & 3,27 & $-3,44$ & 2,73 & 0,152 \\
\hline INTERC3-1 & 0,30 & 1,53 & 0,47 & 2,47 & 0,778 \\
\hline INTERPB3-1 & 2,51 & 1,67 & 1,04 & 1,52 & $0,003^{*}$ \\
\hline INTERPB'3-1 & 3,05 & 1,82 & 0,89 & 1,95 & $0,000^{*}$ \\
\hline INTERMOL3-1 & 2,78 & 3,19 & 0,81 & 1,87 & $0,013^{*}$ \\
\hline COMPR3-1 & 0,93 & 2,41 & $-0,02$ & 3,25 & 0,252 \\
\hline PERIM3-1 & 1,04 & 2,57 & 0,14 & 3,29 & 0,296 \\
\hline
\end{tabular}

* Estatisticamente significante para $p<0,05$ 
Tabela 14. Resultados do teste de correlação de Pearson

\begin{tabular}{c|c|c}
\hline Variáveis & r & p \\
\hline LITTLE1 $\times$ LITTLE3 & 0,252 & 0,071 \\
\hline LITTLE1 $\times$ LITTLE3-2 & 0,241 & 0,084 \\
\hline LITTLE2-1 $\times$ LITTLE3-2 & $-0,264$ & 0,055 \\
\hline
\end{tabular}

Tabela 15. Resultados do teste de correlação de Pearson

\begin{tabular}{c|c|c}
\hline Variáveis & $\mathbf{r}$ & $\mathbf{p}$ \\
\hline LITTLE3-2 $\times$ INTERC3-2 & $-0,459$ & $0,000^{*}$ \\
\hline LITTLE3-2 INTERPB3-2 & $-0,419$ & $0,001^{*}$ \\
\hline LITTLE3-2 $\times$ INTERPB'3-2 & $-0,269$ & 0,053 \\
\hline LITTLE3-2 x INTERMOL3-2 & $-0,064$ & $-0,649$ \\
\hline LITTLE3-2 $\times$ COMPR3-2 & 0,028 & 0,842 \\
\hline LITTLE3-2 $\times$ PERIM3-2 & $-0,012$ & 0,930 \\
\hline
\end{tabular}

*Estatisticamente significante para $p<0,05$ 


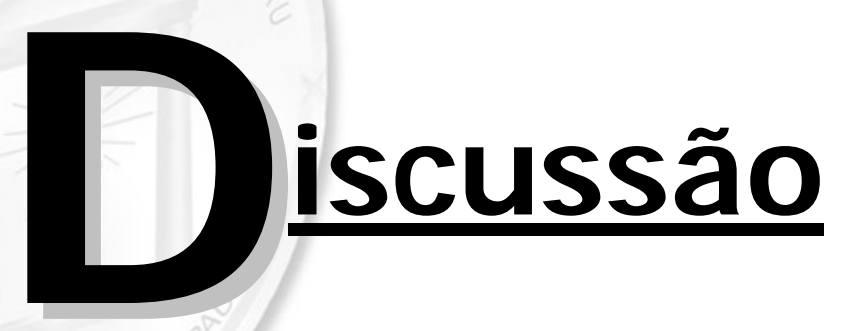





\section{6 - DISCUSSÃO}

A despeito de incontestáveis avanços científicos e tecnológicos no último século, dúvidas e questionamentos ainda persistem sobre a estabilidade dos tratamentos ortodônticos no período pós-contenção e os possíveis fatores capazes de efetivamente influenciá-la. Um dos principais objetivos do tratamento ortodôntico consiste na manutenção em longo prazo dos resultados obtidos, entretanto, não obstante muitos esforços já terem sido despendidos, a Ortodontia ainda não foi capaz de definitivamente resolver o problema.

O presente estudo teve como objetivo proporcionar maiores esclarecimentos sobre a recidiva do apinhamento ântero-superior, buscando verificar uma possível influência da realização do procedimento de expansão rápida da maxila, durante o tratamento ortodôntico, na estabilidade do alinhamento dos dentes ântero-superiores no período pós-contenção.

Apesar da extensa literatura relacionada ao estudo da estabilidade do alinhamento dentário ântero-inferior $8,9,24,25,47,58,65,66,103,106,115,116,121,147,163,165,186-$ $188,206,209,219,220$, os estudos que avaliaram o comportamento dos incisivos superiores após a remoção das contenções apresentam-se em menor número $32,33,57,59,94,137,200$. Possivelmente, este fato se justifique pela maior freqüência de recidiva no segmento ântero-inferior ${ }^{101,178,201,210}$. Apesar da recidiva ântero-superior apresentar-se menos prevalente, a busca por fatores que possam auxiliar na estabilidade no segmento ântero-superior apresenta validade, já que um deterioramento do tratamento neste segmento do arco também pode resultar em um comprometimento estético e funcional da oclusão. Devido à sua localização no arco, o apinhamento na região ântero- 
superior tende a apresentar-se mais visível e conseqüentemente promover maiores prejuízos estéticos que a irregularidade dentária ântero-inferior. Entretanto, deve-se ter consciência que, dependendo da altura do sorriso do paciente, pode-se observar uma inversão desta situação.

Pesquisas que avaliaram os efeitos imediatos da expansão rápida da maxila demonstram aumentos significantes nas dimensões transversais do arco superior, resultantes da combinação de efeitos esqueléticos e dentários ${ }^{2,41,81,82,111}$. Em um curto intervalo após a expansão, nota-se um efeito de "acomodação" dentária, entretanto, observa-se uma relativa estabilidade em relação às alterações esqueléticas promovidas pela expansão ${ }^{43,79,81,82,89,136,137,222}$.

A expansão maxilar por meio da abertura da sutura palatina mediana tem sido considerada um procedimento auxiliar na estabilidade pós-contenção do alinhamento dos incisivos superiores e inferiores ${ }^{8,137,184}$. Especula-se que esta maior estabilidade se deve aos componentes esqueléticos relacionados ao incremento transversal maxilar promovido pelo aparelho expansor, situação contrária à expansão dos arcos promovida exclusivamente durante a mecânica ortodôntica de nivelamento e alinhamento dos dentes ${ }^{137}$. Baseado nestes relatos, decidiu-se investigar a influência da realização do procedimento de ERM sobre a estabilidade do alinhamento dentário ântero-superior.

Com o propósito de facilitar o entendimento e interpretação dos resultados obtidos, são discutidos seqüencialmente: o erro metodológico, a amostra utilizada e sua compatibilidade, a metodologia empregada e os resultados deste trabalho. Adicionalmente, baseadas nos resultados e na literatura consultada, são discutidas as implicações clínicas destes resultados. 


\subsection{Erro metodológico}

Todo o esforço deve ser despendido para minimizar ou, pelo menos, controlar os erros inerentes aos métodos de mensuração empregados nos diferentes trabalhos científicos. Na presente pesquisa, o conhecimento destes erros permitiu que os dados obtidos fossem interpretados de forma íntegra, tornando os resultados mais confiáveis.

Para a obtenção dos dados necessários à condução deste trabalho, foram realizadas medições nos modelos de estudo das três fases estudadas, para cada paciente, com o auxílio de um paquímetro com precisão de até 0,01mm. Foram realizadas sete mensurações em cada um dos modelos iniciais, finais e de cinco anos pós-tratamento dos pacientes selecionados para a constituição da amostra. Como a amostra total apresenta 48 pacientes e para cada paciente constam três pares de modelos, ao final foram então medidos 144 pares de modelos, totalizando 1008 medidas (7 variáveis para cada modelo).

Algum grau de julgamento e subjetividade pode ocorrer por parte do examinador durante a medição das variáveis, o que ressalta a importância da análise do erro metodológico no caso de medições em modelos de gesso. De acordo com Houston ${ }^{92}$, para que a precisão da metodologia fosse adequadamente analisada, deveriam ser reavaliados um mínimo de 15 casos. Desta forma, para a avaliação do erro intra-examinador, novas aferições das variáveis estudadas (índice de irregularidade de Little, distância intercaninos, distâncias entre primeiros e segundos pré-molares, distância intermolares, comprimento e perímetro do arco superior) foram realizadas nos modelos de 
estudo de 15 pacientes selecionados aleatoriamente da amostra total, perfazendo um total de 45 pares de modelos, medidos 1 mês após a realização da primeira aferição.

Os resultados das duas aferições foram então submetidos à fórmula proposta por Dahlberg ${ }^{45}$, para obtenção dos erros casuais. De forma geral, os erros casuais deste trabalho foram bastante reduzidos (Tabela 2). A maior fonte de erros casuais, segundo Houston ${ }^{92}$, acontece pela dificuldade de identificação de um ponto em particular ou pela imprecisão na definição de certos pontos. O maior significado dos erros casuais refere-se ao seu poder de aumentar o desvio-padrão das médias obtidas ${ }^{45}$. Como os erros foram bastante pequenos, conclui-se que os desvios padrão encontrados sejam resultantes da variabilidade dos grupos.

O erro sistemático se manifesta quando o examinador altera, inconscientemente, a técnica de mensuração com o passar do tempo. Para avaliação deste erro, procedeu-se a aplicação do teste t pareado sobre as medidas das sete variáveis dos modelos reavaliadas. Ao analisar os resultados obtidos (Tabela 2), nota-se que não foram observadas diferenças estatisticamente significantes entre as duas medições para todas as variáveis analisadas.

Os resultados favoráveis obtidos em relação à avaliação dos erros casual e sistemático são reflexos da padronização e da precisão na execução das aferições e resultado também da simplicidade e objetividade da aplicação do Índice de Irregularidade de Little aos modelos de estudo. 


\subsection{Amostra utilizada e sua compatibilidade}

Para obtenção da amostra foram selecionados os modelos de grupos de pacientes que apresentassem inicialmente uma relação molar de Classe I ou, no máximo, uma relação molar de meia Classe II, tratados sem extrações. Outro critério de seleção da amostra foi que todos os pacientes tivessem sido tratados com a mecânica ortodôntica fixa, tipo Edgewise, nos arcos superior e inferior.

A seleção da amostra foi realizada de forma a eliminar o maior número possível de fatores que poderiam influenciar os resultados. Desta forma, uma das maiores preocupações na condução deste trabalho consistiu na obtenção de grupos compatíveis, o que viabilizaria uma correta comparação e, conseqüentemente, favoreceria a interpretação e a confiabilidade dos resultados. Para tanto, realizou-se uma homogeneização das características ao início e ao término do tratamento ortodôntico. Os grupos foram compatibilizados quanto ao protocolo de tratamento, o tipo de acessório ortodôntico utilizado e em relação às distribuições dos gêneros e da má oclusão inicial. Além disso, foram compatibilizadas características como: as idades inicial e final, o tempo de tratamento e o tempo de avaliação póscontenção. Desta maneira, as alterações que ocorreram no período póscontenção puderam ser analisadas com maior segurança.

O teste do Qui-Quadrado foi realizado para avaliação da compatibilidade intergrupos com relação à distribuição dos gêneros. Os resultados demonstraram que os grupos não apresentavam diferenças significantes estatisticamente (Tabela 3). Uma distribuição semelhante dos gêneros nos dois 
grupos possibilitou a comparação dos mesmos de forma que esta variável não influenciasse os resultados. Em relação ao dimorfismo sexual, observam-se diferenças nos níveis de colaboração durante o tratamento ${ }^{44}$ e também em relação à estabilidade, pois alguns estudos demonstram que o crescimento terminal da mandíbula ocorre mais tardio no gênero masculino ${ }^{14,175}$. Ormiston et al. $^{142}$, em 2005 , demonstrou uma relação entre o gênero masculino e a manutenção de um maior período de crescimento e uma associação, de ambos os fatores, a uma menor estabilidade.

Em relação à estabilidade, notam-se divergências na literatura sobre o comportamento pós-contenção dos tipos de má oclusão (Classe I e Classe II) $66,102,116,119,142,210$, Além disso, alguns estudos relatam que quanto maior a severidade inicial da má oclusão, maior a recidiva e menor a estabilidade em longo prazo $64,104,108,116$. Sendo assim, optou-se por investigar a estabilidade do alinhamento dentário ântero-superior e as alterações dimensionais do arco superior no período pós-contenção, de dois grupos que apresentassem características similares em relação à má oclusão inicial. Para avaliar a compatibilidade em relação à distribuição dos tipos de má oclusão realizou-se o teste do Qui-quadrado entre os dois grupos estudados (Tabela 4). Os resultados demonstraram que grupos apresentavam-se semelhantes em relação à distribuição das diferentes severidades iniciais das más oclusões. Com o objetivo de verificar a compatibilidade intergrupos em relação à quantidade de apinhamento inicial, realizou-se o teste t para a variável índice de irregularidade de Little inicial (LITTLE1). Os resultados demonstraram que não existiam diferenças estatisticamente significantes entre os grupos nas quantidades de apinhamento ântero-superior pré-tratamento (Tabela 5). 
Assim sendo, os casos selecionados apresentavam má oclusão inicial de Classe I ou Classe II de Angle, com distribuições similares destas más oclusões, quantidades de apinhamento inicial semelhantes e mesmo protocolo (sem extrações) e mecânica (Edgewise) de tratamento, objetivando eliminar o fator severidade e tipo inicial da má oclusão ${ }^{78}$ como possível fator de influência na estabilidade em longo prazo dos pacientes que constituíram os dois grupos analisados.

A presença de todos os dentes permanentes (até os primeiros molares) já irrompidos e a ausência de dentes supranumerários e agenesias constituíram critérios adicionais para a seleção da amostra, visto que a ausência de dentes permanentes, a presença de supranumerários e algumas anomalias relacionadas à forma dos dentes podem interferir no desenvolvimento normal da oclusão e no posicionamento dentário ${ }^{116,119}$.

A idade inicial, a idade final, o tempo de tratamento e o tempo de avaliação pós-tratamento ortodôntico também foram comparados entre os dois grupos para a avaliação da compatibilidade intergrupos quanto a estas variáveis. Pela análise dos resultados (Tabela 5) observa-se que não houve diferenças significantes entre os grupos. Para o tempo de tratamento, a compatibilidade entre os grupos provavelmente seria observada, pois os mesmos apresentavam severidades iniciais das más oclusões similares ${ }^{60,98}$.

Seguindo-se os critérios supracitados, a amostra consistiu de um total de 48 pacientes, selecionados a partir dos registros do arquivo da disciplina de Ortodontia, apresentando em torno de 4.000 documentações ortodônticas de pacientes tratados pelos alunos dos cursos de Pós-graduação (Mestrado, Doutorado e Especialização) do Departamento de Odontopediatria, Ortodontia 
e Saúde Coletiva da Faculdade de Odontologia de Bauru. Selecionaram-se apenas os casos que tivessem a documentação ortodôntica completa, com todas as fichas devidamente preenchidas, apresentando os modelos de estudo das fases inicial, final de tratamento e 5 anos pós-tratamento em bom estado de conservação.

\subsection{Metodologia}

A divisão da amostra total (48 pacientes) em dois grupos foi realizada de acordo com a realização ou não do procedimento de expansão rápida da maxila durante o tratamento ortodôntico sem extrações. A comparação entre os dois grupos, ambos tratados sem extrações e mecânica Edgewise, permitiu efetivamente verificar a influência da realização do procedimento de ERM (somente realizado no grupo 1) sobre a estabilidade longitudinal do alinhamento dos incisivos superiores. Estudos prévios relacionados ao assunto basicamente avaliaram a estabilidade do tratamento de casos tratados com ERM e mecânica ortodôntica fixa utilizando, para tanto, grupos controles sem tratamento $^{70,126}$ ou compararam seus resultados com os obtidos em outros trabalhos $8,59,137$.

Em relação ao Grupo 1 (pacientes submetido à expansão rápida da maxila durante o tratamento ortodôntico), foram incluídos apenas pacientes que se submeteram a um tratamento que incluiu uma fase ortopédica mecânica que priorizou a expansão transversal do arco superior por meio da abertura da sutura palatina mediana. Os pacientes do grupo 1 foram submetidos a ERM por meio de aparelhos expansores fixos tipo Haas ${ }^{79-81}$ modificado, tipo Hyrax, 
ou expansor colado (com cobertura oclusal) ${ }^{42}$ para a correção da deficiência transversal inicial. Embora o procedimento de expansão rápida tenha sido realizado por meio de três diferentes tipos de expansores, a literatura relata que não existem diferenças significantes nos efeitos dentoesqueléticos e nos resultados finais obtidos por estes aparelhos ${ }^{195}$.

Também foram constatadas algumas incertezas em relação ao protocolo de ativação dos aparelhos para ERM, já que nem sempre se apresentavam especificados nos prontuários. Entretanto, pode-se afirmar que a velocidade de expansão foi a do tipo rápida, uma vez que, segundo a literatura ${ }^{79,89,196}$, esta é assim considerada quando maior ou igual a $1 / 2$ volta/dia (até 14 anos de idade) ou maior ou igual a $1 \frac{1}{4}$ volta/dia (a partir dos 15 anos de idade). Geralmente, os pacientes que constituíram o grupo 1 foram instruídos a girar $1 / 4$ do parafuso pela manhã, repetindo-se o mesmo procedimento à noite, até que fosse obtida uma sobrecorreção da discrepância transversal entre os arcos dentários. A sobrecorreção da expansão correspondia clinicamente ao estabelecimento do contato das cúspides palatinas dos dentes póstero-superiores com as cúspides vestibulares dos dentes póstero-inferiores.

Depois de alcançada esta sobrecorreção, o parafuso expansor do aparelho era fixado com resina acrílica ou com fio de amarrilho até que se obtivesse uma posterior evidência radiográfica do restabelecimento da sutura palatina mediana por meio de neoformação óssea. Este período de contenção com o próprio expansor variou de 2 a 6 meses. Em seguida, para prosseguir como contenção, os pacientes utilizaram, por aproximadamente um ano, uma placa removível superior de acrílico. No entanto, como implícito nos prontuários, não se costumava obedecer a este tempo quando se iniciava a 
ortodontia corretiva, de modo que o tempo de contenção pós-remoção dos expansores deve ter variado significantemente entre os pacientes que constituíram este grupo. O protocolo de contenção da expansão utilizado foi similar ao de estudos prévios sobre a ERM ${ }^{35,70,216}$ apesar de alguns autores não optarem pela utilização da placa removível e, imediatamente após a remoção do expansor, instalarem o aparelho ortodôntico fixo ${ }^{35,216}$.

Em relação ao Grupo 2, foram incluídos pacientes cujo tratamento não envolveu a utilização de recursos mecânicos que priorizaram a expansão do arco superior durante o tratamento ortodôntico.

A partir das fichas clínicas presentes nos prontuários ortodônticos dos pacientes que constituíram os dois grupos também foram coletados dados gerais como: data de nascimento, gênero, tipo de aparelho e mecânica utilizados, data de início e término do tratamento, tempo de uso das contenções, data da avaliação pós-contenção. Com estes dados determinouse, para cada paciente, os tempos de tratamento, de contenção e de avaliação pós-tratamento, além das idades ao início e ao final do tratamento.

Uma vez que o propósito deste estudo foi avaliar a estabilidade póscontenção do apinhamento ântero-superior e as alterações nas dimensões do arco superior neste mesmo período, o método proposto para a obtenção dos dados foi a análise dos modelos de estudo.

A quantificação do apinhamento dentário ântero-superior foi realizada nos modelos de estudo baseada na medição do grau de deslocamento vestibulolingual dos pontos de contato anatômico ${ }^{10,30,114,133,140,151,161,166,212}$. Para tanto, utilizou-se o índice de irregularidade proposto por Little ${ }^{114}$, apesar de idealmente elaborado para a avaliação do apinhamento dentário no segmento 
ântero-inferior. A mesma metodologia para o cálculo do índice de irregularidade foi empregada, pois apresenta grande aceitação e reprodutibilidade, sendo praticamente utilizada de forma unânime na literatura científica $27,65,94,101,116,119,137,174,179,211$.

Com o objetivo de favorecer a exatidão dos dados, as medições das variáveis que representam o apinhamento dentário (Índice de Irregularidade) e as dimensões do arco superior (distâncias intercaninos, interpré-molares, intermolares, comprimento e perímetro do arco) foram realizadas nos modelos de estudo referentes aos três tempos analisados por um único examinador (LFGC), utilizando um paquímetro digital com precisão de centésimos de milímetros.

\subsection{Resultados}

\subsubsection{Alterações intragrupos (com e sem ERM) nos tempos avaliados}

Análises de variância (ANOVA) a um critério de seleção foram realizadas para os grupo 1 (com ERM) e 2 (sem ERM), separadamente, com o intuito de avaliar as diferenças intragrupo nos três tempos avaliados (inicial, final e póscontenção).

Os resultados do ANOVA e do teste de Tukey, para o grupo 1 (Tabela 6) demonstraram alterações estatisticamente significantes do índice de irregularidade de Little nos três tempos avaliados. Interpretando estes resultados, pode-se afirmar que o tratamento ortodôntico resultou em

significativa redução do apinhamento dentário ântero-superior e 
posteriormente, durante o período pós-contenção, observou-se um aumento desta irregularidade. Em relação às alterações na dimensão e forma do arco superior durante o tratamento, foram notados incrementos transversais (aumento nas variáveis INTERPB, INTERPB' e INTERMOL) e aumentos no perímetro e comprimento do arco significantes, que se apresentaram estáveis no período pós-contenção. O aumento nas dimensões do arco superior pode ser explicado pelos efeitos da ERM ${ }^{43,80,82,89,105,111,136,137,183,191,222}$, procedimento realizado em todos os pacientes que constituíram este grupo. Moussa; O'Reilly; Close $^{137}$, em 1995, avaliaram a estabilidade longitudinal do tratamento com ERM seguido por aparelhos fixos e observaram ${ }^{137}$ aumentos significantes na distância intermolares superiores. Os autores ${ }^{137}$ relataram uma boa estabilidade da distância intercaninos superiores (75\% desta distância foi mantida) e da distância intermolares superiores ( $81 \%$ foi mantida). Não foram observados aumentos no comprimento do arco superior durante a fase póscontenção. Entretanto, o trabalho ${ }^{137}$ não apresentava grupo controle. Um grupo controle adequado estava presente no estudo de McNamara et al. ${ }^{126}$, em 2003, que avaliou em longo prazo as alterações dimensionais de pacientes submetidos à ERM seguida por aparelhos fixos. O tempo de tratamento foi, em média, 3 anos e os casos foram reavaliados 6 anos pós-contenção. Os resultados demonstraram que o tratamento induziu a aumentos favoráveis e estáveis nas dimensões transversais e no comprimento do arco superior. Os autores $^{126}$ observaram incrementos residuais no perímetro do arco superior de 2,8 $\mathrm{mm}$ e, desta forma, relataram que o procedimento de ERM consiste em uma efetiva opção de tratamento em casos apresentando discrepância entre o tamanho dos dentes e a base óssea. Geran et al. ${ }^{70}$, em 2006, também avaliou 
longitudinalmente a estabilidade do tratamento ortodôntico com ERM seguido por aparelhos fixos. Os resultados demonstraram um ganho de $4 \mathrm{~mm}$ no perímetro do arco superior em relação a um grupo controle sem tratamento. Relataram $^{70}$ que a terapia de ERM na fase de dentadura mista, seguida por aparelhos fixos na dentadura permanente, consiste em uma opção de tratamento favorável em relação à estabilidade para a correção de discrepâncias transversais da maxila.

Os resultados do ANOVA e do teste de Tukey para o grupo 2 (Tabela 7) demonstraram alterações estatisticamente significantes do índice de irregularidade de Little nos três tempos avaliados. Desta forma, observou-se no grupo 2 um comportamento similar ao grupo 1 em relação às alterações da variável LITTLE, ou seja, uma redução significante do apinhamento dentário ântero-superior durante o tratamento e posteriormente, durante o período póscontenção, uma recidiva significante da irregularidade dos incisivos superiores. Em relação às alterações nas dimensões e forma do arco superior durante o tratamento, notou-se uma alteração significante somente na variável INTERPB (distância entre os primeiros pré-molares), que indica uma manutenção das dimensões do arco superior durante o tratamento e uma estabilidade destas dimensões durante o período pós-contenção. Sadowsky et al. ${ }^{179}$, em 1994 , avaliou a estabilidade longitudinal dos arcos superior e inferior de casos tratados sem extrações dentárias e mecânica Edgewise. Também observaram que, durante o tratamento, ocorreu uma significativa correção do apinhamento ântero-superior, entretanto notaram alguma expansão transversal do arco superior. Durante o período pós-contenção, apesar de todas as variáveis medidas nos modelos tenderem a apresentar recidiva, as distâncias 
intercaninos e entre os primeiros e segundos pré-molares superiores também não apresentaram alterações significantes durante um período pós-contenção médio de 5 anos. Erdinc; Nanda; Isiksal ${ }^{57}$, em 2006, avaliaram a estabilidade de casos tratados com e sem extrações. Observaram ${ }^{57}$ uma redução significativa na irregularidade dos incisivos superiores durante o tratamento em ambos os grupos. O grupo tratado sem extrações exibiu, durante o tratamento, incrementos transversais significantes nas distâncias intercaninos e interprémolares. Todas as variáveis que representam as dimensões do arco superior não apresentaram alterações significantes no período pós-contenção, entretanto, a recidiva do apinhamento ântero-superior mostrou-se significante. Os trabalhos supracitados ${ }^{57,179}$ e os resultados desta pesquisa demonstram um prognóstico favorável em relação estabilidade dimensional em longo prazo do arco superior em casos tratados sem extrações.

\subsubsection{Comparação intergrupos das características pré, pós-tratamento e pós-contenção}

Ao início do tratamento (T1) os dois grupos estudados apresentavam-se compatíveis em relação às quantidades de apinhamento ântero-superior. Os grupos 1 e 2 apresentaram índices de irregularidade de 7,65 mm (d.p.=2,96) e 6,56 mm (d.p.= 2,84), respectivamente, valores que não representaram diferença estatisticamente significante $(p<0,05)$ entre os grupos (Tabela 8).

Alguns trabalhos que avaliaram a recidiva do apinhamento no período pós-contenção citam que a quantidade de apinhamento inicial está diretamente relacionada com a quantidade de recidiva ${ }^{6,9,101}$, embora outros autores ${ }^{121,130,141}$ 
não tenham observado esta relação. Portanto, como citado anteriormente, a compatibilização intergrupos do apinhamento inicial (LITTLE1) permitiu eliminar qualquer interferência que pudesse ocorrer nos resultados, conseqüente das discrepâncias entre os grupos na quantidade de irregularidade dentária ao início do tratamento.

Em relação às dimensões do arco superior, nota-se que os pacientes pertencentes ao grupo 1 (submetido à expansão rápida) apresentavam dimensões transversais reduzidas em relação ao grupo 2 (tratado sem expansão) (Tabela 8). O Grupo 1, por incluir pacientes cujo tratamento envolveu a expansão maxilar, era constituído por pacientes que apresentavam algum grau de deficiência transversal maxilar ao início do tratmento, o que justifica a presença de menores dimensões iniciais, significantes estatisticamente na região de pré-molares. McNamara ${ }^{125}$, em 2000, comentou que, geralmente, um arco superior que apresenta uma distância transpalatina de 36 a 39 mm é capaz de acomodar uma dentição permanente de tamanho médio, sem apinhamento ou espaçamento. Arcos superiores menores que 31 $\mathrm{mm}$ de largura podem apresentar-se apinhados e, desta forma, necessitar de expansão maxilar ortopédica. Ressaltou ${ }^{125}$ que outros fatores, como o tipo facial, o perfil facial e o tônus muscular também devem ser levados em consideração ao se decidir entre extrair ou expandir. As más oclusões que apresentam deficiências transversais maxilares, como a Classe I com apinhamento, a Classe II com maxila em forma de V e a Classe III com atresia maxilar, são comumente corrigidas por meio da ERM ${ }^{79,207}$. Este procedimento foi utilizado nos pacientes pertencentes ao grupo 1 para a correção da deficiência transversal inicial, por promover incrementos transversais maxilares 
de forma rápida, seguidos por neoformação óssea na região da sutura palatina mediana $^{79,207}$.

Ao final do tratamento (T2) a quantidade de irregularidade dentária ântero-superior mostrou-se bastante semelhante entre os grupos. Observou-se que, ao término do tratamento, os grupos não apresentaram diferenças significantes em relação a todas as variáveis dimensionais estudadas. A semelhança dos dois grupos ao final do tratamento em relação às dimensões do arco superior demonstra, mesmo que indiretamente, a eficiência do procedimento de expansão rápida da maxila no incremento transversal do arco superior dos pacientes que constituíram o grupo 1, como já amplamente descrito na literatura ${ }^{43,70,79,81,82,89,110,136,137,222}$. Pinheiro ${ }^{149}$, em 2002, cita que parece ser vantajoso realizar a ERM, pois além da correção da atresia maxilar, a verticalização dentária pós-expansão rápida não compromete a nova relação interarcos. O alargamento transversal da base óssea superior minimiza a necessidade de uma extensa movimentação ortodôntica ${ }^{149}$.

Ao final da fase pós-contenção (T3) os dois grupos apresentavam quantidade de apinhamento (LITTLE3) e dimensões do arco (variáveis INTERC3, INTERPB3, INTERPB'3, INTERMOL3, PERIM3 e COMPR3) similares. Estes resultados sugeriram um comportamento similar dos grupos no transcorrer do período pós-contenção, uma vez que ambos apresentaram, tanto ao final do tratamento quanto ao final do período pós-contenção, características bastante semelhantes. Em relação à abordagem científica, uma comparação longitudinal entre casos tratados sem extrações, com ou sem a realização do procedimento de ERM ainda não foi realizada. Em relação aos estudos comparativos, a literatura apresenta trabalhos que avaliaram as 
alterações oclusais, durante o tratamento e em longo prazo, de pacientes tratados com ERM e aparelhos fixos em relação à um grupo controle sem tratamento ${ }^{59,70,126}$

\subsubsection{Comparação intergrupos das alterações do tratamento}

Não houve diferença significante entre os dois grupos em relação à quantidade de correção de apinhamento ântero-superior (LITTLE2-1). Este resultado era esperado, já que não existiam diferenças estatisticamente significantes entre os grupos nas quantidades de apinhamento inicial e final. A redução da irregularidade dos incisivos superiores do grupo 1 (com ERM) durante o tratamento foi similar à de estudos anteriores que utilizaram o procedimento de ERM associado à terapia ortodôntica fixa como mecanismo para a correção do apinhamento, em casos tratados sem extrações dentárias $59,91,137$.

Em relação às dimensões transversais do arco superior, observou-se um maior incremento no grupo submetido à expansão rápida da maxila (Tabela 9). A expansão maxilar no grupo 1 ocorreu de forma mais efetiva na região posterior do arco, como já relatada na literatura por Krebs ${ }^{105}$ e Bell ${ }^{15}$. Não foi observada diferença entre os grupos na alteração da distância intercaninos superiores (Tabela 11), diferentemente de estudos prévios realizados por Linder-Aronson; Lindgren ${ }^{111}$, em 1979 e Herold ${ }^{87}$, em 1989.

No que diz respeito às alterações no comprimento e perímetro do arco superior durante o tratamento, os resultados deste trabalho não indicaram diferenças significantes entre as alterações do grupo tratado com ERM (grupo 
1) àquelas ocorridas no grupo tratado sem a realização deste mesmo procedimento (grupo 2). Entretanto, uma revisão da literatura pertinente suporta a afirmação que o procedimento de expansão rápida da maxila pode promover espaço adicional nos arcos para corrigir problemas relacionados à falta de espaço ${ }^{70,110,126}$. Por exemplo, Adkins; Nanda; Currier ${ }^{2}$, em 1990, demonstraram que cada milímetro de aumento transversal na região de prémolares produz um ganho no perímetro do arco superior de $0,7 \mathrm{~mm}(70 \%)$. No presente trabalho observou-se um aumento de $3,65 \mathrm{~mm}($ d.p. $=1,84)$ na distância entre os primeiros pré-molares. Esta expansão correspondeu a um aumento no perímetro do arco superior durante o tratamento equivalente a 2,69 mm (d.p.= 2,48), que representa $73 \%$ da expansão obtida na região de prémolares (Tabela 11).

Nota-se, na tabela 11 , que ambos os grupos apresentaram algum aumento no perímetro e no comprimento do arco. Entretanto, apesar de ocorrerem aumentos no comprimento e perímetro do arco superior do grupo 1 (2,50 e 2,69 mm, respectivamente), estes não foram significantemente maiores que aqueles observados no grupo tratado sem a realização da ERM (1,67 e $1,34 \mathrm{~mm}$, respectivamente). O grupo 2 , apesar de constituir-se de pacientes que não foram submetidos à procedimentos que teriam por finalidade a expansão maxilar, apresentou alguma expansão do arco superior conseqüente ao tratamento com mecânica Edgewise, já observada em estudos prévios de casos tratados sem extrações ${ }^{56,69,75,179}$. Especula-se que, provavelmente, se o grupo 1 fosse comparado a um grupo controle compatível, sem tratamento, os ganhos no perímetro do arco como resultado do procedimento de ERM 
poderiam se apresentar significantes estatisticamente, já que existe uma tendência natural de redução do perímetro do arco com a idade $118,126,193,206$.

Gianelly ${ }^{72}$, em 2003, baseado em trabalhos relacionados aos efeitos da $\mathrm{ERM}^{2,77}$, afirmou que, apesar de incrementos moderados (3-4 mm) no perímetro do arco superior após a expansão rápida da maxila, o aumento transversal do arco inferior e, conseqüentemente, o ganho de espaço para correção de apinhamento dos incisivos inferiores são mínimos. Portanto, segundo o autor ${ }^{72}$, os dados disponíveis indicam que a expansão mandibular não fornece espaço suficiente para a correção do apinhamento ântero-inferior. Ressaltou $^{72}$ que o uso da ERM como recurso para obtenção de espaço em tratamentos sem extrações deve ser realizado de forma mais racional e, principalmente, que o planejamento dos tratamentos deve ser baseado nos problemas presentes no arco inferior.

\subsubsection{Comparação intergrupos das alterações pós-contenção}

Os resultados demonstraram que a quantidade média de recidiva do apinhamento ântero-superior durante o período pós-contenção foi a mesma nos dois grupos $(1,52 \mathrm{~mm})$. Ocorreu recidiva do apinhamento ântero-superior na grande maioria dos pacientes avaliados com uma porcentagem média de 24,39\% e 30,64\% para os grupos com e sem expansão rápida da maxila, respectivamente.

Diferentemente do sugerido por Moussa; O'Reilly; Close ${ }^{137}$, neste estudo, verificou-se que a expansão ortopédica do arco superior não influenciou na estabilidade pós-contenção do alinhamento dos incisivos superiores. Os 
resultados confirmam a imprevisibilidade e grande variabilidade em relação à recidiva do apinhamento e, desta forma, demonstra-se novamente que a habilidade para identificar os pacientes de maior risco apresenta-se limitada $54,121,123,127,171$.

Sadowsky et al. ${ }^{179}$, em 1994, avaliando a estabilidade de casos tratados sem extrações, observaram uma recidiva após 5 anos de remoção das contenções relativamente similar $(1,1 \mathrm{~mm})$. Entretanto, Moussa; O'Reilly; Close $^{137}$, em 1995, observaram resultados mais favoráveis em relação à esta recidiva, 8-10 anos após a remoção das contenções. Avaliando ${ }^{137}$ casos tratados com expansão rápida e aparelhos fixos observaram uma recidiva ântero-superior média de 0,6 mm (d.p.= 1,30). Vaden; Harris; Gardner ${ }^{211}$, em 1997, observaram que 96\% da correção do apinhamento ântero-superior durante o tratamento foi mantida após 15 anos do término do tratamento. A quantidade de apinhamento aumentou de $1,5 \mathrm{~mm}$ ao final do tratamento para $1,8 \mathrm{~mm}$ na avaliação pós-contenção. Em 2005, Ferris et al. ${ }^{59}$, também avaliando a recidiva deste segmento do arco em casos tratados sem extrações, observaram durante o período pós-contenção (7,9 anos) um aumento da irregularidade dos incisivos superiores de apenas 0,47 mm (d.p. = 1,19). A maior estabilidade do alinhamento dos dentes ântero-superiores destes trabalhos talvez possa ser explicada pelo prolongamento do tempo de uso das contenções ${ }^{8,137,179,184}$ após o tratamento ortodôntico fixo. No trabalho realizado por Sadowsky et al. ${ }^{179}$, o tempo médio de uso da contenção foi de 8,4 anos. O trabalho realizado por Moussa; O'Reilly; Close $^{137}$, apresentou um tempo de contenção para o arco inferior de 6,6 anos e o uso contínuo de uma Placa de Hawley no arco superior por 2 anos. Na pesquisa realizada por Vaden; Harris; 
Gardner ${ }^{211}$, os pacientes utilizaram placas de Hawley nos arcos superior e inferior ou uma placa de Hawley no arco superior e uma contenção fixa (3 x 3) no arco inferior. O primeiro controle pós-tratamento foi realizado somente após 6 anos. O estudo realizado por Ferris et al. ${ }^{59}$, apresentou um protocolo de contenção que incluía o uso de contenção removível no arco superior por 3 anos (1 ano de uso contínuo) e o uso de 3 × 3 ou placa de Hawley no arco inferior por um período médio de 3 anos. No presente trabalho, observou-se um tempo de contenção menos extenso. Todos os pacientes receberam como contenção uma placa de Hawley no arco superior por um período médio de 1 ano e um fio de aço colado de canino a canino no arco inferior (3x3) por um período de 3 anos.

Erdinc; Nanda; Isiksal ${ }^{57}$, em 2006, propuseram a avaliação em longo prazo do apinhamento dos incisivos superiores e inferiores em pacientes ortodônticos tratados com e sem extrações de pré-molares. Observaram ${ }^{57}$ um aumento na irregularidade dos incisivos superiores de 0,19 mm e 0,12 mm em casos tratados com e sem extrações, respectivamente, 4 anos e 11 meses póscontenção. O grupo tratado com extração apresentava um apinhamento inicial de 4,4 mm, enquanto que o grupo tratado sem extrações apresentava uma apinhamento inicial de apenas $1,94 \mathrm{~mm}$. As contenções superior e inferior (Placas de Hawley) foram removidas pelo menos dois anos antes da avaliação pós-contenção. A excepcional estabilidade deste trabalho pode estar relacionada à pequena quantidade de apinhamento inicial e à um curto intervalo entre a remoção das contenções e a avaliação pós-contenção.

Ainda que o procedimento de ERM não tenha exercido qualquer influência sobre a estabilidade ântero-superior e os resultados demonstrarem 
uma recidiva ântero-superior pós-contenção maior que a relatada em estudos prévios $^{57,59,137,179,211}$, os índices de irregularidade ao final do período póscontenção para os grupos 1 e 2 (2,93 e 3,12 mm, respectivamente) podem ser considerados clinicamente aceitáveis de acordo com Little ${ }^{114}$.

Surbeck et al. ${ }^{200}$, em 1998, observaram uma influência da quantidade de apinhamento ântero-superior inicial sobre a quantidade de recidiva póscontenção e, desta forma, sugeriu o emprego de diferentes protocolos de contenção e o esclarecimento aos pacientes de forma individualizada sobre a possibilidade de instabilidade pós-contenção de acordo com a irregularidade inicial $^{200}$. Entretanto, analisando os resultados de outros autores e os resultados obtidos, uma correlação positiva entre a quantidade de apinhamento ântero-superior inicial e a quantidade de recidiva pós-contenção parece improvável. Por exemplo, no presente trabalho, os grupos 1 e 2 apresentavam, ao início do tratamento, 7,65 mm (d.p.= 2,96) e 6,56mm (d.p.= 2,84), respectivamente, em relação à quantidade de apinhamento inicial e observouse uma recidiva pós-contenção média de $1,52 \mathrm{~mm}$ em ambos os grupos. A quantidade média de recidiva deste trabalho apresentou-se maior que a verificada por Ferris et al. ${ }^{59}$, Sadowsky et al. ${ }^{179}$ e Vaden; Harris; Gardner ${ }^{211}$ que apresentavam maiores valores para a irregularidade inicial dos incisivos superiores: $10,45 \mathrm{~mm}, 8,0 \mathrm{~mm}$ e $7,9 \mathrm{~mm}$, respectivamente. Estes trabalhos, mesmo apresentando quantidade ligeiramente maior de apinhamento inicial que o presente estudo, demonstraram uma menor quantidade de recidiva do apinhamento no período pós-contenção $(0,47 \mathrm{~mm} ; 1,1 \mathrm{~mm} ; 0,3 \mathrm{~mm}$, respectivamente). 
Os pacientes submetidos à expansão (grupo 1) apresentaram redução em todas as variáveis que representam as dimensões do arco superior durante o período de pós-contenção. O grupo tratado sem ERM (grupo 2) apresentou comportamento similar, exceto para a distância intermolares que aumentou 0,42 mm. Estes resultados confirmam os relatados por Moussa; O'Reilly; Close $^{137}$ e Ferris et al. $^{59}$ que também observaram alguma redução nas dimensões do arco superior após a remoção da contenção. Entretanto, os autores $^{59,137}$ ressaltaram que os incrementos dimensionais do arco superior proporcionados pelo tratamento foram mantidos em sua maioria durante o período pós-contenção. No presente trabalho, não foram observadas diferenças significantes entre os grupos na quantidade média de redução das variáveis que avaliaram as dimensões do arco superior, exceto para a variável INTERPB (distância entre os primeiros pré-molares). Uma maior redução desta distância no grupo 1 pode ser explicada pela aplicação de forças intensas sobre estes dentes durante o procedimento de expansão rápida da maxila. Por ser um dente utilizado como ancoragem pelo aparelho expansor, a aplicação de forças de grande magnitude sobre estes dentes pode ter resultado em uma maior inclinação vestibular que, durante o período pós-contenção, resultou em maior quantidade de recidiva (movimentação no sentido palatino) que os demais dentes posteriores. Especula-se que esta maior movimentação no sentido palatino possa ter resultado em uma maior redução na distância entre os primeiros pré-molares (variável INTERPB). 


\subsubsection{Comparação intergrupos das alterações totais}

Em relação às alterações totais o índice de irregularidade dos incisivos superiores apresentou uma redução de 4,71 mm (d.p.= 3,27) e 3,44 mm (d.p.= 2,73) para os grupos 1 e 2, respectivamente, e não foram observadas diferenças estatisticamente significantes entre os grupos. Um estudo realizado por Moussa; O'Reilly; Close ${ }^{137}$, em 1995, demonstrou uma redução de 5,3 mm (d.p. $=5,4)$ do índice de irregularidade do início do tratamento ao término do período pós-contenção em pacientes tratados com ERM e mecânica edgewise. Ferris et al. ${ }^{59}$, em 2005, observou uma redução de 8,25 mm (d.p.= 3,55) em relação às alterações totais de pacientes tratados com ERM, placa lábio-ativa e mecânica edgewise.

Os resultados apresentados na tabela 13 demonstram que as maiores diferenças entre os grupos ocorreram nas variáveis que representam as dimensões do arco superior na região posterior. O grupo 1, submetido à ERM durante o tratamento ortodôntico, apresentou ao final do período póscontenção maiores incrementos na dimensão transversal quando comparado ao grupo 2. Estes resultados demonstram que o procedimento de ERM foi capaz de promover efetivas alterações transversais no arco superior e que estes incrementos transversais apresentaram estabilidade em longo prazo. 0 aumento na distância intermolares superiores $(+2,78 \mathrm{~mm})$ no grupo 1 , com ERM, foi significantemente maior que no grupo 2, sem ERM (+0,81 mm). Entretanto, Moussa; O'Reilly; Close ${ }^{137}$ observaram resultados mais favoráveis em pacientes submetidos à ERM e mecânica ortodôntica fixa. Relataram ${ }^{137}$ um incremento na distância intermolares de $6,7 \mathrm{~mm}($ d.p.= 4,1) durante 0 
tratamento e uma redução de $1,2 \mathrm{~mm}($ d.p.= 1,7) no período pós-contenção resultando em um ganho residual de 5,5 mm (d.p.= 4,0 mm) na distância intermolares superiores.

Em relação às alterações totais no comprimento e perímetro do arco dos grupos 1 e 2, os resultados demonstraram incrementos residuais de 0,93 mm e 1,04 mm, respectivamente, não havendo diferença significante entre os grupos. Moussa; O’Reilly; Close ${ }^{137}$, em 1995, não observou qualquer alteração no comprimento do arco durante o tratamento com ERM e aparelhos fixos. Entretanto, relataram ${ }^{137}$ um aumento no perímetro do arco superior de 1,6 mm, após 8-10 anos de remoção das contenções.

McNamara et al. ${ }^{126}$, em 2003, avaliaram as alterações dimensionais dos arcos de casos tratados com ERM e mecânica ortodôntica fixa. Observaram ${ }^{126}$ que, em relação a um grupo controle sem tratamento, houve um ganho ao final do período pós-contenção de $6,0 \mathrm{~mm}$ no perímetro do arco superior. Relataram ${ }^{126}$ que, em longo prazo, o protocolo de tratamento utilizado foi capaz de se opor à tendência fisiológica de redução do perímetro do arco (-3,0 mm) e produzir um ganho de espaço de 3,0 $\mathrm{mm}$ no arco superior.

\subsubsection{Testes de Correlação}

Testes de correlação foram realizados na amostra total para obtenção de coeficientes de correlação de Pearson. Desta forma, verificou-se a existência ou não de correlação entre a irregularidade dos incisivos na fase inicial (LITTLE1) e a irregularidade no estágio pós-contenção (LITTLE3), entre o apinhamento inicial (LITTLE1) e a quantidade de recidiva do apinhamento 
ântero-superior no período pós-contenção (LITTLE3-2) e entre a quantidade de correção do apinhamento durante o tratamento (LITTLE2-1) e a quantidade de recidiva após a remoção das contenções (LITTLE3-2). Buscou-se também verificar uma possível correlação entre a recidiva do apinhamento ânterosuperior (LITTLE3-2) e as variáveis que refletem as alterações em todas as dimensões do arco superior no período pós-contenção (INTERC3-2, INTERPB3-2, INTERPB'3-2, INTERMOL3-2, COMPR3-2 e PERIM3-2). Os resultados obtidos encontram-se na Tabela 14 e 15.

Os testes de correlação apresentaram, em sua maioria, resultados não significantes. Observou-se que a quantidade de apinhamento inicial não influenciou na recidiva pós-contenção, como já descrito em estudos prévios $^{6,8,121,144}$. Surbeck et al. ${ }^{200}$, em 1998, em contrapartida, relatou uma correlação positiva entre a quantidade de irregularidade dentária ânterosuperior e a quantidade de recidiva neste segmento do arco. Afirmaram ${ }^{200}$ que a tendência em se observar uma recidiva da irregularidade dos incisivos superiores aumenta 2,3 vezes para cada $0,2 \mathrm{~mm}$ de deslocamento dos pontos de contato dos incisivos em relação ao arco dentário. Além disso, a cada $4^{\circ}$ de rotação dos incisivos ao inicio do tratamento tem-se um aumento de 2,7 vezes na probabilidade de recidiva da irregularidade. Os autores ${ }^{200}$ também $^{2}$ ressaltaram que dentes parcialmente alinhados durante o tratamento também apresentam significantes riscos de recidiva.

A quantidade de recidiva do apinhamento ântero-superior no período póscontenção (LITTLE3-2) apresentou correlação estatisticamente significante $(p<$ 0,05) com as alterações das distâncias intercaninos (INTERC3-2) e entre os primeiros pré-molares (INTERPB3-2) durante este mesmo período. As 
correlações observadas apresentaram coeficiente de valor negativo. Interpretando estes resultados, verifica-se que quanto maior a redução das distâncias intercaninos e entre os primeiros pré-molares na fase póscontenção, maior a recidiva do apinhamento ântero-superior. Embora estas correlações apresentem significância estatística, os valores de seus coeficientes revelam uma correlação fraca (valores de 'r' -0,459 e -0,419, respectivamente). Portanto, pode-se afirmar que a correlação observada entre recidiva do apinhamento ântero-superior e a redução destas distâncias apresenta pouca significância clínica. Além disso, parece óbvio que a redução destas distâncias seja reflexo de um estreitamento do arco superior na região anterior. Conseqüentemente, não seria incomum observar uma diminuição do espaço disponível e o aumento da quantidade de apinhamento

Apesar de numerosos estudos que avaliaram uma possível relação entre as alterações da distância intercaninos inferiores e a recidiva ortodôntica ântero-inferior, uma correlação entre a recidiva da distância intercaninos superiores e a recidiva da apinhamento ântero-superior somente foi investigada por Surbeck et al. ${ }^{200}$, em 1998, e Erdinc; Nanda; Isiksal ${ }^{57}$, em 2006 . Surbeck et al. $^{200}$, encontrou uma associação significante $(p<0,001)$ entre a redução da distância intercaninos e a recidiva ântero-superior, entretanto, o resultado do teste de correlação revela uma associação fraca ('r' < 0,70). Erdinc; Nanda; Isiksal ${ }^{57}$, em 2006, não encontraram correlação entre o aumento na irregularidade dos incisivos e a redução da distância intercaninos, corroborando os resultados obtidos no presente trabalho. Além disso, nenhuma variável estudada apresentou correlação estatisticamente significante com a recidiva do apinhamento ântero-inferior. 
Em 1995, Williams; Andersen ${ }^{224}$ observaram que a recidiva da irregularidade dos incisivos inferiores se relacionou levemente com a diminuição da distância intercaninos. Para Vaden; Harris; Gardner ${ }^{211}$, pacientes que apresentam as maiores diminuições nas larguras do arco após o tratamento tenderão a experimentar os maiores aumentos no apinhamento ântero-inferior. A alteração na largura intercaninos inferior foi significativamente correlacionada com o aumento na irregularidade dos incisivos inferiores no período pós-contenção. Resultados contrários foram relatados por Freitas ${ }^{66}$, em 1993, e Freitas; Henriques; Pinzan ${ }^{67}$, em 1996, que observaram ${ }^{66,67}$, por meio de uma análise comparativa de modelos de estudo, que a diminuição das distâncias intercaninos, intermolares e do comprimento do arco, não foram os fatores responsáveis por uma maior instabilidade no alinhamento dos incisivos inferiores no período pós-contenção.

\subsection{Implicações clínicas e considerações finais}

A busca por recursos auxiliares à estabilidade dos tratamentos ortodônticos tem sido o foco de muitas pesquisas por décadas e, apesar de vários avanços científico-tecnológicos, o problema da recidiva ortodôntica ainda persiste como um desafio cotidiano aos ortodontistas. Continua-se pesquisando e buscando por evidências mais específicas que favoreçam a estabilidade oclusal em longo prazo, no entanto, tem-se conhecimento que mesmo indivíduos que não foram submetidos à qualquer tipo de intervenção ortodôntica exibem algumas alterações no posicionamento dentário com o passar do tempo ${ }^{3,206}$. Da mesma forma, pacientes tratados com aparelhos 
ortodônticos também experimentam estas alterações durante o período póscontenção.

Os resultados apresentados neste trabalho indicam que a realização do procedimento de ERM não apresenta influência sobre a recidiva do apinhamento ântero-superior. Além disso, pode-se afirmar que a obtenção de espaço por meio da ERM para a correção do apinhamento deve ser uma opção de tratamento a ser analisada com ressalvas, pois apesar de algum ganho no arco superior em relação ao perímetro do arco, a literatura demonstra que as alterações dimensionais no arco inferior não apresentam significância clínica ${ }^{32}$. Deve-se ressaltar que o planejamento ortodôntico deve se basear primordialmente nas deficiências presentes no arco inferior. Sendo assim, o emprego da ERM como forma de obter espaço adicional para a correção do apinhamento ântero-inferior apresenta-se pouco plausível.

Os resultados demonstraram que os grupos tratados com ou sem a realização da ERM apresentaram alterações nas dimensões transversais do arco na região anterior muito parecidas, tanto durante o tratamento quanto durante o período pós-contenção. Desta forma, a despeito da efetividade da ERM na correção de deficiências transversais na região posterior, amplamente relatada na literatura ${ }^{33,59,70,126}$, a estabilidade do alinhamento dentário ânterosuperior em casos onde este recurso foi utilizado para a obtenção de espaço adicional no arco apresentou-se similar a de casos ortodônticos em que o apinhamento ântero-superior foi corrigido simplesmente com mecânica ortodôntica fixa.

O emprego dos diversos procedimentos mecânico-terapêuticos em Ortodontia e Ortopedia Facial deve ser realizado sobre as bases sólidas do 
conhecimento, refletindo primordialmente as informações adquiridas a partir de evidências científicas. Desta forma, pode-se afirmar, baseado nos resultados obtidos, que a realização da ERM com o objetivo exclusivo de corrigir o apinhamento dentário do arco superior, seja suave ou moderado, mostra-se injustificável, já que o espaço ganho com a expansão, utilizado para o alinhamento e nivelamento dos incisivos, não permanece estável na fase póscontenção. Possivelmente, o emprego deste procedimento nesta situação poderá resultar em prolongamento do tempo do tratamento, aumento dos gastos despendidos e, em síntese, uma redução da eficiência do tratamento.

\subsection{Sugestão para trabalhos futuros}

Como observado ao longo da Revisão de Literatura, alguns autores $^{8,137,184}$ atribuem ao procedimento de ERM uma influência positiva em relação à estabilidade da correção do apinhamento ântero-inferior. Portanto, parece pertinente avaliar a recidiva pós-contenção do apinhamento ânteroinferior de pacientes submetidos ao procedimento de expansão maxilar durante os tratamentos ortodônticos comparando-os com um grupo de pacientes tratados somente com mecânica ortodôntica fixa. Desta forma, pode-se determinar se a realização do procedimento de expansão da maxila influencia na recidiva pós-contenção do segmento ântero-inferior. 


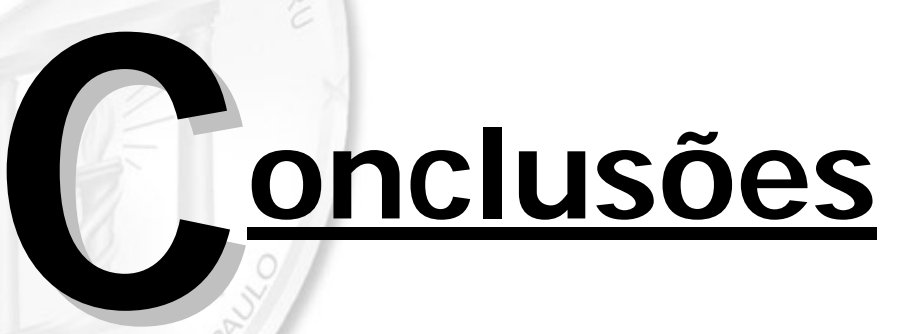





\section{7 - CONCLUSÕES}

De acordo com a amostra e a metodologia utilizada e a partir dos resultados expostos e discutidos, pode-se concluir que:

7.1 - Ocorreu recidiva do apinhamento ântero-superior na grande maioria dos pacientes avaliados com uma porcentagem média de $24,39 \%$ e $30,64 \%$ para os grupos com e sem expansão rápida da maxila, respectivamente.

7.2 - Não houve influência da realização do procedimento de expansão rápida da maxila durante o tratamento sobre a recidiva ântero-superior, uma vez que ambos os grupos apresentaram, em média, a mesma quantidade de recidiva (1,52 mm), cinco anos após a remoção das contenções. 



\section{eferências}

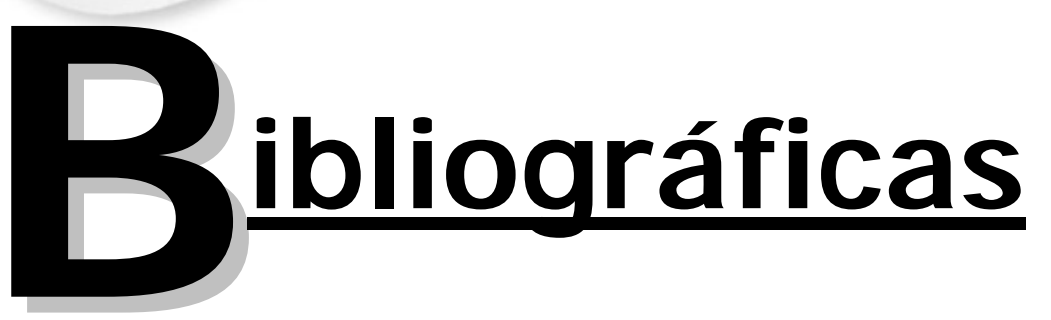





\section{REFERÊNCIAS BIBLIOGRÁFICAS}

1. Ades AG, Joondeph DR, Little RM, Chapko MK. A long-term study of the relationship of third molars to changes in the mandibular dental arch. Am J Orthod Dentofacial Orthop. 1990;97(4):323-35.

2. Adkins MD, Nanda RS, Currier GF. Arch perimeter changes on rapid palatal expansion. Am J Orthod Dentofacial Orthop. 1990;97(3):194-9.

3. Al Yami EA, Kuijpers-Jagtman AM, van't Hof MA. Assessment of biological changes in a nonorthodontic sample using the PAR index. Am J Orthod Dentofacial Orthop. 1998;114(2):224-8.

4. Angell EC. Treatment of irregularity of the permanent or adult teeth. Dental Cosmos. 1860;1: 540-600.

5. Arndt WV. Nickel titanium palatal expander. J Clin Orthod. 1993;27(3):12937.

6. Artun J, Garol JD, Little RM. Long-term stability of mandibular incisors following successful treatment of Class II, Division 1, malocclusions. Angle Orthod. 1996;66(3):229-38.

7. Artun J, Krogstad O, Little RM. Stability of mandibular incisors following excessive proclination: a study in adults with surgically treated mandibular prognathism. Angle Orthod. 1990;60(2):99-106.

8. Azizi M, Shrout MK, Haas AJ, Russell CM, Hamilton EH, Jr. A retrospective study of Angle Class I malocclusions treated orthodontically without extractions using two palatal expansion methods. Am J Orthod Dentofacial Orthop. 1999;116(1):101-7.

9. Barrer HG. Protecting the integrity of mandibular incisor position through keystoning procedure and spring retainer appliance. J Clin Orthod. 1975;9(8):486-94.

10. Barrow DB, White JR. Developmental changes of the maxillary and mandibular dental arches. Angle Orthod. 1952;22(1):41-6.

11. Beazley WW. Assessment of mandibular arch length discrepancy utilizing an individualized arch form. Angle Orthod. 1971;41(1):45-54. 
12. Beertsen W. Remodeling of collagen fibers in the periodontal ligament and the supra-alveolar region. Angle Orthod. 1979;49(3):218-24.

13. BeGole EA, Sadowsky C. Methodologies for evaluating long-term stability of dental relationships after orthodontic treatment. Semin Orthod. 1999;5(3):142-50.

14. Behrents RG, Harris EF, Vaden JL, Williams RA, Kemp DH. Relapse of orthodontic treatment results: growth as an etiologic factor. $\mathrm{J}$ Charles $\mathrm{H}$ Tweed Int Found. 1989;17:65-80.

15. Bell RA. A review of maxillary expansion in relation to rate of expansion and patient's age. Am J Orthod. 1982;81(1):32-7.

16. Betteridge MA. Index for measurement of lower labial segment crowding. Br J Orthod. 1976;3(2):113-6.

17. Betts NJ, Vanarsdall RL, Barber HD, Higgins-Barber K, Fonseca RJ. Diagnosis and treatment of transverse maxillary deficiency. Int J Adult Orthod Orthog Surg. 1995;10(2):75-96.

18. Biederman W. Rapid correction of Class III malocclusion by midpalatal expansion. Am J Orthod. 1973;63(1):47-55.

19. Bishara SE, Jakobsen JR, Treder JE, Stasi MJ. Changes in the maxillary and mandibular tooth size-arch length relationship from early adolescence to early adulthood. A longitudinal study. Am J Orthod Dentofacial Orthop. 1989;95(1):46-59.

20. Bishara SE, Staley RN. Maxillary expansion: clinical implications. Am J Orthod Dentofacial Orthop. 1987;91(1):3-14.

21. Bjerregaard J, Bundgaard AM, Melsen B. The effect of the mandibular lip bumper and maxillary bite plate on tooth movement, occlusion and space conditions in the lower dental arch. Eur J Orthod. 1980;2(4):25765.

22. Björk A, Krebs AA, Solow B. A method for epidemiological registration of malocclusion. Acta Odontol Scand. 1964;22:27-41. 
23. Björk A, Skieller V. Normal and abnormal growth of the mandible. A synthesis of longitudinal cephalometric implant studies over a period of 25 years. Eur J Orthod. 1983;5(1):1-46.

24. Blake M, Bibby K. Retention and stability: a review of the literature. Am J Orthod Dentofacial Orthop. 1998;114(3):299-306.

25. Boese LR. Fiberotomy and reproximation without lower retention, nine years in retrospect: part I. Angle Orthod. 1980;50(2):88-97.

26. Boese LR. Commentary. Am J Orthod Dentofacial Orthop. 2000;118(6):623.

27. Boley JC, Mark JA, Sachdeva RC, Buschang PH. Long-term stability of Class I premolar extraction treatment. Am J Orthod Dentofacial Orthop. 2003;124(3):277-87.

28. Brodie AG. Cephalometric appraisal of orthodontic results. Angle Orthod. 1938;8:261-351.

29. Brodie AG. Retention. Angle Orthod. 1939;9:3-16.

30. Buckley LA. The relationship between malocclusion and periodontal disease. J Periodontol. 1972;43(7):415-7.

31. Burstone CJ. Dr. Charles J. Burstone on the uses of the computer in orthodontic practice (part 1). J Clin Orthod. 1979;13(7):442-53.

32. Buschang PH. Maxillomandibular expansion: short-term relapse potential and long-term stability. Am J Orthod Dentofacial Orthop. 2006;129(4 Suppl):S75-9.

33. Buschang PH, Horton-Reuland SJ, Legler L, Nevant C. Nonextraction approach to tooth size arch length discrepancies with the Alexander discipline. Semin Orthod. 2001;7(2):117-31.

34. Byrum AG, Jr. Evaluation of anterior-posterior and vertical skeletal change vs. dental change in rapid palatal expansion cases as studied by lateral cephalograms. Am J Orthod. 1971;60(4):419. 
35. Cameron CG, Franchi L, Baccetti T, McNamara JA, Jr. Long-term effects of rapid maxillary expansion: a posteroanterior cephalometric evaluation. Am J Orthod Dentofacial Orthop. 2002;121(2):129-35.

36. Carey CW. Treatment planning and technical program in the four fundamental treatments forms. Am J Orthod. 1958;44:887-98.

37. Carlos JP. Evaluation of indices of malocclusion. Int Dent $\mathrm{J}$. 1970;20(4):606-17.

38. Chang JY, McNamara JA, Jr., Herberger TA. A longitudinal study of skeletal side effects induced by rapid maxillary expansion. Am J Orthod Dentofacial Orthop. 1997;112(3):330-7.

39. Chuck G. Ideal arch form. Angle Orthod. 1934;4:312-27.

40. Chung $\mathrm{CH}$, Font B. Skeletal and dental changes in the sagittal, vertical, and transverse dimensions after rapid palatal expansion. Am J Orthod Dentofacial Orthop. 2004;126(5):569-75.

41. Ciambotti C, Ngan P, Durkee M, Kohli K, Kim H. A comparison of dental and dentoalveolar changes between rapid palatal expansion and nickel-titanium palatal expansion appliances. Am J Orthod Dentofacial Orthop. 2001;119(1):11-20.

42. Cohen M, Silverman E. A new and simple palate splitting device. J Clin Orthod. 1973;7(6):368-9.

43. Cotton LA. Slow maxillary expansion: skeletal versus dental response to low magnitude force in Macaca mulatta. Am J Orthod. 1978;73(1):1-23.

44. Cucalon A, 3rd, Smith RJ. Relationship between compliance by adolescent orthodontic patients and performance on psychological tests. Angle Orthod. 1990;60(2):107-14.

45. Dahlberg G. Statistical methods for medical and biological students. New York: Interscience; 1940.

46. Davis LM, BeGole EA. Evaluation of orthodontic relapse using the cubic spline function. Am J Orthod Dentofacial Orthop. 1998;113(3):300-6. 
47. de la Cruz A, Sampson P, Little RM, Artun J, Shapiro PA. Long-term changes in arch form after orthodontic treatment and retention. Am J Orthod Dentofacial Orthop. 1995;107(5):518-30.

48. Debbane EF. A cephalometric and histologic study of the effects of orthodontic expansion of the midpalatal suture of the cat. Am J Orthod. 1958;44:187-219.

49. Deporter DA, Svoboda EL, Howley TP, Shiga A. A quantitative comparison of collagen phagocytosis in periodontal ligament and transseptal ligament of the rat periodontium. Am J Orthod. 1984;85(6):519-22.

50. Draker HL. Handicapping labio-lingual deviations: a proposed index for public health purposes. Am J Orthod. 1960;46(4):295-305.

51. Edwards JG. A study of the periodontium during orthodontic rotation of teeth. Am J Orthod. 1968;54(6):441-61.

52. Edwards JG. A surgical procedure to eliminate rotational relapse. Am J Orthod. 1970;57(1):35-46.

53. Edwards JG. The diastema, the frenum, the frenectomy: a clinical study. Am J Orthod. 1977;71(5):489-508.

54. Edwards JG. A long-term prospective evaluation of the circumferential supracrestal fiberotomy in alleviating orthodontic relapse. Am J Orthod Dentofacial Orthop. 1988;93(5):380-7.

55. Ekstrom C, Henrikson CO, Jensen R. Mineralization in the midpalatal suture after orthodontic expansion. Am J Orthod. 1977;71(4):449-55.

56. Elms TN, Buschang PH, Alexander RG. Long-term stability of Class II, Division 1, nonextraction cervical face-bow therapy: II. Cephalometric analysis. Am J Orthod Dentofacial Orthop. 1996;109(4):386-92.

57. Erdinc AE, Nanda RS, Isiksal E. Relapse of anterior crowding in patients treated with extraction and nonextraction of premolars. Am J Orthod Dentofacial Orthop. 2006;129(6):775-84.

58. Fastlicht J. Crowding of mandibular incisors. Am J Orthod. 1970;58(2):15663. 
59. Ferris T, Alexander RG, Boley J, Buschang PH. Long-term stability of combined rapid palatal expansion-lip bumper therapy followed by full fixed appliances. Am J Orthod Dentofacial Orthop. 2005;128(3):310-25.

60. Fink DF, Smith RJ. The duration of orthodontic treatment. Am J Orthod Dentofacial Orthop. 1992;102(1):45-51.

61. Foster TD, Hamilton MC, Lavelle CL. A study of dental arch crowding in four age-groups. Dent Pract Dent Rec. 1970;21(1):9-12.

62. Freer TJ, Grewe JM, Little RM. Agreement among the subjective severity assessments of ten orthodontists. Angle Orthod. 1973;43(2):185-90.

63. Freitas KMS. Recidiva do apinhamento ântero-inferior de casos tratados ortodonticamente sem extrações e mecânica Edgewise, na fase póscontenção. [Dissertação de Mestrado]. Bauru: Faculdade de Odontologia de Bauru, Universidade de São Paulo; 2002.

64. Freitas KMS. Análise retrospectiva dos resultados dos tratamentos ortodônticos estáveis e não estáveis na fase pós-contenção. [Tese (Doutorado)]. Bauru: Faculdade de Odontologia de Bauru, Universidade de São Paulo; 2005.

65. Freitas KMS, de Freitas MR, Henriques JF, Pinzan A, Janson G. Postretention relapse of mandibular anterior crowding in patients treated without mandibular premolar extraction. Am $\mathrm{J}$ Orthod Dentofacial Orthop. 2004;125(4):480-7.

66. Freitas MR. Recidiva do apinhamento ântero-inferior em pacientes tratados ortodonticamente, com extrações dos primeiros pré-molares, 5 e 10 anos pós-contenção. Estudo cefalométrico e de modelos. [Tese de Livre-Docência]. Bauru: Faculdade de Odontologia de Bauru, Universidade de São Paulo; 1993.

67. Freitas MR, Henriques JFC, Pinzan A. Estudo em modelos da recidiva do apinhamento ântero-inferior em pacientes tratados ortodonticamente, com extrações dos primeiros pré-molares, 5 e 10 anos pós-contenção. Ortodontia. 1996;29(1):19-30.

68. Gardner GE, Kronman JH. Cranioskeletal displacements caused by rapid palatal expansion in the rhesus monkey. Am J Orthod. 1971;59(2):14655. 
69. Gardner SD, Chaconas SJ. Posttreatment and postretention changes following orthodontic therapy. Angle Orthod. 1976;46(2):151-61.

70. Geran RG, McNamara JA, Jr., Baccetti T, Franchi L, Shapiro LM. A prospective long-term study on the effects of rapid maxillary expansion in the early mixed dentition. Am J Orthod Dentofacial Orthop. 2006;129(5):631-40.

71. Ghafari J, Locke SA, Bentley JM. Longitudinal evaluation of the Treatment Priority Index (TPI). Am J Orthod Dentofacial Orthop. 1989;96(5):382-9.

72. Gianelly AA. Rapid palatal expansion in the absence of crossbites: added value? Am J Orthod Dentofacial Orthop. 2003;124(4):362-5.

73. Gianelly AA, Goldman HM. Biologic basis of orthodontics. Philadelphia: Lea \& Febiger.; 1973.356-61.

74. Gilmore CA, Little RM. Mandibular incisor dimensions and crowding. Am J Orthod. 1984;86(6):493-502.

75. Glenn G, Sinclair PM, Alexander RG. Nonextraction orthodontic therapy: posttreatment dental and skeletal stability. Am J Orthod Dentofacial Orthop. 1987;92(4):321-8.

76. Grainger RM. Orthodontic treatment priority index. Washington, D.C.: U.S.Government Printing Office; 1967.

77. Grayson JA. Changes in mandibular interdental distances concurrent with rapid palatal expansion. Angle Orthod. 1977;47:186-92.

78. Grewe JM, Hagan DV. Malocclusion indices: a comparative evaluation. Am J Orthod. 1972;61(3):286-94.

79. Haas AJ. Rapid expansion of the maxillary dental arch and nasal cavity by opening the midpalatal suture. Angle Orthod. 1961;31(2):73-90.

80. Haas AJ. The treatment of maxillary deficiency by opening the midpalatal suture. Angle Orthod. 1965;35:200-17.

81. Haas AJ. Palatal expansion; just the beginning of dentofacial orthopedics. Am J Orthod. 1970;57(3):219-55. 
82. Haas AJ. Longterm post treatment evaluation of rapid palatal expansion. Angle Orthod. 1980;50:189-217.

83. Hahn GW. Retention: The step-child of orthodontia. Angle Orthod. 1944;14:3-12.

84. Heiser W, Niederwanger A, Bancher B, Bittermann G, Neunteufel N, Kulmer S. Three-dimensional dental arch and palatal form changes after extraction and nonextraction treatment. Part 1. Arch length and area. Am J Orthod Dentofacial Orthop. 2004;126(1):71-81.

85. Heiser W, Niederwanger A, Bancher B, Bittermann G, Neunteufel N, Kulmer S. Three-dimensional dental arch and palatal form changes after extraction and nonextraction treatment. Part 3. Transversal and sagittal palatal form. Am J Orthod Dentofacial Orthop. 2004;126(1):919.

86. Hermanson PC, Grewe JM. Examiner variability of several malocclusion indices. Angle Orthod. 1970;40(3):219-25.

87. Herold JS. Maxillary expansion: a retrospective study of three methods of expansion and their long-term sequelae. Br J Orthod. 1989;16(3):195200.

88. Herren $\mathrm{P}$, Schmoker $\mathrm{R}$, Jordi $\mathrm{T}$. Arch shape and space balance determined by arcogramme technique. Trans Eur Orthod Soc. 1973:6173.

89. Hicks EP. Slow maxillary expansion. A clinical study of the skeletal versus dental response to low-magnitude force. Am J Orthod. 1978;73(2):12141.

90. Horowitz SL, Hixon EH. Physiologic recovery following orthodontic treatment. Am J Orthod. 1969;55(1):1-4.

91. Horton SJ. The transverse stability of combined rapid palatal expansion and lip bumper therapy following comprehensive orthodontic treatment [Thesis]. Dallas: Baylor College of Dentistry, Texas A \& M University System; 1997.

92. Houston WJB. The analysis of errors in orthodontic measurements. Am J Orthod. 1983;83(5):382-90. 
93. Howe RP, McNamara JA, Jr., O'Connor KA. An examination of dental crowding and its relationship to tooth size and arch dimension. Am J Orthod. 1983;83(5):363-73.

94. Huang L, Artun J. Is the postretention relapse of maxillary and mandibular incisor alignment related? Am J Orthod Dentofacial Orthop. 2001;120(1):9-19.

95. Huckaba GW. Arch size analysis and tooth size prediction. Dental Clinics of North America. 1964:431-40.

96. Isaacson RJ, Ingram AH. Forces produced by rapid maxillary expansion 2 . Forces present during treatment. Angle Orthod. 1964;34:261-70.

97. Johal AS, Battagel JM. Dental crowding: a comparison of three methods of assessment. Eur J Orthod. 1997;19(5):543-51.

98. John W, Kerr S, Buchanan IB, McNair FI, McColl JH. Factors influencing the outcome and duration of removable appliance treatment. Eur $\mathrm{J}$ Orthod. 1994;16(3):181-6.

99. Johnson KC. Cases six years postretention. Angle Orthod. 1977;47(3):210-21.

100. Jones ML, Richmond S. An assessment of the fit of a parabolic curve to pre- and post-treatment dental arches. Br J Orthod. 1989;16(2):85-93.

101. Kahl-Nieke B, Fischbach H, Schwarze CW. Post-retention crowding and incisor irregularity: a long-term follow-up evaluation of stability and relapse. Br J Orthod. 1995;22(3):249-57.

102. Kahl-Nieke B, Fischbach $\mathrm{H}$, Schwarze CW. Treatment and postretention changes in dental arch width dimensions-a long-term evaluation of influencing cofactors. Am J Orthod Dentofacial Orthop. 1996;109(4):368-78.

103. Kaplan RG. Mandibular third molars and postretention crowding. Am J Orthod. 1974;66(4):411-30.

104. Kashner JE. Does higher quality of treatment translate into a higher quality long-term result? [Master's Thesis]. Seattle: University of Washington; 1999. 
105. Krebs A. Midpalatal suture expansion studies by the implant method over a seven-year period. Rep Congr Eur Orthod Soc. 1964;40:131-42.

106. Kuftinec MM, Stom D. Effect of edgewise treatment and retention on mandibular incisors. Am J Orthod. 1975;68(3):316-22.

107. Ladner PT, Muhl ZF. Changes concurrent with orthodontic treatment when maxillary expansion is a primary goal. Am J Orthod Dentofacial Orthop. 1995;108(2):184-93.

108. Lang G, Alfter G, Goz G, Lang GH. Retention and stability - taking various treatment parameters into account. J Orofac Orthop. 2002;63(1):26-41.

109. Lavergne J, Gasson N. Direction and intensity of mandibular rotation in the sagittal adjustment during growth of the jaws. Scand J Dent Res. 1977;85(3):193-6.

110. Lima AC, Lima AL, Filho RM, Oyen OJ. Spontaneous mandibular arch response after rapid palatal expansion: a long-term study on Class I malocclusion. Am J Orthod Dentofacial Orthop. 2004;126(5):576-82.

111. Linder-Aronson S, Lindgren J. The skeletal and dental effects of rapid maxillary expansion. Br J Orthod. 1979;6(1):25-9.

112. Lindqvist B, Thilander B. Extraction of third molars in cases of anticipated crowding in the lower jaw. Am J Orthod. 1982;81(2):130-9.

113. Liou EJ, Chen LI, Huang CS. Nickel-titanium mandibular bonded lingual 33 retainer: for permanent retention and solving relapse of mandibular anterior crowding. Am J Orthod Dentofacial Orthop. 2001;119(4):443-9.

114. Little RM. The irregularity index: a quantitative score of mandibular anterior alignment. Am J Orthod. 1975;68(5):554-63.

115. Little RM. Stability and relapse of dental arch alignment. $\mathrm{Br} \mathrm{J}$ Orthod. 1990;17(3):235-41.

116. Little RM. Stability and relapse of mandibular anterior alignment: University of Washington studies. Semin Orthod. 1999;5(3):191-204. 
117. Little RM. Stability and relapse: early treatment of arch length deficiency. Am J Orthod Dentofacial Orthop. 2002;121(6):578-81.

118. Little RM, Riedel RA. Postretention evaluation of stability and relapse mandibular arches with generalized spacing. Am J Orthod Dentofacial Orthop. 1989;95(1):37-41.

119. Little RM, Riedel RA, Artun J. An evaluation of changes in mandibular anterior alignment from 10 to 20 years postretention. Am J Orthod Dentofacial Orthop. 1988;93(5):423-8.

120. Little RM, Riedel RA, Stein A. Mandibular arch length increase during the mixed dentition: postretention evaluation of stability and relapse. Am J Orthod Dentofacial Orthop. 1990;97(5):393-404.

121. Little RM, Wallen TR, Riedel RA. Stability and relapse of mandibular anterior alignment - first premolar extraction cases treated by traditional edgewise orthodontics. Am J Orthod. 1981;80(4):349-65.

122. Lundströn A. Early loss of deciduous teeth in the aetiology of malocclusion. Am J Orthod. 1955;41:819-26.

123. Luppanapornlarp S, Johnston LE, Jr. The effects of premolar-extraction: a long-term comparison of outcomes in "clear-cut" extraction and nonextraction Class II patients. Angle Orthod. 1993;63(4):257-72.

124. McCauley D. The canine and its function in retention. Int $\mathrm{J}$ Orthod. 1944;30:196-205.

125. McNamara JA, Jr. Maxillary transverse deficiency. Am J Orthod Dentofacial Orthop. 2000;117(5):567-70.

126. McNamara JA, Jr., Baccetti T, Franchi L, Herberger TA. Rapid maxillary expansion followed by fixed appliances: a long-term evaluation of changes in arch dimensions. Angle Orthod. 2003;73(4):344-53.

127. McReynolds DC, Little RM. Mandibular second premolar extraction-postretention evaluation of stability and relapse. Angle Orthod. 1991;61(2):133-44. 
128. Melsen B. A histological study of the influence of sutural morphology and skeletal maturation on rapid palatal expansion in children. Trans Eur Orthod Soc. 1972:499-507.

129. Minkoff R, Engstrom TG. A long-term comparison of protein turnover in subcrestal vs supracrestal fiber tracts in the mouse periodontium. Arch Oral Biol. 1979;24(10-11):817-24.

130. Miyazaki $\mathrm{H}$, Motegi $\mathrm{E}$, Yatabe $\mathrm{K}$, Isshiki $\mathrm{Y}$. Occlusal stability after extraction orthodontic therapy in adult and adolescent patients. Am J Orthod Dentofacial Orthop. 1998;114(5):530-7.

131. Moorrees CCA, The dentition of the growing child. A longitudinal study of dental development between 3 and 18 years of age: Cambridge: Harvard University Press; 1959.

132. Moorrees CCA, Chadha MJ. Available space to the incisors during dental development. Angle Orthod. 1965;35(1):12-22.

133. Moorrees CCA, Reed B. Biometrics of crowding and spacing of the teeth of the mandible. Am Journal of Phisiological Anthropology. 1954;12:7788.

134. Moss JP. Rapid expansion of the maxillary arch. Part I. J Pract Orthod. 1968;2(4):165-71.

135. Moss JP. Rapid expansion of the maxillary arch. Part II. J Pract Orthod. 1968;2(5):215-23 concl.

136. Mossaz-Joelson K, Mossaz CF. Slow maxillary expansion: a comparison between banded and bonded appliances. Eur J Orthod. 1989;11(1):6776.

137. Moussa R, O'Reilly MT, Close JM. Long-term stability of rapid palatal expander treatment and edgewise mechanotherapy. Am J Orthod Dentofacial Orthop. 1995;108(5):478-88.

138. Musich DR, Ackerman JL. The catenometer: a reliable device for estimating dental arch perimeter. Am J Orthod. 1973;63(4):366-75.

139. Nance HN. Limitations of orthodontic treatment in the permanent dentition. Am J Orthod. 1947;33:253-301. 
140. Norderval K, Wisth PJ, Boe OE. Mandibular anterior crowding in relation to tooth size and craniofacial morphology. Scand J Dent Res. 1975;83(5):267-73.

141. Oliveira G, Jr., Freitas MR, Pinzan A, Martins DR. Estudo da recidiva do apinhamento ântero-inferior de casos tratados com extrações de quatro primeiros pré-molares e mecânica do Arco de Canto. Ortodontia. 1991;24(1):24-3.

142. Ormiston JP, Huang GJ, Little RM, Decker JD, Seuk GD. Retrospective analysis of long-term stable and unstable orthodontic treatment outcomes. Am J Orthod Dentofacial Orthop. 2005;128(5):568-74.

143. Owman G, Bjërklin K, Kurol J. Mandibular incisor stability after orthodontic treatment in the upper arch. Eur J Orthod. 1989;11(4):341-50.

144. Paquette DE, Beattie JR, Johnston LE, Jr. A long-term comparison of nonextraction and premolar extraction edgewise therapy in "borderline" Class II patients. Am J Orthod Dentofacial Orthop. 1992;102(1):1-14.

145. Parker WS. Retention: retainers may be forever. Am J Orthod Dentofacial Orthop. 1989;95(6):505-13.

146. Peak JD. Cuspid stability. Am J Orthod. 1956;42:608-14.

147. Peck S, Peck $H$. Crown dimensions and mandibular incisor alignment. Angle Orthod. 1972;42(2):148-53.

148. Pepe SH. Polynomial and catenary curve fits to human dental arches. J Dent Res. 1975;54(6):1124-32.

149. Pinheiro FHSL. Avaliação longitudinal das alterações das distâncias interdentárias superiores após a correção da mordida cruzada posterior, comparando-se duas modalidades de tratamento: expansão rápida da maxila e expansão lenta (dentoalveolar) do arco superior, seguidas do aparelho edgewise. [Dissertação de Mestrado]. Bauru: Faculdade de Odontologia de Bauru - Universidade de São Paulo; 2002.

150. Popovich F, Thompson GW. A longitudinal comparison of the orthodontic treatment priority index and the subjective appraisal of the orthodontist. J Public Health Dent. 1971;31(1):2-8. 
151. Poulton DR, Aarronson SA. Relationship between occlusion and periodontal status. Am J Orthod. 1961;35:983-9.

152. Proffit WR. Equilibrium theory revisited: factors influencing position of the teeth. Angle Orthod. 1978;48(3):175-86.

153. Proffit WR, Ackerman JL. Rating the characteristics of malocclusion: a systematic approach for planning treatment. Am J Orthod. 1973;64(3):258-69.

154. Rannie I. Observations on the oxylatan fibers of the periodontal membrane. Trans Eur Orthod Soc. 1963:127-37.

155. Redlich M, Rahamim E, Gaft A, Shoshan S. The response of supraalveolar gingival collagen to orthodontic rotation movement in dogs. Am J Orthod Dentofacial Orthop. 1996;110(3):247-55.

156. Reitan K. Tissue rearrangement during rotation of orthodontically rotated teeth. Angle Orthod. 1959;29:105-13.

157. Reitan K. Clinical and histologic observations on tooth movement during and after orthodontic treatment. Am J Orthod. 1967;53(10):721-45.

158. Reitan K. Biomedical principles and reactions. In: Graber TM. Current orthodontic concepts and techniques. Philadelphia.: WB Saunders Company; 1969. p. 56- 159.

159. Reitan K. Principles of retention and avoidance of posttreatment relapse. Am J Orthod. 1969;55(6):776-90.

160. Richards LC, Townsend GC, Brown T, Burgess VB. Dental arch morphology in south Australian twins. Arch Oral Biol. 1990;35(12):9839.

161. Richardson ME. The relationship between the relative amount of space present in the deciduous dental arch and the rate and degree of space closure subsequent to the extraction of a deciduous molar. Dent Pract Dent Rec. 1965;16(3):111-8.

162. Richardson ME. Late lower arch crowding in relation to primary crowding. Angle Orthod. 1982;52(4):300-12. 
163. Richardson ME. The etiology of late lower arch crowding alternative to mesially directed forces: a review. Am J Orthod Dentofacial Orthop. 1994;105(6):592-7.

164. Richardson ME. Late lower arch crowding in relation to soft tissue maturation. Am J Orthod Dentofacial Orthop. 1997;112(2):159-64.

165. Richardson ME. A review of changes in lower arch alignment from seven to fifty years. Semin Orthod. 1999;5(3):151-9.

166. Richmond S. Recording the dental cast in three dimensions. Am J Orthod Dentofacial Orthop. 1987;92(3):199-206.

167. Richmond S, Shaw WC, O'Brien KD, Buchanan IB, Jones R, Stephens $C D$, et al. The development of the PAR Index (Peer Assessment Rating): reliability and validity. Eur J Orthod. 1992;14(2):125-39.

168. Richmond S, Shaw WC, Roberts CT, Andrews M. The PAR Index (Peer Assessment Rating): methods to determine outcome of orthodontic treatment in terms of improvement and standards. Eur $\mathrm{J}$ Orthod. 1992;14(3):180-7.

169. Riedel RA. A review of the retention problem. Angle Orthod. 1960;30:17999.

170. Riedel RA, Brandt S. Interviews on retention and relapse. J Clin Orthod. 1976;10(6):454-72.

171. Riedel RA, Little RM, Bui TD. Mandibular incisor extraction-postretention evaluation of stability and relapse. Angle Orthod. 1992;62(2):103-16.

172. Rinderer $\mathrm{L}$. The effects of expansion of the palatal suture. Rep Congr Eur Orthod Soc. 1966;42:365-82.

173. Rogers AP. Making facial muscles our allies in treatment and retention. Dent Cosmos. 1922;64(7):711-30.

174. Rossouw PE, Preston CB, Lombard C. A longitudinal evaluation of extraction versus nonextraction treatment with special reference to the posttreatment irregularity of the lower incisors. Semin Orthod. 1999;5(3):160-70. 
175. Rossouw PE, Preston CB, Lombard CJ. Longitudinal changes in male and female orthodontic stability. In: McNamara JA, Jr., Trotman C. Orthodontic treatment: management of unfavorable sequelae. Michigan: Ann Arbor; 1996. p. 389-437.

176. Rossouw PE, Preston CB, Lombard CJ, Truter JW. A longitudinal evaluation of the anterior border of the dentition. Am $\mathrm{J}$ Orthod Dentofacial Orthop. 1993;104(2):146-52.

177. Rudge SJ. A computer program for the analysis of study models. Eur J Orthod. 1982;4(4):269-73.

178. Sadowsky C, Sakols EI. Long-term assessment of orthodontic relapse. Am J Orthod. 1982;82(6):456-63.

179. Sadowsky C, Schneider BJ, BeGole EA, Tahir E. Long-term stability after orthodontic treatment: nonextraction with prolonged retention. Am J Orthod Dentofacial Orthop. 1994;106(3):243-9.

180. Salzmann JA. Handicapping malocclusion assessment to establish treatment priority. Am J Orthod. 1968;54(10):749-65.

181. Sampson WJ. Current controversies in late incisor crowding. Ann Acad Med Singapore. 1995;24(1):129-37.

182. Sandstrom RA, Klapper L, Papaconstantinou S. Expansion of the lower arch concurrent with rapid maxillary expansion. Am J Orthod Dentofacial Orthop. 1988;94(4):296-302.

183. Santos-Pinto CCM, Henriques JFC. Expansão rápida da maxila: preceitos clínicos e radiográficos. Rev Odont USP. 1990;4(2):164-6.

184. Shah AA. Postretention changes in mandibular crowding: a review of the literature. Am J Orthod Dentofacial Orthop. 2003;124(3):298-308.

185. Shah AA, Elcock C, Brook AH. Incisor crown shape and crowding. Am J Orthod Dentofacial Orthop. 2003;123(5):562-7.

186. Shapiro PA. Mandibular dental arch form and dimension. Treatment and postretention changes. Am J Orthod. 1974;66(1):58-70. 
187. Shields TE, Little RM, Chapko MK. Stability and relapse of mandibular anterior alignment: a cephalometric appraisal of first-premolarextraction cases treated by traditional edgewise orthodontics. Am J Orthod. 1985;87(1):27-38.

188. Siatkowski RE. Incisor uprighting: mechanism for late secondary crowding in the anterior segments of the dental arches. Am $\mathrm{J}$ Orthod. 1974;66(4):398-410.

189. Sillman JH. Dimensional changes of the dental arches: longitudinal study from birth to 25 years. Am J Orthod. 1964;50(11):824-41.

190. Silva OG, Filho, Boas MC, Capelozza L, Filho. Rapid maxillary expansion in the primary and mixed dentitions: a cephalometric evaluation. Am J Orthod Dentofacial Orthop. 1991;100(2):171-9.

191. Silva OG, Filho, Capelozza L, Filho, Fornazari RF, Cavassan AO. Expansão rápida da maxila: um ensaio sobre a sua instabilidade. Rev Dent Press Ortod Ortop Facial. 2003;8(1):17-36.

192. Sims MR. Reconstitution of the human oxytalan system during orthodontic tooth movement. Am J Orthod. 1976;70(1):38-58.

193. Sinclair PM, Little RM. Maturation of untreated normal occlusions. Am J Orthod. 1983;83(2):114-23.

194. Sinclair PM, Little RM. Dentofacial maturation of untreated normals. Am J Orthod. 1985;88(2):146-56.

195. Siqueira DF, Almeida RR, Henriques JFC. Estudo comparativo, por meio de análise cefalométrica em norma frontal, dos efeitos dentoesqueléticos produzidos por três tipos de expansores palatinos. Rev Dent Press Ortod Ortop Facial. 2002;7(6):27-47.

196. Skieller V. Expansion of the midpalatal suture by removable plates, analyzed by the implant method. Rep Congr Eur Orthod Soc. 1964;40:143-58.

197. Stallard RE. The utilization of H-proline by the connective tissue element of the periodontium. Periodontics. 1963;1:185-8. 
198. Strang RHW. The fallacy of denture expansion as a treatment procedure. Angle Orthod. 1949;19(1):12-7.

199. Summers CJ. The occlusal index: a system for identifying and scoring occlusal disorders. Am J Orthod. 1971;59(6):552-67.

200. Surbeck BT, Artun J, Hawkins NR, Leroux B. Associations between initial, posttreatment, and postretention alignment of maxillary anterior teeth. Am J Orthod Dentofacial Orthop. 1998;113(2):186-95.

201. Swanson WD, Riedel RA, D'Anna JA. Postretention study: incidence and stability of rotated teeth in humans. Angle Orthod. 1975;45(3):198-203.

202. Taner TU, Haydar B, Kavuklu I, Korkmaz A. Short-term effects of fiberotomy on relapse of anterior crowding. Am J Orthod Dentofacial Orthop. 2000;118(6):617-23.

203. Tang EL, Wei SH. Recording and measuring malocclusion: a review of the literature. Am J Orthod Dentofacial Orthop. 1993;103(4):344-51.

204. Ten Cate AR. Morphological studies of fibrocytes in connective tissue undergoing rapid remodeling. J Anat. 1972;112(Pt 3):401-14.

205. Ten Cate AR, Deporter DA, Freeman E. The role of fibroblasts in the remodeling of periodontal ligament during physiologic tooth movement. Am J Orthod. 1976;69(2):155-68.

206. Thilander B. Orthodontic relapse versus natural development. Am J Orthod Dentofacial Orthop. 2000;117(5):562-3.

207. Timms DJ. A study of basal movement with rapid maxillary expansion. Am J Orthod. 1980;77(5):500-7.

208. Timms DJ. The dawn of rapid maxillary expansion. Angle Orthod. 1999;69(3):247-50.

209. Toigo E, Mandetta S. Estudo das alterações das dimensões e formas dos arcos dentários inferiores ocorridas no final e cinco anos póstratamento, em pacientes com má-oclusão de Classe II, Divisão $1^{\mathrm{a}}$, tratadas com extrações de pré-molares pela técnica do Arco de Canto. Ortodontia. 2000;33(2):20-35. 
210. Uhde MD, Sadowsky C, BeGole EA. Long-term stability of dental relationships after orthodontic treatment. Angle Orthod. 1983;53(3):240-52.

211. Vaden JL, Harris EF, Gardner RL. Relapse revisited. Am J Orthod Dentofacial Orthop. 1997;111(5):543-53.

212. Van Kirk LE, Jr., Pennel EH. Assessment of malocclusion in population groups. Am J Orthod. 1959;45(10):752-8.

213. Vardimon AD, Brosh T, Spiegler A, Lieberman M, Pitaru S. Rapid palatal expansion. Part 2: Dentoskeletal changes in cats with patent versus synostosed midpalatal suture. Am J Orthod Dentofacial Orthop. 1998;113(5):488-97.

214. Vardimon AD, Brosh T, Spiegler A, Lieberman M, Pitaru S. Rapid palatal expansion: Part 1. Mineralization pattern of the midpalatal suture in cats. Am J Orthod Dentofacial Orthop. 1998;113(4):371-8.

215. Vargo J, Buschang PH, Boley JC, English JD, Behrents RG, Owen, AH. III. Short-term relapse after phase I maxillomandibular expansion. Am J Orthod Dentofacial Orthop. 2006 (in press).

216. Velazquez P, Benito E, Bravo LA. Rapid maxillary expansion. A study of the long-term effects. Am J Orthod Dentofacial Orthop. 1996;109(4):361-7.

217. Walter DG. Changes in the form and dimensions of dental arches resulting from orthodontic treatment. Angle Orthod. 1953;23:3-18.

218. Walter DG. Comparative changes in mandibular canine and first molar widths. Angle Orthod. 1962;32(4):232-41.

219. Weiland FJ. The role of occlusal discrepancies in the long-term stability of the mandibular arch. Eur J Orthod. 1994;16(6):521-9.

220. Weinberg M, Sadowsky C. Resolution of mandibular arch crowding in growing patients with Class I malocclusions treated nonextraction. Am J Orthod Dentofacial Orthop. 1996;110(4):359-64.

221. Wertz R, Dreskin M. Midpalatal suture opening: a normative study. Am J Orthod. 1977;71(4):367-81. 
222. Wertz RA. Skeletal and dental changes accompanying rapid midpalatal suture opening. Am J Orthod. 1970;58(1):41-66.

223. White LW. Accurate arch-discrepancy measurements. Am J Orthod. 1977;72(3):303-8.

224. Williams S, Andersen CE. Incisor stability in patients with anterior rotational mandibular growth. Angle Orthod. 1995;65(6):431-42.

225. Woodside DG, Rossouw PE, Shearer D. Postretention mandibular incisor stability after premolar serial extractions. Semin Orthod. 1999;5(3):18190.

226. Zachrisson BU. Important aspects of long-term stability. J Clin Orthod. 1997;31(9):562-83.

227. Zimring JF, Isaacson RJ. Forces produced by rapid maxillary expansion. 3. Forces present during retention. Angle Orthod. 1965;35:178-86. 


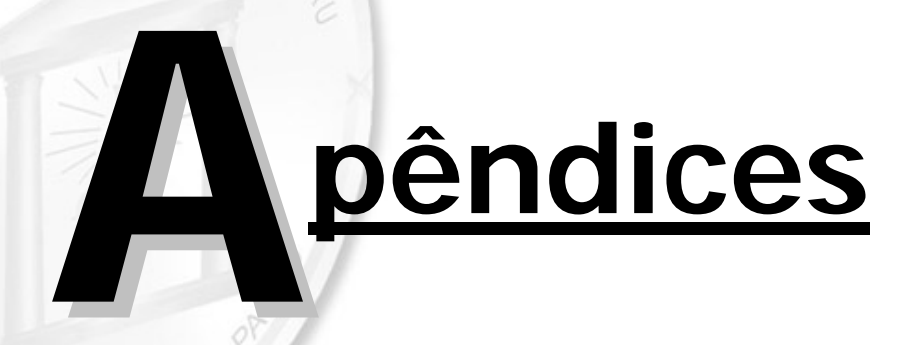





\section{APÊNDICES}

No Apêndice A1 encontram-se os gêneros, as idades iniciais e finais, os tempos de tratamento e de avaliação pós-contenção, a severidade inicial da má oclusão e o tipo de expansor utilizado dos pacientes que constituíram a amostra. No Apêndice A2, A3, A4, A5, A6, A7, A8 e A9, encontram-se todas as variáveis estudadas nos modelos de estudo nas fases inicial - T1, final - T2 e de avaliação pós-contenção - T3 (LITTLE, INTERC, INTERPB, INTERPB', INTERMOL. COMPR e PERIM), assim como as alterações destas variáveis durante o tratamento (T2-1), durante o período pós-contenção (T3-2) e totais (T3-1) 
Apêndice A1.

\begin{tabular}{|c|c|c|c|c|c|c|c|c|}
\hline Pacientes & Grupo & Gênero & Id T1 & Id T2 & TTRAT & TPOS & Sev. inicial & Expansor \\
\hline 1. & 1 & $\mathrm{~F}$ & 12,91 & 14,66 & 1,75 & 3,17 & 1 & HAAS \\
\hline 2. & 1 & $\mathrm{~F}$ & 14,83 & 15,08 & 1,25 & 5,66 & $\mathrm{I}$ & HAAS \\
\hline 3. & 1 & $\mathrm{M}$ & 14,00 & 15,75 & 1,75 & 6,91 & $\mathrm{I}$ & HAAS \\
\hline 4. & 1 & $\mathrm{~F}$ & 10,17 & 12,00 & 1,83 & 5,42 & $1 / 2 \mathrm{cl} \mathrm{II}$ & HAAS \\
\hline 5. & 1 & $\mathrm{~F}$ & 12,66 & 15,25 & 2,58 & 5,58 & 1 & HAAS \\
\hline 6. & 1 & $M$ & 14,25 & 16,91 & 2,66 & 5,25 & $\mathrm{I}$ & HAAS \\
\hline 7. & 1 & $\mathrm{~F}$ & 13,25 & 16,75 & 3,50 & 5,66 & 1 & HAAS \\
\hline 8. & 1 & $F$ & 14,00 & 16,25 & 2,25 & 5,83 & 1 & HAAS \\
\hline 9. & 1 & $F$ & 15,83 & 17,42 & 1,58 & 9,25 & 1 & HYRAX \\
\hline 10. & 1 & $\mathrm{~F}$ & 10,50 & 12,42 & 1,91 & 9,25 & $1 / 4 \mathrm{cl} \mathrm{II}$ & HYRAX \\
\hline 11. & 1 & $\mathrm{~F}$ & 14,58 & 16,83 & 2,25 & 3,33 & $1 / 4 \mathrm{cl} \mathrm{II}$ & HAAS \\
\hline 12. & 1 & $F$ & 12,75 & 14,08 & 1,83 & 5,33 & 1 & HYRAX \\
\hline 13. & 1 & $\mathrm{~F}$ & 14,83 & 17,91 & 3,08 & 5,91 & I & HAAS \\
\hline 14. & 1 & $\mathrm{~F}$ & 15,58 & 16,91 & 1,33 & 6,91 & 1 & HYRAX \\
\hline 15. & 1 & $F$ & 13,91 & 15,25 & 2,33 & 5,66 & $\mathrm{I}$ & HAAS \\
\hline 16. & 1 & $M$ & 13,42 & 15,25 & 1,83 & 6,25 & 1 & HYRAX \\
\hline 17. & 1 & $\mathrm{~F}$ & 17,58 & 19,75 & 2,17 & 4,50 & $1 / 4 \mathrm{cl} \mathrm{II}$ & HAAS \\
\hline 18. & 1 & $M$ & 13,66 & 16,66 & 3,00 & 4,00 & 1 & COLADO \\
\hline 19. & 1 & $M$ & 12,75 & 14,33 & 1,58 & 5,50 & 1 & HYRAX \\
\hline 20. & 1 & $M$ & 12,50 & 14,00 & 1,50 & 5,50 & $1 / 4 \mathrm{cl} \mathrm{II}$ & HYRAX \\
\hline 21. & 1 & $M$ & 14,00 & 16,08 & 2,08 & 4,91 & $1 / 4 \mathrm{cl} \mathrm{II}$ & HAAS \\
\hline 22. & 1 & $M$ & 11,66 & 13,58 & 1,91 & 5,08 & $1 / 4 \mathrm{cl} \mathrm{II}$ & HYRAX \\
\hline 23. & 1 & $M$ & 11,58 & 13,75 & 2,17 & 4,83 & 1 & COLADO \\
\hline 24. & 1 & $\mathrm{~F}$ & 13,08 & 15,08 & 2,00 & 5,00 & $1 / 2 \mathrm{cl} \mathrm{II}$ & COLADO \\
\hline 25. & 1 & $\mathrm{~F}$ & 14,08 & 15,75 & 1,66 & 5,33 & $1 / 4 \mathrm{cl} \mathrm{II}$ & HYRAX \\
\hline 26. & 2 & $M$ & 13,25 & 14,83 & 1,58 & 5,00 & $1 / 4 \mathrm{cl} \mathrm{Il}$ & - \\
\hline 27. & 2 & $M$ & 16,17 & 18,66 & 2,50 & 4,33 & 1 & - \\
\hline 28. & 2 & $\mathrm{~F}$ & 12,17 & 14,58 & 2,42 & 4,00 & 1 & - \\
\hline 29. & 2 & $M$ & 13,25 & 15,75 & 2,50 & 6,08 & $1 / 4 \mathrm{cl} \mathrm{II}$ & - \\
\hline 30. & 2 & $\mathrm{~F}$ & 12,25 & 13,91 & 1,66 & 6,33 & 1 & - \\
\hline 31. & 2 & $\mathrm{~F}$ & 13,00 & 13,66 & 0,66 & 5,33 & 1 & - \\
\hline 32. & 2 & $M$ & 19,83 & 22,33 & 2,50 & 4,75 & $1 / 4 \mathrm{cl} \mathrm{II}$ & - \\
\hline 33. & 2 & $\mathrm{~F}$ & 14,00 & 16,33 & 2,33 & 3,00 & 1 & - \\
\hline 34. & 2 & $\mathrm{~F}$ & 13,58 & 15,83 & 2,25 & 5,17 & I & - \\
\hline 35. & 2 & $\mathrm{~F}$ & 12,25 & 16,17 & 3,91 & 5,00 & $\mathrm{I}$ & - \\
\hline 36. & 2 & $\mathrm{M}$ & 14,42 & 15,66 & 1,25 & 5,08 & $\mathrm{I}$ & - \\
\hline 37. & 2 & $\mathrm{~F}$ & 12,91 & 13,66 & 0,75 & 3,25 & 1 & - \\
\hline 38. & 2 & $M$ & 13,42 & 15,33 & 1,91 & 4,42 & $1 / 2 \mathrm{cl} \mathrm{II}$ & - \\
\hline 39. & 2 & $M$ & 12,33 & 13,66 & 1,33 & 5,00 & $1 / 2 \mathrm{cl} \mathrm{II}$ & - \\
\hline 40. & 2 & $\mathrm{~F}$ & 13,08 & 14,91 & 1,83 & 7,75 & $1 / 4 \mathrm{cl} \mathrm{II}$ & - \\
\hline 41. & 2 & $F$ & 12,66 & 15,08 & 2,50 & 6,08 & $1 / 4 \mathrm{cl} \mathrm{II}$ & - \\
\hline 42. & 2 & $\mathrm{~F}$ & 11,00 & 15,75 & 4,75 & 4,08 & $1 / 4 \mathrm{cl} \mathrm{II}$ & - \\
\hline 43. & 2 & $\mathrm{~F}$ & 12,00 & 14,42 & 2,42 & 5,42 & $1 / 2 \mathrm{cl} \mathrm{II}$ & - \\
\hline 44. & 2 & $\mathrm{~F}$ & 15,25 & 16,66 & 1,42 & 4,17 & $1 / 4 \mathrm{cl} \mathrm{II}$ & - \\
\hline 45. & 2 & $\mathrm{~F}$ & 11,83 & 14,91 & 3,08 & 4,66 & 1 & - \\
\hline 46. & 2 & $\mathrm{M}$ & 12,25 & 15,17 & 2,91 & 5,08 & $1 / 2 \mathrm{cl} \mathrm{II}$ & - \\
\hline 47. & 2 & $M$ & 13,25 & 14,91 & 1,66 & 6,08 & $1 / 2 \mathrm{cl} \mathrm{II}$ & - \\
\hline 48. & 2 & $\mathrm{M}$ & 13,17 & 15,17 & 2,00 & 3,17 & $1 / 4 \mathrm{cl} \mathrm{Il}$ & - \\
\hline
\end{tabular}


Apêndice A2.

\begin{tabular}{|c|c|c|c|c|c|}
\hline Pacientes & LITTLE1 & INTERC1 & INTERPB1 & INTERPB'1 & INTERMOL1 \\
\hline 1. & 7,88 & 33,14 & 35,53 & 43,81 & 53,54 \\
\hline 2. & 6,2 & 36,27 & 33,23 & 38,08 & 38,42 \\
\hline 3. & 13,57 & 37,42 & 32,21 & 32,07 & 43,93 \\
\hline 4. & 11,18 & 33,49 & 31,55 & 36,45 & 49,07 \\
\hline 5. & 7,09 & 31,51 & 32,06 & 39,34 & 49,89 \\
\hline 6. & 5,07 & 33,09 & 31,21 & 38,56 & 53,61 \\
\hline 7. & 2,02 & 36,21 & 34,90 & 39,78 & 52,64 \\
\hline 8. & 11,41 & 34,83 & 32,84 & 36,23 & 46,86 \\
\hline 9. & 10,93 & 34,91 & 33,57 & 39,85 & 51,40 \\
\hline 10. & 7,27 & 31,27 & 32,68 & 37,12 & 46,63 \\
\hline 11. & 5,91 & 37,20 & 35,15 & 35,58 & 48,26 \\
\hline 12. & 5,75 & 32,22 & 30,66 & 39,51 & 52,71 \\
\hline 13. & 4,64 & 38,28 & 33,64 & 38,46 & 50,91 \\
\hline 14. & 7,54 & 33,71 & 33,62 & 36,70 & 46,13 \\
\hline 15. & 7,31 & 30,86 & 32,85 & 36,55 & 46,07 \\
\hline 16. & 8,98 & 34,66 & 32,57 & 39,41 & 51,65 \\
\hline 17. & 6,42 & 30,82 & 28,63 & 32,26 & 41,38 \\
\hline 18. & 9,55 & 30,75 & 32,52 & 38,62 & 50,09 \\
\hline 19. & 4,59 & 39,42 & 38,35 & 43,31 & 55,8 \\
\hline 20. & 5,02 & 34,20 & 32,69 & 39,41 & 51,06 \\
\hline 21. & 7,99 & 35,98 & 37,31 & 42,84 & 52,66 \\
\hline 22. & 3,84 & 34,72 & 35,72 & 42,87 & 55,23 \\
\hline 23. & 13,53 & 32,58 & 30,60 & 35,38 & 50,71 \\
\hline 24. & 7,14 & 32,29 & 33,48 & 38,57 & 47,62 \\
\hline 25. & 10,44 & 34,29 & 33,84 & 38,87 & 50,21 \\
\hline 26. & 6,19 & 35,88 & 32,89 & 38,09 & 48,71 \\
\hline 27. & 9,63 & 36,12 & 32,99 & 38,70 & 52,19 \\
\hline 28. & 6,65 & 34,78 & 34,20 & 40,05 & 47,15 \\
\hline 29. & 4,91 & 36,43 & 32,93 & 36,56 & 51,12 \\
\hline 30. & 6,45 & 30,88 & 32,87 & 37,60 & 45,63 \\
\hline 31. & 3,65 & 34,13 & 34,81 & 40,01 & 49,68 \\
\hline 32. & 13,77 & 23,71 & 35,61 & 41,88 & 53,7 \\
\hline 33. & 8,93 & 35,79 & 34,71 & 40,19 & 50,3 \\
\hline 34. & 5,40 & 33,07 & 34,14 & 37,68 & 50,46 \\
\hline 35. & 6,49 & 33,72 & 34,80 & 40,19 & 50,43 \\
\hline 36. & 3,84 & 33,10 & 35,93 & 42,46 & 54,89 \\
\hline 37. & 3,72 & 32,24 & 34,02 & 40,20 & 50,73 \\
\hline 38. & 3,30 & 34,89 & 36,09 & 41,91 & 54,15 \\
\hline 39. & 10,33 & 40,31 & 37,16 & 42,94 & 53,27 \\
\hline 40. & 9,64 & 32,68 & 33,92 & 39,14 & 51,23 \\
\hline 41. & 9,82 & 35,64 & 32,19 & 37,24 & 49,85 \\
\hline 42. & 5,33 & 32,50 & 34,68 & 40,26 & 47,9 \\
\hline 43. & 5,15 & 35,6 & 31,84 & 38,26 & 49,13 \\
\hline 44. & 4,69 & 31,76 & 33,50 & 39,10 & 50,32 \\
\hline 45. & 10,18 & 32,68 & 36,31 & 42,34 & 52,72 \\
\hline 46. & 3,95 & 35,05 & 36,55 & 41,67 & 51,77 \\
\hline 47. & 3,58 & 35,71 & 36,40 & 41,30 & 53,87 \\
\hline 48. & 5,34 & 37,14 & 39,89 & 46,77 & 56,81 \\
\hline
\end{tabular}


Apêndice A3.

\begin{tabular}{|c|c|c|c|c|c|c|}
\hline Pacientes & COMPR1 & PERIM1 & LITTLE2 & INTERC2 & INTERPB2 & INTERPB'2 \\
\hline 1. & 70,01 & 73,40 & 4,47 & 34,75 & 37,95 & 46,11 \\
\hline 2. & 69,92 & 74,49 & 2,14 & 36,64 & 36,74 & 42,74 \\
\hline 3. & 63,91 & 68,86 & 1,36 & 34,55 & 36,67 & 40,62 \\
\hline 4. & 76,85 & 75,98 & 0,00 & 35,58 & 35,59 & 41,46 \\
\hline 5. & 73,04 & 74,85 & 0,00 & 33,68 & 37,57 & 42,82 \\
\hline 6. & 71,42 & 74,62 & 0,80 & 36,09 & 36,46 & 43,62 \\
\hline 7. & 73,68 & 78,78 & 0,00 & 35,41 & 38,41 & 43,93 \\
\hline 8. & 64,71 & 69,01 & 3,10 & 34,46 & 37,65 & 42,56 \\
\hline 9. & 66,02 & 68,93 & 2,67 & 33,41 & 35,63 & 42,54 \\
\hline 10. & 70,57 & 73,63 & 0,60 & 33,54 & 35,60 & 40,14 \\
\hline 11. & 68,39 & 74,08 & 1,49 & 35,05 & 36,18 & 40,49 \\
\hline 12. & 68,27 & 72,19 & 0,69 & 36,40 & 39,33 & 45,48 \\
\hline 13. & 68,05 & 73,54 & 1,39 & 36,20 & 38,16 & 44,79 \\
\hline 14. & 63,54 & 71,66 & 2,05 & 34,00 & 35,72 & 40,59 \\
\hline 15. & 68,49 & 71,00 & 0,34 & 33,63 & 36,40 & 41,84 \\
\hline 16. & 74,66 & 74,88 & 2,65 & 35,82 & 37,34 & 42,39 \\
\hline 17. & 68,23 & 73,33 & 1,34 & 34,13 & 34,10 & 38,05 \\
\hline 18. & 71,79 & 73,80 & 1,59 & 32,99 & 33,31 & 39,14 \\
\hline 19. & 74,95 & 78,61 & 1,00 & 38,99 & 40,06 & 43,28 \\
\hline 20. & 73,73 & 77,92 & 1,85 & 37,22 & 39,12 & 43,47 \\
\hline 21. & 73,08 & 78,49 & 1,07 & 36,35 & 39,08 & 45,20 \\
\hline 22. & 82,43 & 84,54 & 1,28 & 34,67 & 37,54 & 42,17 \\
\hline 23. & 72,87 & 74,29 & 1,42 & 34,24 & 35,09 & 39,44 \\
\hline 24. & 75,72 & 77,18 & 1,67 & 34,31 & 36,01 & 40,83 \\
\hline 25. & 69,85 & 72,30 & 0,44 & 33,98 & 36,90 & 41,35 \\
\hline 26. & 70,18 & 77,14 & 0,70 & 33,03 & 34,49 & 39,20 \\
\hline 27. & 71,89 & 72,50 & 1,13 & 37,07 & 39,07 & 44,67 \\
\hline 28. & 74,76 & 78,10 & 2,87 & 35,37 & 35,75 & 41,17 \\
\hline 29. & 73,79 & 78,62 & 2,48 & 35,88 & 36,02 & 40,66 \\
\hline 30. & 78,97 & 79,71 & 1,49 & 33,99 & 35,25 & 40,81 \\
\hline 31. & 70,15 & 75,54 & 0,88 & 33,14 & 35,10 & 39,45 \\
\hline 32. & 67,08 & 70,67 & 0,00 & 33,15 & 35,95 & 42,12 \\
\hline 33. & 69,68 & 71,68 & 2,32 & 34,96 & 36,41 & 40,95 \\
\hline 34. & 70,81 & 74,69 & 2,32 & 34,80 & 37,08 & 40,29 \\
\hline 35. & 67,54 & 68,71 & 1,64 & 33,18 & 35,17 & 40,67 \\
\hline 36. & 72,20 & 75,21 & 1,09 & 34,63 & 37,45 & 42,89 \\
\hline 37. & 68,91 & 73,36 & 0,77 & 32,68 & 34,66 & 40,14 \\
\hline 38. & 72,97 & $\begin{array}{l}77,83 \\
\end{array}$ & 1,68 & 36,82 & 39,52 & 44,75 \\
\hline 39. & 71,45 & 73,83 & 1,29 & 37,46 & 41,03 & 47,57 \\
\hline 40. & 68,69 & 74,82 & 2,59 & 33,44 & 34,30 & 39,71 \\
\hline 41. & 65,90 & 68,23 & 0,73 & 34,00 & 35,10 & 39,92 \\
\hline 42. & 74,86 & 78,17 & 2,28 & 33,11 & 34,66 & 39,72 \\
\hline 43. & 68,96 & 70,78 & 2,10 & 34,77 & 34,43 & 37,57 \\
\hline 44. & 73,19 & 74,00 & 2,05 & 34,58 & 35,94 & 40,74 \\
\hline 45. & 78,23 & 78,04 & 1,31 & 34,87 & 37,53 & 42,45 \\
\hline 46. & 68,49 & 74,95 & 1,14 & 33,46 & 35,44 & 41,53 \\
\hline 47. & 78,65 & $\begin{array}{l}78,86 \\
\end{array}$ & 1,92 & 36,06 & 36,79 & 41,56 \\
\hline 48. & 80,71 & 83,74 & 1,95 & 36,62 & 38,61 & 42,54 \\
\hline
\end{tabular}


Apêndice A4.

\begin{tabular}{|c|c|c|c|c|c|c|}
\hline Pacientes & INTERMOL2 & COMPR2 & PERIM2 & LITTLE3 & INTERC3 & INTERPB3 \\
\hline 1. & 55,73 & 72,51 & 74,48 & 6,30 & 34,19 & 37,54 \\
\hline 2. & 54,71 & 74,57 & 79,32 & 0,65 & 36,43 & 37,20 \\
\hline 3. & 50,21 & 73,71 & 78,79 & 2,02 & 35,27 & 36,19 \\
\hline 4. & 51,81 & 73,86 & 76,13 & 0,00 & 35,43 & 35,17 \\
\hline 5. & 51,51 & 73,77 & 77,83 & 1,17 & 32,38 & 33,87 \\
\hline 6. & 54,70 & 74,27 & 76,05 & 0,89 & 35,11 & 34,80 \\
\hline 7. & 54,12 & 77,94 & 78,36 & 1,27 & 35,88 & 37,25 \\
\hline 8. & 50,87 & 70,33 & 74,71 & 4,96 & 34,35 & 36,18 \\
\hline 9. & 53,43 & 68,17 & 72,48 & 1,77 & 32,52 & 34,59 \\
\hline 10. & 51,32 & 72,49 & 76,13 & 1,31 & 33,08 & 34,91 \\
\hline 11. & 52,48 & 73,36 & 76,30 & 1,60 & 35,50 & 35,86 \\
\hline 12. & 55,06 & 72,34 & 76,73 & 1,37 & 34,95 & 37,56 \\
\hline 13. & 53,85 & 71,37 & 77,00 & 2,39 & 35,87 & 36,65 \\
\hline 14. & 50,88 & 69,44 & 73,92 & 4,92 & 33,03 & 34,00 \\
\hline 15. & 49,54 & 72,02 & 75,63 & 1,99 & 32,96 & 35,69 \\
\hline 16. & 52,70 & 75,74 & 79,16 & 6,91 & 34,40 & 34,60 \\
\hline 17. & 47,18 & 71,41 & 75,87 & 4,85 & 31,73 & 32,73 \\
\hline 18. & 47,73 & 69,19 & 73,67 & 4,36 & 32,76 & 32,26 \\
\hline 19. & 57,56 & 76,42 & 80,01 & 0,49 & 39,38 & 39,64 \\
\hline 20. & 53,84 & 77,11 & 82,80 & 4,12 & 36,48 & 37,92 \\
\hline 21. & 54,84 & 73,34 & 77,32 & 3,92 & 35,43 & 38,47 \\
\hline 22. & 51,16 & 81,64 & 84,99 & 4,52 & 34,55 & 37,51 \\
\hline 23. & 52,21 & 74,01 & 77,87 & 2,37 & 33,85 & 34,48 \\
\hline 24. & 49,00 & 73,89 & 76,13 & 3,66 & 32,92 & 34,48 \\
\hline 25. & 54,35 & 73,73 & 75,91 & 5,52 & 33,16 & 34,56 \\
\hline 26. & 48,86 & 75,27 & 77,88 & 1,56 & 33,67 & 33,97 \\
\hline 27. & 56,07 & 76,03 & 76,00 & 3,75 & 36,17 & 37,32 \\
\hline 28. & 49,98 & 75,53 & 77,43 & 3,84 & 34,81 & 34,82 \\
\hline 29. & 51,49 & 75,70 & 80,27 & 2,52 & 35,63 & 35,18 \\
\hline 30. & 51,83 & 74,02 & 76,03 & 2,57 & 33,48 & 35,19 \\
\hline 31. & 50,27 & 74,14 & 77,09 & 3,36 & 34,22 & 34,03 \\
\hline 32. & 53,38 & 71,87 & 72,79 & 4,62 & 33,42 & 35,93 \\
\hline 33. & 50,16 & 72,86 & 75,68 & 4,04 & 35,03 & 36,00 \\
\hline 34. & 48,80 & 72,65 & 76,74 & 4,85 & 34,39 & 35,56 \\
\hline 35. & 49,23 & 68,58 & 71,14 & 3,98 & 33,04 & 34,43 \\
\hline 36. & 53,66 & 69,39 & 75,95 & 2,64 & 33,49 & 36,20 \\
\hline 37. & 50,75 & 71,50 & 73,78 & 1,94 & 33,16 & 34,39 \\
\hline 38. & 54,65 & 75,06 & 79,04 & 1,19 & 37,98 & 40,03 \\
\hline 39. & 58,21 & 78,72 & 81,55 & 0,55 & 38,69 & 38,88 \\
\hline 40. & 50,98 & 73,08 & 75,10 & 5,19 & 33,81 & 34,50 \\
\hline 41. & 52,26 & 73,52 & 75,06 & 1,59 & 34,29 & 34,91 \\
\hline 42. & 49,49 & 70,36 & 71,70 & 2,97 & 31,91 & 33,75 \\
\hline 43. & 47,25 & 71,70 & 75,33 & 3,43 & 33,89 & 34,79 \\
\hline 44. & 50,49 & 73,13 & 77,12 & 5,09 & 32,55 & 33,80 \\
\hline 45. & 51,76 & 76,58 & 77,40 & 5,33 & 32,93 & 35,24 \\
\hline 46. & 53,21 & 74,34 & 76,70 & 1,27 & 32,90 & 36,06 \\
\hline 47. & 51,42 & 77,03 & 80,52 & 1,72 & 37,94 & 38,02 \\
\hline 48. & 50,86 & 75,42 & 79,61 & 3,72 & 37,14 & 39,43 \\
\hline
\end{tabular}


Apêndice A5.

\begin{tabular}{|c|c|c|c|c|c|c|}
\hline Pacientes & INTERPB'3 & INTERMOL3 & COMPR3 & PERIM3 & LITTLE2-1 & LITTLE3-2 \\
\hline 1. & 45,73 & 54,69 & 71,17 & 73,26 & $-3,41$ & 1,83 \\
\hline 2. & 41,41 & 53,61 & 71,84 & 76,03 & $-4,06$ & $-1,49$ \\
\hline 3. & 40,71 & 51,63 & 72,10 & 78,81 & $-12,21$ & 0,66 \\
\hline 4. & 40,79 & 50,91 & 73,34 & 75,97 & $-11,18$ & 0,00 \\
\hline 5. & 40,57 & 52,57 & 71,95 & 76,61 & $-7,09$ & 1,17 \\
\hline 6. & 41,69 & 54,12 & 70,75 & 74,81 & $-4,27$ & 0,09 \\
\hline 7. & 42,91 & 54,92 & 75,63 & 78,90 & $\begin{array}{l}-2,02 \\
\end{array}$ & 1,27 \\
\hline 8. & 41,03 & 50,79 & 69,29 & 75,03 & $-8,31$ & 1,86 \\
\hline 9. & 42,01 & 52,81 & 66,70 & 70,22 & $-8,26$ & $-0,90$ \\
\hline 10. & 39,41 & 50,06 & 69,12 & 73,12 & $-6,67$ & 0,71 \\
\hline 11. & 39,46 & 50,68 & 71,99 & 76,28 & $-4,42$ & 0,11 \\
\hline 12. & 44,80 & 55,79 & 71,18 & 72,96 & $-5,06$ & 0,68 \\
\hline 13. & 42,29 & 53,02 & 70,26 & 74,75 & $-3,25$ & 1,00 \\
\hline 14. & 40,28 & 49,47 & 65,65 & 70,79 & $-5,49$ & 2,87 \\
\hline 15. & 40,75 & 49,07 & 70,96 & 73,88 & $-6,97$ & 1,65 \\
\hline 16. & 40,37 & 51,37 & 73,61 & 76,81 & $-6,33$ & 4,26 \\
\hline 17. & 36,07 & 46,11 & 69,60 & 73,09 & $-5,08$ & 3,51 \\
\hline 18. & 39,40 & 47,94 & 70,77 & 72,57 & $-7,96$ & 2,77 \\
\hline 19. & 44,77 & 57,10 & 75,76 & 79,41 & $-3,59$ & $-0,51$ \\
\hline 20. & 43,45 & 55,22 & 74,68 & 79,11 & $-3,17$ & 2,27 \\
\hline 21. & 44,81 & 54,44 & 72,78 & 76,29 & $-6,92$ & 2,85 \\
\hline 22. & 43,72 & 57,41 & 81,42 & 81,99 & $-2,56$ & 3,24 \\
\hline 23. & 39,66 & 52,18 & 72,95 & 76,15 & $-12,11$ & 0,95 \\
\hline 24. & 38,96 & 47,54 & 73,77 & 75,66 & $-5,47$ & 1,99 \\
\hline 25. & 40,79 & 52,46 & 70,21 & 73,79 & $-10,00$ & 5,08 \\
\hline 26. & 39,12 & 49,79 & 73,69 & 77,74 & $-5,49$ & 0,86 \\
\hline 27. & 43,65 & 55,45 & 73,07 & 74,02 & $-8,50$ & 2,62 \\
\hline 28. & 40,58 & 48,98 & 74,38 & 76,35 & $-3,78$ & 0,97 \\
\hline 29. & 40,13 & 53,25 & 73,88 & 78,01 & $-2,43$ & 0,04 \\
\hline 30. & 41,32 & 50,30 & 71,08 & 73,82 & $-4,96$ & 1,08 \\
\hline 31. & 38,71 & 49,85 & 71,04 & 76,65 & $-2,77$ & 2,48 \\
\hline 32. & 42,38 & 53,22 & 69,62 & 72,79 & $-13,77$ & 4,62 \\
\hline 33. & 40,14 & 50,51 & 71,23 & 74,78 & $-6,61$ & 1,72 \\
\hline 34. & 39,02 & 49,99 & 71,90 & 76,45 & $-3,08$ & 2,53 \\
\hline 35. & 40,07 & 49,95 & 67,23 & 70,43 & $-4,85$ & 2,34 \\
\hline 36. & 42,51 & 54,21 & 69,97 & 73,54 & $-2,75$ & 1,55 \\
\hline 37. & 39,97 & 50,65 & 69,20 & 72,69 & $-2,95$ & 1,17 \\
\hline 38. & 44,89 & 55,34 & 72,44 & 77,95 & $-1,62$ & $-0,49$ \\
\hline 39. & 46,38 & 58,52 & 76,25 & 80,06 & $-9,04$ & $-0,74$ \\
\hline 40. & 39,74 & 51,44 & 68,62 & 74,17 & $-7,05$ & 2,60 \\
\hline 41. & 39,88 & 51,84 & 71,70 & 74,15 & $-9,09$ & 0,86 \\
\hline 42. & 39,59 & 48,64 & 69,03 & 71,03 & $-3,05$ & 0,69 \\
\hline 43. & 38,71 & 49,51 & 71,66 & 75,41 & $-3,05$ & 1,33 \\
\hline 44. & 39,00 & 50,34 & 71,68 & 72,73 & $-2,64$ & 3,04 \\
\hline 45. & 40,00 & 51,61 & 76,17 & 77,72 & $-8,87$ & 4,02 \\
\hline 46. & 42,29 & 53,28 & 71,53 & 75,35 & $-2,81$ & 0,13 \\
\hline 47. & 43,14 & 54,52 & 75,81 & 77,71 & $-1,66$ & $-0,20$ \\
\hline 48. & 43,97 & 53,45 & 76,42 & 78,86 & $-3,39$ & 1,77 \\
\hline
\end{tabular}


Apêndice A6.

\begin{tabular}{|c|c|c|c|c|c|}
\hline Pacientes & LITTLE3-1 & INTERC2-1 & INTERC3-2 & INTERC3-1 & INTERPB2-1 \\
\hline 1. & $-1,58$ & 1,61 & $-0,56$ & 1,05 & 2,42 \\
\hline 2. & $-5,55$ & 0,37 & $-0,21$ & 0,16 & 3,51 \\
\hline 3. & $-11,55$ & $-2,87$ & 0,72 & $-2,15$ & 4,46 \\
\hline 4. & $-11,18$ & 2,09 & $-0,15$ & 1,94 & 4,04 \\
\hline 5. & $-5,92$ & 2,17 & $-1,30$ & 0,87 & 5,51 \\
\hline 6. & $-4,18$ & 3,00 & $-0,98$ & 2,02 & 5,25 \\
\hline 7. & $-0,75$ & $-0,80$ & 0,47 & $-0,33$ & 3,51 \\
\hline 8. & $-6,45$ & $-0,37$ & $-0,11$ & $-0,48$ & 4,81 \\
\hline 9. & $-9,16$ & $-1,50$ & $-0,89$ & $-2,39$ & 2,06 \\
\hline 10. & $-5,96$ & 2,27 & $-0,46$ & 1,81 & 2,92 \\
\hline 11. & $-4,31$ & $-2,15$ & 0,45 & $-1,70$ & 1,03 \\
\hline 12. & $-4,38$ & 4,18 & $-1,45$ & 2,73 & 8,67 \\
\hline 13. & $-2,25$ & $-2,08$ & $-0,33$ & $-2,41$ & 4,52 \\
\hline 14. & $-2,62$ & 0,29 & $-0,97$ & $-0,68$ & 2,10 \\
\hline 15. & $-5,32$ & 2,77 & $-0,67$ & 2,10 & 3,55 \\
\hline 16. & $-2,07$ & 1,16 & $-1,42$ & $-0,26$ & 4,77 \\
\hline 17. & $-1,57$ & 3,31 & $-2,40$ & 0,91 & 5,47 \\
\hline 18. & $-5,19$ & 2,24 & $-0,23$ & 2,01 & 0,79 \\
\hline 19. & $-4,10$ & $-0,43$ & 0,39 & $-0,04$ & 1,71 \\
\hline 20. & $-0,90$ & 3,02 & $-0,74$ & 2,28 & 6,43 \\
\hline 21. & $-4,07$ & 0,37 & $-0,92$ & $-0,55$ & 1,77 \\
\hline 22. & 0,68 & $-0,05$ & $-0,12$ & $-0,17$ & 1,82 \\
\hline 23. & $-11,16$ & 1,66 & $-0,39$ & 1,27 & 4,49 \\
\hline 24. & $-3,48$ & 2,02 & $-1,39$ & 0,63 & 2,53 \\
\hline 25. & $-4,92$ & $-0,31$ & $-0,82$ & $-1,13$ & 3,06 \\
\hline 26. & $-4,63$ & $-2,85$ & 0,64 & $-2,21$ & 1,60 \\
\hline 27. & $-5,88$ & 0,95 & $-0,90$ & 0,05 & 6,08 \\
\hline 28. & $-2,81$ & 0,59 & $-0,56$ & 0,03 & 1,55 \\
\hline 29. & $-2,39$ & $-0,55$ & $-0,25$ & $-0,80$ & 3,09 \\
\hline 30. & $-3,88$ & 3,11 & $-0,51$ & 2,60 & 2,38 \\
\hline 31. & $-0,29$ & $-0,99$ & 1,08 & 0,09 & 0,29 \\
\hline 32. & $-9,15$ & 9,44 & 0,27 & 9,71 & 0,34 \\
\hline 33. & $-4,89$ & $-0,83$ & 0,07 & $-0,76$ & 1,70 \\
\hline 34. & $-0,55$ & 1,73 & $-0,41$ & 1,32 & 2,94 \\
\hline 35. & $-2,51$ & $-0,54$ & $-0,14$ & $-0,68$ & 0,37 \\
\hline 36. & $-1,20$ & 1,53 & $-1,14$ & 0,39 & 1,52 \\
\hline 37. & $-1,78$ & 0,44 & 0,48 & 0,92 & 0,64 \\
\hline 38. & $-2,11$ & 1,93 & 1,16 & 3,09 & 3,43 \\
\hline 39. & $-9,78$ & $-2,85$ & 1,23 & $-1,62$ & 3,87 \\
\hline 40. & $-4,45$ & 0,76 & 0,37 & 1,13 & 0,38 \\
\hline 41. & $-8,23$ & $-1,64$ & 0,29 & $-1,35$ & 2,91 \\
\hline 42. & $-2,36$ & 0,61 & $-1,20$ & $-0,59$ & $-0,02$ \\
\hline 43. & $-1,72$ & $-0,83$ & $-0,88$ & $-1,71$ & 2,59 \\
\hline 44. & 0,40 & 2,82 & $-2,03$ & 0,79 & 2,44 \\
\hline 45. & $-4,85$ & 2,19 & $-1,94$ & 0,25 & 1,22 \\
\hline 46. & $-2,68$ & $-1,59$ & $-0,56$ & $-2,15$ & $-1,11$ \\
\hline 47. & $-1,86$ & 0,35 & 1,88 & 2,23 & 0,39 \\
\hline 48. & $-1,62$ & $-0,52$ & 0,52 & 0,00 & $-1,28$ \\
\hline
\end{tabular}


Apêndice A7.

\begin{tabular}{|c|c|c|c|c|c|}
\hline Pacientes & INTERPB3-2 & INTERPB3-1 & INTERB'2-1 & INTERPB'3-2 & INTERPB'3-1 \\
\hline 1. & $-0,41$ & 2,01 & 2,30 & $-0,38$ & 1,92 \\
\hline 2. & 0,46 & 3,97 & 4,66 & $-1,33$ & 3,33 \\
\hline 3. & $-0,48$ & 3,98 & 8,55 & 0,09 & 8,64 \\
\hline 4. & $-0,42$ & 3,62 & 5,01 & $-0,67$ & 4,34 \\
\hline 5. & $-3,70$ & 1,81 & 3,48 & $-2,25$ & 1,23 \\
\hline 6. & $-1,66$ & 3,59 & 5,06 & $-1,93$ & 3,13 \\
\hline 7. & $-1,16$ & 2,35 & 4,15 & $-1,02$ & 3,13 \\
\hline 8. & $-1,47$ & 3,34 & 6,33 & $-1,53$ & 4,80 \\
\hline 9. & $-1,04$ & 1,02 & 2,69 & $-0,53$ & 2,16 \\
\hline 10. & $-0,69$ & 2,23 & 3,02 & $-0,73$ & 2,29 \\
\hline 11. & $-0,32$ & 0,71 & 4,91 & $-1,03$ & 3,88 \\
\hline 12. & $-1,77$ & 6,90 & 5,97 & $-0,68$ & 5,29 \\
\hline 13. & $-1,51$ & 3,01 & 6,33 & $-2,50$ & 3,83 \\
\hline 14. & $-1,72$ & 0,38 & 3,89 & $-0,31$ & 3,58 \\
\hline 15. & $-0,71$ & 2,84 & 5,29 & $-1,09$ & 4,20 \\
\hline 16. & $-2,74$ & 2,03 & 2,98 & $-2,02$ & 0,96 \\
\hline 17. & $-1,37$ & 4,10 & 5,79 & $-1,98$ & 3,81 \\
\hline 18. & $-1,05$ & $-0,26$ & 0,52 & 0,26 & 0,78 \\
\hline 19. & $-0,42$ & 1,29 & $-0,03$ & 1,49 & 1,46 \\
\hline 20. & $-1,20$ & 5,23 & 4,06 & $-0,02$ & 4,04 \\
\hline 21. & $-0,61$ & 1,16 & 2,36 & $-0,39$ & 1,97 \\
\hline 22. & $-0,03$ & 1,79 & $-0,70$ & 1,55 & 0,85 \\
\hline 23. & $-0,61$ & 3,88 & 4,06 & 0,22 & 4,28 \\
\hline 24. & $-1,53$ & 1,00 & 2,26 & $-1,87$ & 0,39 \\
\hline 25. & $-2,34$ & 0,72 & 2,48 & $-0,56$ & 1,92 \\
\hline 26. & $-0,52$ & 1,08 & 1,11 & $-0,08$ & 1,03 \\
\hline 27. & $-1,75$ & 4,33 & 5,97 & $-1,02$ & 4,95 \\
\hline 28. & $-0,93$ & 0,62 & 1,12 & $-0,59$ & 0,53 \\
\hline 29. & $\begin{array}{l}-0,84 \\
\end{array}$ & 2,25 & 4,10 & $\begin{array}{l}-0,53 \\
\end{array}$ & 3,57 \\
\hline 30. & $-0,06$ & 2,32 & 3,21 & 0,51 & 3,72 \\
\hline 31. & $-1,07$ & $-0,78$ & $-0,56$ & $-0,74$ & $-1,30$ \\
\hline 32. & $-0,02$ & 0,32 & 0,24 & 0,26 & 0,50 \\
\hline 33. & $-0,41$ & 1,29 & 0,76 & $-0,81$ & $-0,05$ \\
\hline 34. & $-1,52$ & 1,42 & 2,61 & $-1,27$ & 1,34 \\
\hline 35. & $-0,74$ & $-0,37$ & 0,48 & $-0,60$ & $-0,12$ \\
\hline 36. & $-1,25$ & 0,27 & 0,43 & $-0,38$ & 0,05 \\
\hline 37. & $-0,27$ & 0,37 & $-0,06$ & $-0,17$ & $-0,23$ \\
\hline 38. & 0,51 & 3,94 & 2,84 & 0,14 & 2,98 \\
\hline 39. & $-2,15$ & 1,72 & 4,63 & $-1,19$ & 3,44 \\
\hline 40. & 0,20 & 0,58 & 0,57 & 0,03 & 0,60 \\
\hline 41. & $-0,19$ & 2,72 & 2,68 & $-0,04$ & 2,64 \\
\hline 42. & $-0,91$ & $-0,93$ & $-0,54$ & $-0,13$ & $-0,67$ \\
\hline 43. & 0,36 & 2,95 & $-0,69$ & 1,14 & 0,45 \\
\hline 44. & $-2,14$ & 0,30 & 1,64 & $-1,96$ & $-0,32$ \\
\hline 45. & $-2,29$ & $-1,07$ & 0,11 & $-2,45$ & $-2,34$ \\
\hline 46. & 0,62 & $-0,49$ & $-0,14$ & 0,76 & 0,62 \\
\hline 47. & 1,23 & 1,62 & 0,26 & 1,58 & 1,84 \\
\hline 48. & 0,82 & $-0,46$ & $-4,23$ & 1,43 & $-2,80$ \\
\hline
\end{tabular}


Apêndice A8.

\begin{tabular}{|c|c|c|c|c|c|}
\hline Pacientes & INTERMOL2-1 & INTERMOL3-2 & INTERMOL3-1 & COMPR2-1 & COMPR3-2 \\
\hline 1. & 2,19 & $-1,04$ & 1,15 & 2,50 & $-1,34$ \\
\hline 2. & 16,29 & $-1,10$ & 15,19 & 4,65 & $-2,73$ \\
\hline 3. & 6,28 & 1,42 & 7,70 & 9,8 & $-1,61$ \\
\hline 4. & 2,74 & $-0,90$ & 1,84 & $-2,99$ & $-0,52$ \\
\hline 5. & 1,62 & 1,06 & 2,68 & 0,73 & $-1,82$ \\
\hline 6. & 1,09 & $-0,58$ & 0,51 & 2,85 & $-3,52$ \\
\hline 7. & 1,48 & 0,80 & 2,28 & 4,26 & $-2,31$ \\
\hline 8. & 4,01 & $-0,08$ & 3,93 & 5,62 & $-1,04$ \\
\hline 9. & 2,03 & $-0,62$ & 1,41 & 2,15 & $-1,47$ \\
\hline 10. & 4,69 & $-1,26$ & 3,43 & 1,92 & $-3,37$ \\
\hline 11. & 4,22 & $-1,80$ & 2,42 & 4,97 & $-1,37$ \\
\hline 12. & 2,35 & 0,73 & 3,08 & 4,07 & $-1,16$ \\
\hline 13. & 2,94 & $-0,83$ & 2,11 & 3,32 & $-1,11$ \\
\hline 14. & 4,75 & $-1,41$ & 3,34 & 5,9 & $-3,79$ \\
\hline 15. & 3,47 & $-0,47$ & 3,00 & 3,53 & $-1,06$ \\
\hline 16. & 1,05 & $-1,33$ & $-0,28$ & 1,08 & $-2,13$ \\
\hline 17. & 5,80 & $-1,07$ & 4,73 & 3,18 & $-1,81$ \\
\hline 18. & $-2,36$ & 0,21 & $-2,15$ & $-2,6$ & 1,58 \\
\hline 19. & 1,76 & $-0,46$ & 1,30 & 1,47 & $-0,66$ \\
\hline 20. & 2,78 & 1,38 & 4,16 & 3,38 & $-2,43$ \\
\hline 21. & 2,18 & $-0,4$ & 1,78 & 0,26 & $-0,56$ \\
\hline 22. & $-4,07$ & 6,25 & 2,18 & $-0,79$ & $-0,22$ \\
\hline 23. & 1,50 & $-0,03$ & 1,47 & 1,14 & $-1,06$ \\
\hline 24. & 1,38 & $-1,46$ & $-0,08$ & $-1,83$ & $-0,12$ \\
\hline 25. & 4,14 & $-1,89$ & 2,25 & 3,88 & $-3,52$ \\
\hline 26. & 0,15 & 0,93 & 1,08 & 5,09 & $-1,58$ \\
\hline 27. & 3,88 & $-0,62$ & 3,26 & 4,14 & $-2,96$ \\
\hline 28. & 2,83 & $-1,00$ & 1,83 & 0,77 & $-1,15$ \\
\hline 29. & 0,37 & 1,76 & 2,13 & 1,91 & $-1,82$ \\
\hline 30. & 6,20 & $-1,53$ & 4,67 & $-4,95$ & $-2,94$ \\
\hline 31. & 0,59 & $-0,42$ & 0,17 & 3,99 & $-3,10$ \\
\hline 32. & $-0,32$ & $-0,16$ & $-0,48$ & 4,79 & $-2,25$ \\
\hline 33. & $-0,14$ & 0,35 & 0,21 & 3,18 & $-1,63$ \\
\hline 34. & $-1,66$ & 1,19 & $-0,47$ & 1,84 & $-0,75$ \\
\hline 35. & $-1,20$ & 0,72 & $-0,48$ & 1,04 & $-1,35$ \\
\hline 36. & $-1,23$ & 0,55 & $-0,68$ & $-2,81$ & 0,58 \\
\hline 37. & 0,02 & $-0,10$ & $-0,08$ & 2,59 & $-2,30$ \\
\hline 38. & 0,50 & 0,69 & 1,19 & 2,09 & $-2,62$ \\
\hline 39. & 4,94 & 0,31 & 5,25 & 7,27 & $-2,47$ \\
\hline 40. & $-0,25$ & 0,46 & 0,21 & 4,39 & $-4,46$ \\
\hline 41. & 2,41 & $-0,42$ & 1,99 & 7,62 & $-1,82$ \\
\hline 42. & 1,59 & $-0,85$ & 0,74 & $-4,50$ & $-1,33$ \\
\hline 43. & $-1,88$ & 2,26 & 0,38 & 2,74 & $-0,04$ \\
\hline 44. & 0,17 & $-0,15$ & 0,02 & $-0,06$ & $-1,45$ \\
\hline 45. & $-0,96$ & $-0,15$ & $-1,11$ & $-1,65$ & $-0,41$ \\
\hline 46. & 1,44 & 0,07 & 1,51 & 5,85 & $-2,81$ \\
\hline 47. & $-2,45$ & 3,10 & 0,65 & $-1,62$ & $-1,22$ \\
\hline 48. & $-5,95$ & 2,59 & $-3,36$ & $-5,29$ & 1,00 \\
\hline
\end{tabular}


Apêncice A9.

\begin{tabular}{|c|c|c|c|c|}
\hline Pacientes & COMPR3-1 & PERIM2-1 & PERIM3-2 & PERM3-1 \\
\hline 1. & 1,16 & 1,08 & $-1,22$ & $-0,14$ \\
\hline 2. & 1,92 & 4,83 & $-3,29$ & 1,54 \\
\hline 3. & 8,19 & 9,93 & 0,02 & 9,95 \\
\hline 4. & $-3,51$ & 0,15 & $-0,16$ & $-0,01$ \\
\hline 5. & $-1,09$ & 2,98 & $-1,22$ & 1,76 \\
\hline 6. & $-0,67$ & 1,43 & $-1,24$ & 0,19 \\
\hline 7. & 1,95 & $-0,42$ & 0,54 & 0,12 \\
\hline 8. & 4,58 & 5,70 & 0,32 & 6,02 \\
\hline 9. & 0,68 & 3,55 & $-2,26$ & 1,29 \\
\hline 10. & $-1,45$ & 2,50 & $-3,01$ & $-0,51$ \\
\hline 11. & 3,60 & 2,22 & $-0,02$ & 2,20 \\
\hline 12. & 2,91 & 4,54 & $-3,77$ & 0,77 \\
\hline 13. & 2,21 & 3,46 & $-2,25$ & 1,21 \\
\hline 14. & 2,11 & 2,26 & $-3,13$ & $-0,87$ \\
\hline 15. & 2,47 & 4,63 & $-1,75$ & 2,88 \\
\hline 16. & $-1,05$ & 4,28 & $-2,35$ & 1,93 \\
\hline 17. & 1,37 & 2,54 & $-2,78$ & $-0,24$ \\
\hline 18. & $-1,02$ & $-0,13$ & $-1,10$ & $-1,23$ \\
\hline 19. & 0,81 & 1,40 & $-0,60$ & 0,80 \\
\hline 20. & 0,95 & 4,88 & $-3,69$ & 1,19 \\
\hline 21. & $-0,30$ & $-1,17$ & $-1,03$ & $-2,20$ \\
\hline 22. & $-1,01$ & 0,45 & $-3,00$ & $-2,55$ \\
\hline 23. & 0,08 & 3,58 & $-1,72$ & 1,86 \\
\hline 24. & $-1,95$ & $-1,05$ & $-0,47$ & $-1,52$ \\
\hline 25. & 0,36 & 3,61 & $-2,12$ & 1,49 \\
\hline 26. & 3,51 & 0,74 & $-0,14$ & 0,60 \\
\hline 27. & 1,18 & 3,50 & $-1,98$ & 1,52 \\
\hline 28. & $-0,38$ & $-0,67$ & $-1,08$ & $-1,75$ \\
\hline 29. & 0,09 & 1,65 & $-2,26$ & $-0,61$ \\
\hline 30. & $-7,89$ & $-3,68$ & $-2,21$ & $-5,89$ \\
\hline 31. & 0,89 & 1,55 & $-0,44$ & 1,11 \\
\hline 32. & 2,54 & 2,12 & 0,00 & 2,12 \\
\hline 33. & 1,55 & 4,00 & $-0,90$ & 3,10 \\
\hline 34. & 1,09 & 2,05 & $-0,29$ & 1,76 \\
\hline 35. & $-0,31$ & 2,43 & $-0,71$ & 1,72 \\
\hline 36. & $-2,23$ & 0,74 & $-2,41$ & $-1,67$ \\
\hline 37. & 0,29 & 0,42 & $-1,09$ & $-0,67$ \\
\hline 38. & $-0,53$ & 1,21 & $-1,09$ & 0,12 \\
\hline 39. & 4,80 & 7,72 & $-1,49$ & 6,23 \\
\hline 40. & $-0,07$ & 0,28 & $-0,93$ & $-0,65$ \\
\hline 41. & 5,80 & 6,83 & $-0,91$ & 5,92 \\
\hline 42. & $-5,83$ & $-6,47$ & $-0,67$ & $-7,14$ \\
\hline 43. & 2,70 & 4,55 & 0,08 & 4,63 \\
\hline 44. & $-1,51$ & 3,12 & $-4,39$ & $-1,27$ \\
\hline 45. & $-2,06$ & $-0,64$ & 0,32 & $-0,32$ \\
\hline 46. & 3,04 & 1,75 & $-1,35$ & 0,40 \\
\hline 47. & $-2,84$ & 1,66 & $-2,81$ & $-1,15$ \\
\hline 48. & $-4,29$ & $-4,13$ & $-0,75$ & $-4,88$ \\
\hline
\end{tabular}

